\title{
Development of a novel technology to engineer heart muscle for contractile and paracrine support in heart failure
}

\author{
Doctoral Thesis \\ In partial fulfillment of the requirements for the degree \\ "Doctor rerum naturalium (Dr. rer. nat.)"
}

in the Molecular Medicine Study Program

at the Georg-August University Göttingen

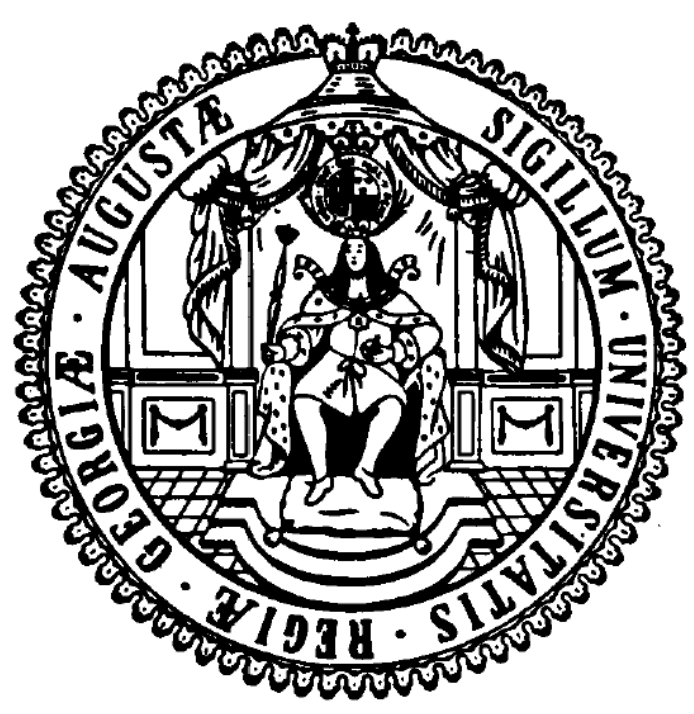

Submitted by

Poh Loong SOONG

born in Kuala Lumpur, Malaysia

Göttingen, 2012 
Prof. Dr. med. Wolfram, H- Zimmermann (Supervisor)

Email: w.zimmermann@med.uni-goettingen.de

Phone: $\quad$ +49551395787

Postal Address: Department of Pharmacology

Heart Center / Center of Pharmacology and Toxicology

University Medical Center Goettingen

Georg-August University Göttingen

Robert-Koch-Str. 40

37075 Goettingen

Germany

Prof. Andreas Wodarz

Email:_awodarz@gwdg.de

Phone: $\quad$ +495513913711

Postal Address Stammzellbiologie,

Abt. Anatomie und Zellbiologie

GZMB

Justus-von-Liebig-Weg 11

37077 Göttingen

Germany

Prof. Stefan Luther

Email: $\quad$ stefan.luther@ds.mpg.de

Phone: $\quad$ +495515176 370

Postal Address Max-Planck-Institut für Dynamik und Selbstorganisation Biomedizinische Physik

Am Fassberg 17

37077 Goettingen

Germany

Date of Disputation: 
Here I declare that my doctoral thesis entitled:

"Development of a novel technology to engineer heart muscle for contractile and paracrine support in heart failure"

has been written independently with no other sources and aids than quoted.

Poh Loong SOONG

Göttingen, 30 ${ }^{\text {th }}$ September 2012 


\section{Peer-Reviewed Articles:}

1. Soong PL, Tiburcy M, Zimmermann W-H (2012) Cardiac Differentiation of Human Embryonic Stem Cells and their Assembly into Engineered Heart Muscle. Curr Protoc Cell Biol 2012. 23.8.1-23.8.21

\section{Peer-Reviewed Abstract Presentations:}

2. Soong PL, Tiburcy M, Hudson J, Christoph J, Luther S, Zimmermann WH (2012) A Biomimetic Approach to Scale Up Engineered Human Myocardium. 10 ${ }^{\text {th }}$ Annual Meeting, ISSCR, Yokohama, Japan 2012. Poster presentation 
Acknowledgements.

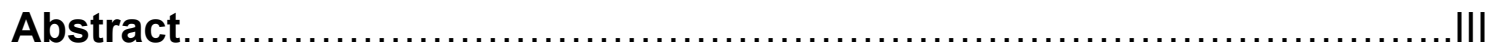

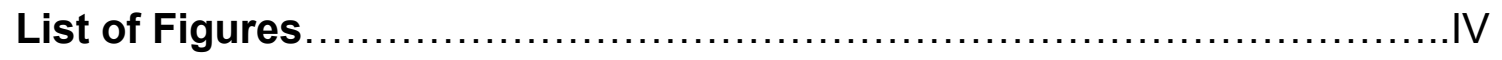

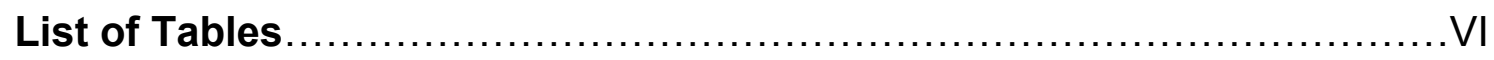

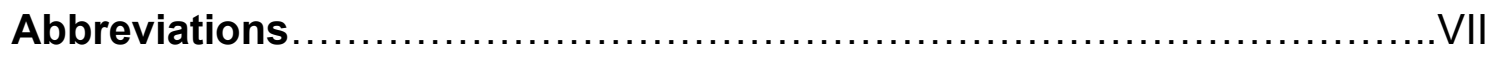

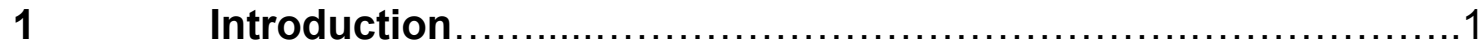

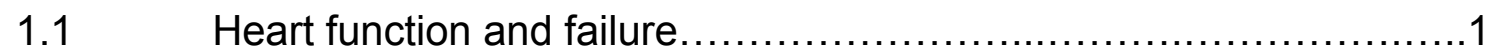

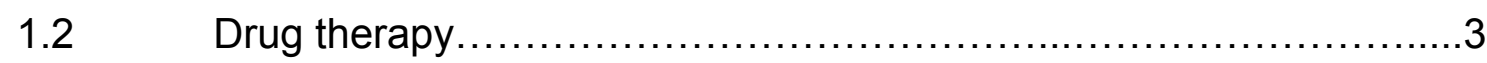

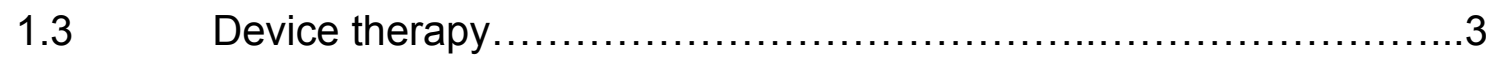

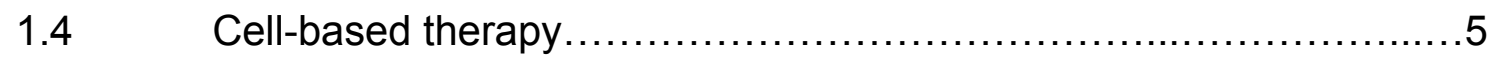

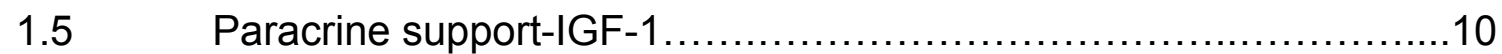

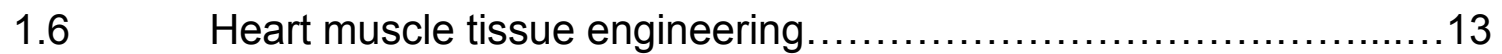

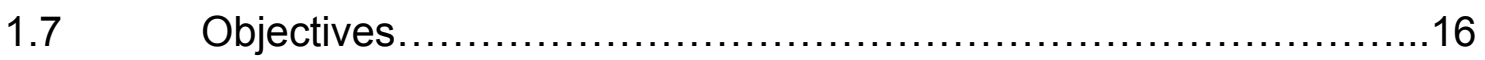

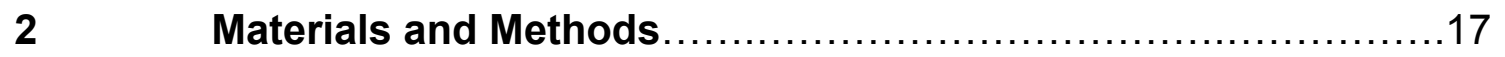

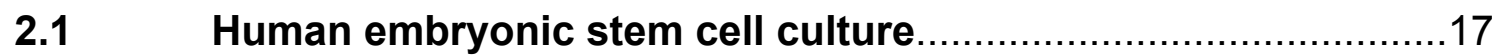

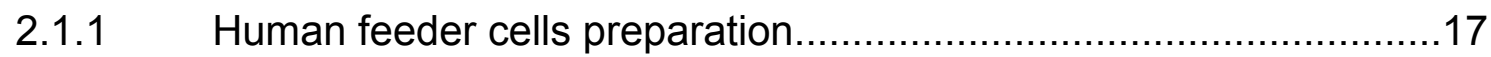

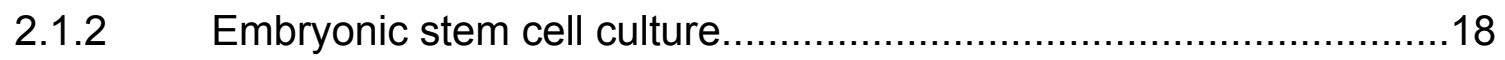

2.1.2.1 "Cut and Paste" passaging.............................................. 18

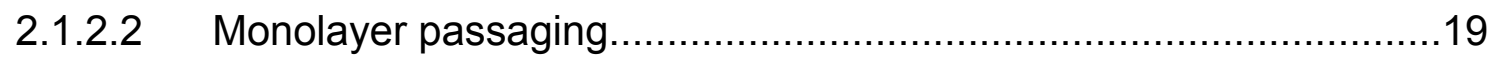

2.1.3 Embryonic stem cell differentiation.....................................20

2.1.3.1 Embryoid body differentiation.............................................20 


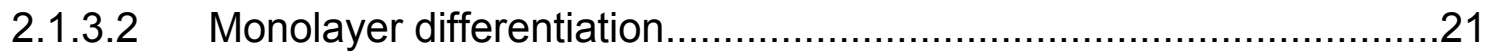

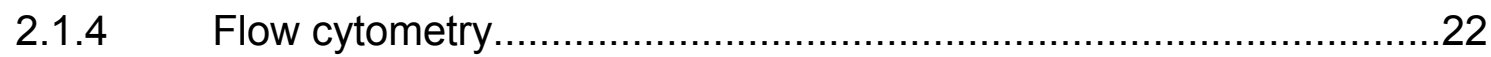

2.2 Generation and characterization of Engineered Heart Muscle

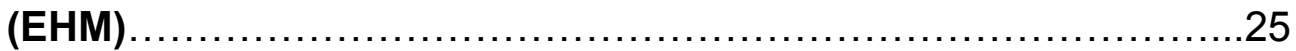

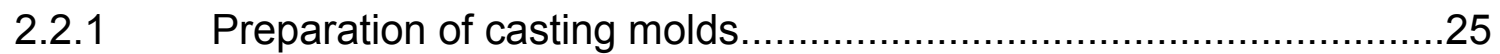

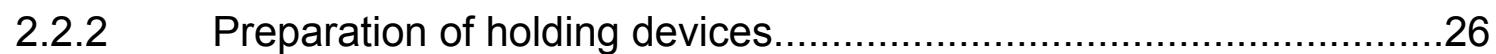

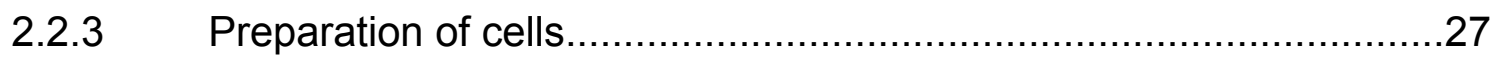

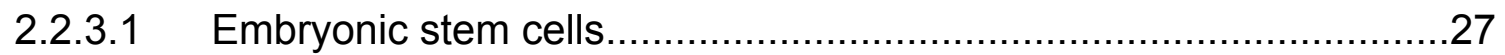

2.2.3.2 Human foreskin fibroblasts (HFF) ......................................2

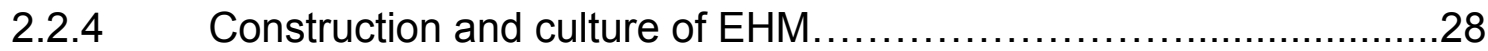

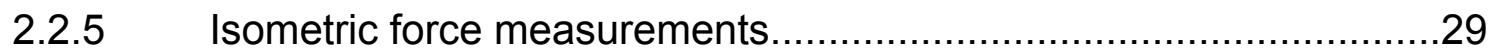

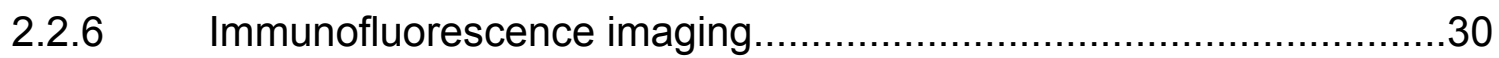

2.2.7 Dissociation of EHM for flow cytometry ......................................30

2.3 Generation and characterization of BioVADs ............................31

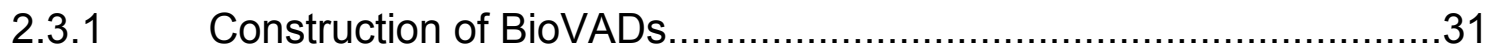

2.3.2 Preparation of casting molds for biomimetic support.......................32

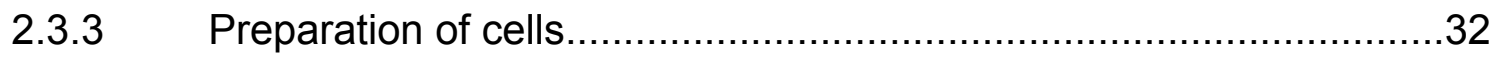

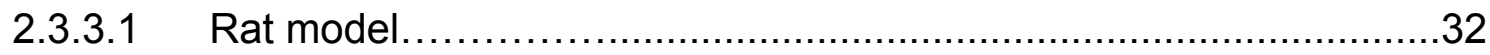

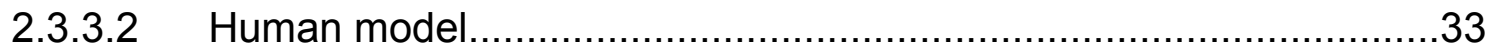

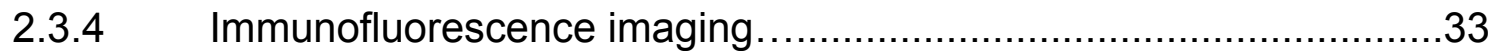

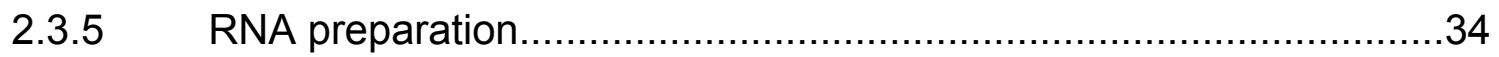

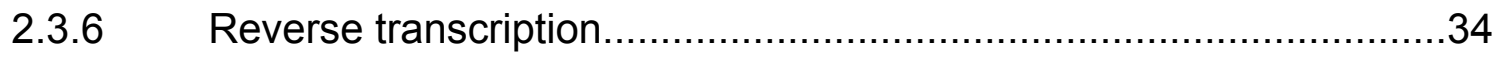

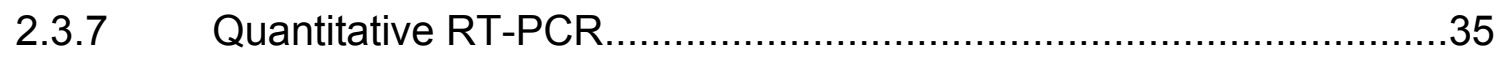


2.4 Development of a cell based IGF-1 secretion technology..........36

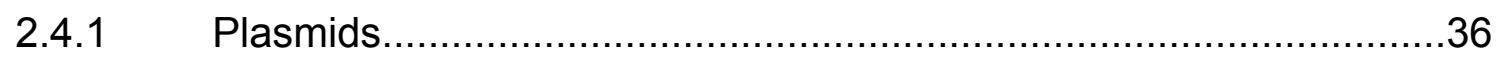

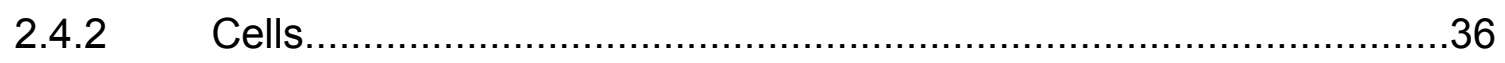

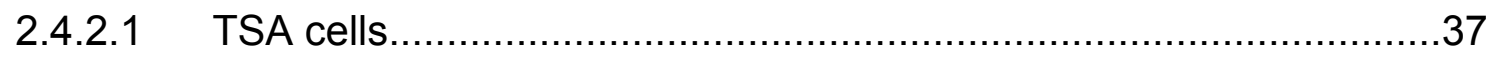

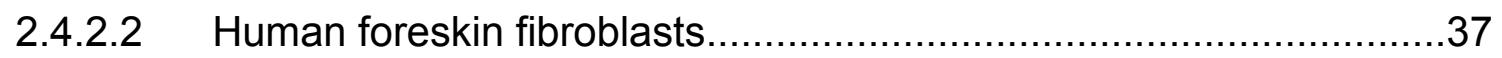

2.4.3 Lipofection of $p$ CMV-XL4 into TSA cells...................................

2.4.4 Analysis of IGF-1 expression and secretion...........................37

2.4.4.1 Western blot detection of IGF-1 $\quad$ W......................................

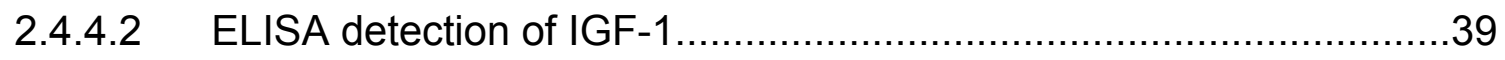

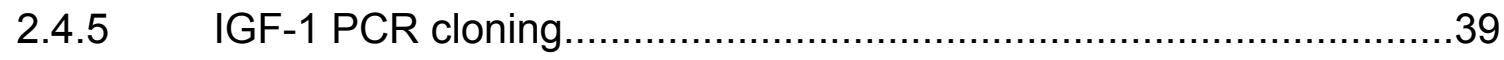

2.4.6 Construction of IGF-1 encoding lentivirus ........................40

2.4.7 Lentivirus production....................................... 41

2.4.8 Lentiviral transduction of human foreskin fibroblasts....................42

2.4.9 Cell size measurement......................................43

2.5 In vivo testing of human BioVAD (hBioVAD) with paracrine

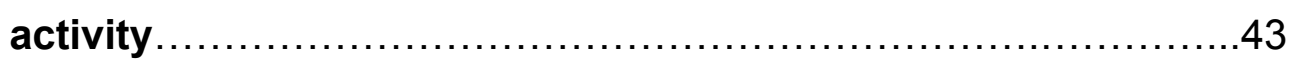

2.5.1 Assembly of hBioVAD with paracrine activity ............................43

2.5.2 Implantation of hBioVAD in Wistar rat...................................43

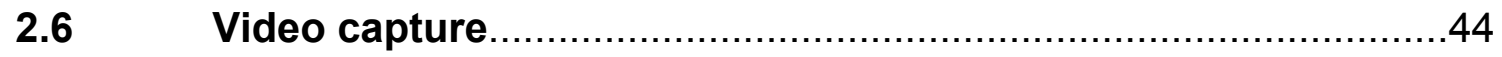

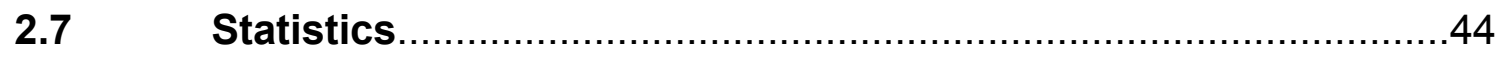




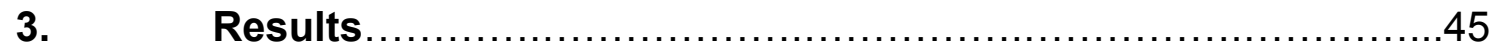

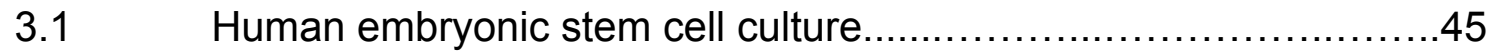

3.1.1 Human embryonic stem cell quality ............................................

3.1.2 Cardiomyocyte differentiation.......................................46

3.2 Generation of human Engineered heart muscle $\ldots \ldots \ldots \ldots \ldots \ldots \ldots \ldots . . .48$

3.2.1 EHM exhibit heart like morphology and functionality .................48

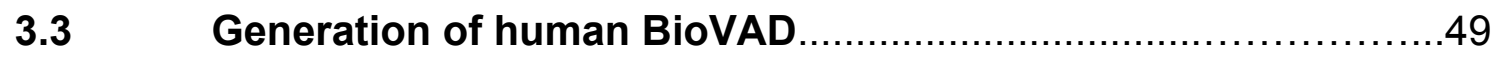

3.3.1 Construction of novel casting molds ..................................49

3.3.2 Cells tested to generate BioVAD ......................................50

3.3.2.1 BioVADs from fibroblasts..............................................

3.3.2.2 BioVADs from neonatal rat heart cells ..................................51

3.3.2.3 BioVAD from human embryonic stem cell derived

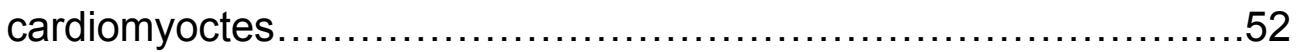

3.3.3 Biomimetic pulsatile load on BioVAD.................................53

3.3.3.1 Pulsatile load confers morphological rearrangements in fibroblasts. .53

3.3.3.2 Pulsatile load confers morphological rearrangements in cardiomyocytes........................................................

3.3.3.3 Pulsatile load leads to tissue maturation..............................56

3.3.3.4 Pulsatile load enhances cell cycle activity............................57

3.4 Pharmacological control of IGF-1 release from cells............57

3.4.1 PCR cloning of human IGF-1 gene .................................59 
3.4.2 Transient expression of human IGF-1 in TSA cells..................60

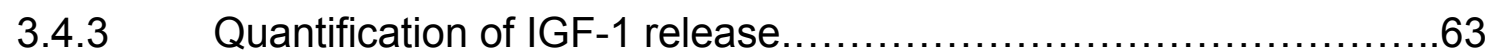

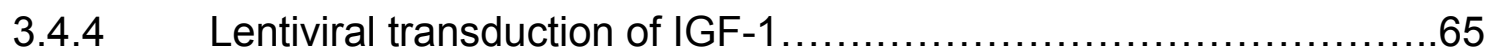

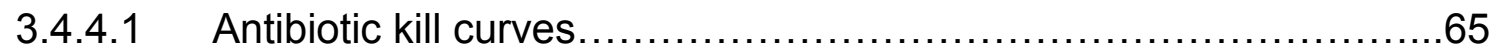

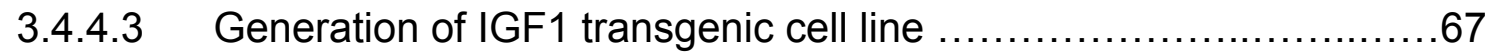

3.4.5 Expression of IGF-1 from lentiviral transduced fibroblasts..........67

3.4.5.1 Detection of IGF-1 in transgenic fibroblasts.........................68

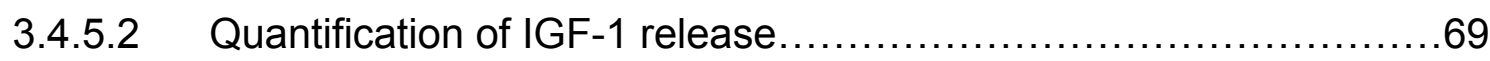

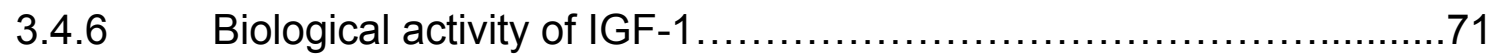

3.4.6.1 Hypertrophy in IGF-1 transgenic fibroblasts......................71

3.4.6.2 Paracrine action of IGF-1 activates Akt in cardiomyocytes ...........71

3.4.6.3 IGF-1 enhances force generation of human EHMs ..................74

3.4.6.4 IGF-1 induces cell hypertrophy in human EHMs...................75

3.4.6.5 IGF-1 improves morphology of human EHMs $\ldots \ldots \ldots \ldots \ldots \ldots \ldots \ldots \ldots 77$

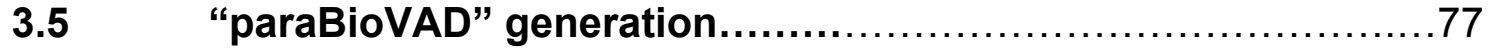

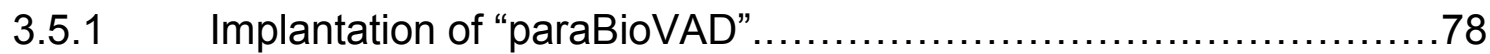

3.5.2 Histological observations of explanted "paraBioVAD" ................79

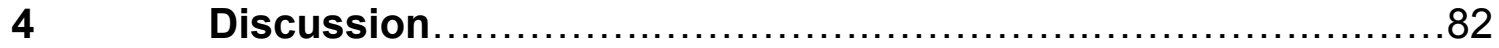

4.1 hESC differentiation to generate cardiomyocytes for tissue

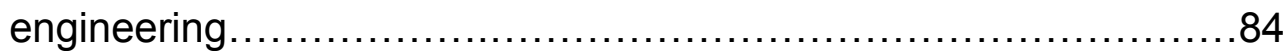

4.2 Generation of human EHM from ESC derived cardiomyocytes.......86

G.3 Generation of a large humanized BioVAD $\ldots \ldots \ldots \ldots \ldots \ldots \ldots \ldots \ldots . \ldots \ldots$

4.4 Drug-inducible IGF-1 release for paracrine heart support............88 
Bibliography 95

Appendix 
I would like to thank my primary supervisor Prof. Dr. Wolfram-Hubertus Zimmermann for the opportunity to undertake this thesis and also the freedom, support and advice he has given me throughout my project. I would also like to thank my co-supervisors Prof. Stefan Luther and Prof. Andreas Wodarz for their sound advice, challenging ideas, encouragement and patient support.

I would like to thank Prof. Susanne Lutz who helped me with critical and valuable advice during the lentiviral production and cloning steps as well as for the provision of TSA cell lines. Many thanks to Dr. Gordon Keller and Dr. Robert Zweigerdt for the HES2 and HES3 cell lines.

Special appreciation goes to Dr. Malte Tiburcy for his tremendous patience, constant advice, encouragement and his commitment to help tackle tough issues in this project. Your mentorship and friendship is very much treasured. Many thanks also goes out to Dr. James Hudson, who has selflessly taught me his high efficiency cardiac differentiation protocol.

Heaps of appreciation goes out to all the post docs and graduate students especially to Sumon Sur, Mei-Ling Chang Liao and Farah Raad for sharing my ups and downs. Thank you for keeping me sane and keeping my spirits up. I am indebted to you. Also, sincere thanks to Jan Christoph for producing the BioVAD casting blocks. I would also like to thank all the members of the technical staff in our department, especially Iris Quentin, who provided me with great technical support, Kerstin Schenck, who prepared neonatal rat cardiomyocytes every week, and Ines Muller, who did great paraffin sections and histological stainings.

I would also like to thank my parents and brother for their support and also to my extended family. All your encouragements from the Skype calls to emails from Singapore allowed me to stay in contact with home.

Last but not least, my wife, Simin Chen for all her love, support and her great baking skills she has given to keep me well fed during my PhD. 
This work is dedicated to my paternal grandmother and maternal uncle who have both passed on during my PhD candidature. 


\section{Abstract}

The human heart has poor endogenous regeneration. If myocytes are lost due to injury, the myocardium is unable to restore its myocyte content and instead undergoes compensatory hypertrophy and remodeling. Cardiac tissue engineering aims to recreate and provide functional myocardium that replaces the injured myocardium. In this study, human engineered heart muscle (EHM) from cardiomyogenically differentiated human embryonic stem cells was generated. EHMs consisted of elongated, anisotropically organized cardiomyocyte bundles and responded "physiologically" to increasing calcium concentrations. To generate large myocardium capable of encompassing the ventricles, a novel process to systematically upscale the dimensions of engineered myocardium to a humanized Biological Ventricular Assisted Device (hBioVAD) was introduced. The hBioVADs formed a "pouch-like" myocardium at rabbit heart dimensions and were beating spontaneously. Further enhancement by biomimetic pulsatile loading generated "more mature" myocardium. Additional paracrine functionality was integrated by generating insulin-like growth factor-1 (IGF-1) secreting fibroblasts for tissue engineering applications. IGF-1 release induced higher levels of Akt phosphorylation and hypertrophy in cardiomyocytes resulting in increased force generation of EHM. Finally, feasibility of "paraBioVAD" (IGF-1 cell line and cardiomyocytes) implantation was demonstrated in a healthy rat model. Histological observations demonstrated engraftment on the heart and the presence of vascular structures. In conclusion, a humanized "paraBioVAD" technology for mechanic and paracrine heart support was developed. Future studies will assess its therapeutic utility in heart failure. 
Figure 1. Summary of therapeutic strategies in heart failure ....................2

Figure 2. Schematic overview of IGF-1 splice variants..........................12

Figure 3. Schematic overview of IGF-1R signaling pathways.................13

Figure 4. Experimental outline of the dissertation.............................16

Figure 5. hESC colonies scored with the EZ Passage tool.....................19

Figure 6. Embryoid body differentiation .....................................

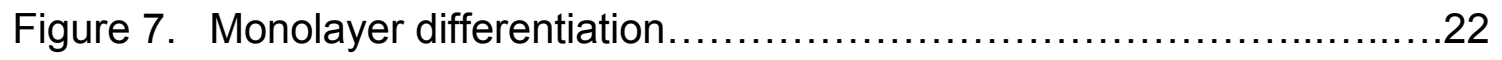

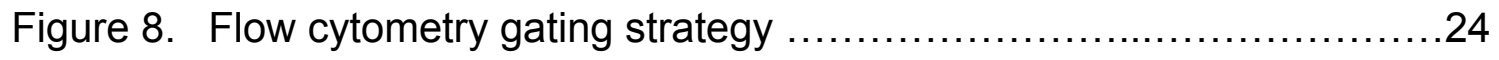

Figure 9. Casting mold and silicone holder for EHM culture ...................26

Figure 10. Detection of pluripotency surrogate markers in monolayer hESC cultures.

Figure 11. Enhanced cardiogenesis in 2D vs. 3D cultures.....................47

Figure 12. Morphological and functional parameters of human EHMs..........49

Figure 13. Casting molds construction for BioVAD technology ..................50

Figure 14. Pouch like tissue structure made from HFF .........................51

Figure 15. BioVAD from neonatal rat cardiomyocytes..........................52

Figure 16. BioVAD from hESC derived cardiomyocytes.........................53

Figure 17. Mechanical load directs morphology in HFFBioVADs .54

Figure 18. Mechanical pulsing improved morphology of hESCBioVADs .55

Figure 19. Pulsatile loading improves BioVAD maturation.......................56

Figure 20. Pulsatile loading enhances cell cycle activity in BioVAD ..............57

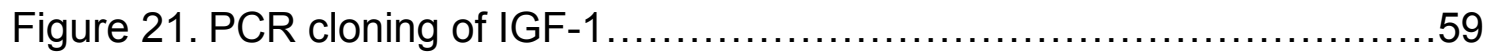




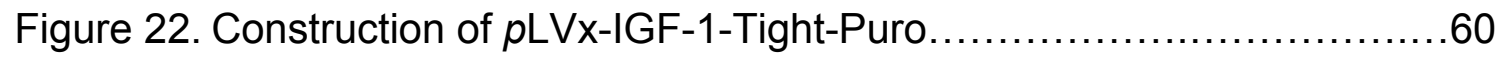

Figure 23. Secretion of IGF-1 from pCMV-XL4 transfected TSA cells...........61

Figure 24. Expression of IGF-1 from $p L V x-I G F$ transfected TSA cells............62

Figure 25. Quantification of secreted IGF-1 from transfected TSA cells. 64

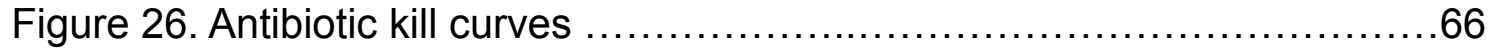

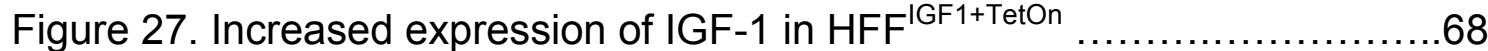

Figure 28. Human IGF-1 protein secretion from inducible HFFs .................70

Figure 29. Hypertrophy in IGF-1 transduced HFFs...............................71

Figure 30. IGF-1 conditioned medium induces Akt phosphorylation in

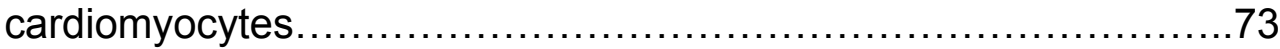

Figure 31. Force generation of EHMs is enhanced by doxycycline activiation of

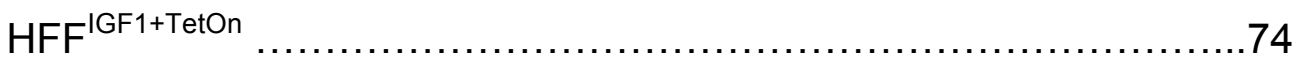

Figure 32. IGF-1 induces cardiomyocytes hypertrophy in EHMs................76

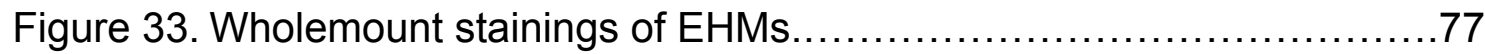

Figure 34. Human "paraBioVAD" .................................................

Figure 35. Explant of human "paraBioVAD" ....................................78

Figure 36. Histological sections of "paraBioVAD" on rat heart.....................80

Figure 37. Morphology of "paraBioVAD" stained with Sirius red...................81 


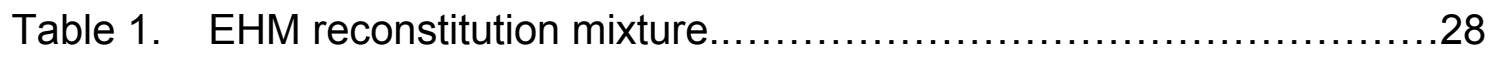

Table 2. Components required to generate human BioVADs..................33

Table 3. Primers and probes used in quantitative PCR ....................127 


\begin{tabular}{|c|c|}
\hline ALB & albumin \\
\hline$\alpha-\mathrm{MHC}$ & $\alpha-m y o s i n$ heavy chain \\
\hline AP & action potential \\
\hline$\alpha-S M A$ & $\alpha$-smooth muscle actin \\
\hline bp & base pairs \\
\hline$\beta-\mathrm{ME}$ & $\beta$-mercaptoethanol \\
\hline BSA & bovine serum albumin \\
\hline cDNA & complementary DNA \\
\hline DAPI & 4',6-diamidino-2-phenylindole \\
\hline $\mathrm{DCM}$ & dilated cardiomyopathy \\
\hline DEPC & diethylpyrocarbonate \\
\hline DMEM & Dulbecco's modified Eagle's medium \\
\hline DMSO & dimethyl sulfoxide \\
\hline DNA & deoxyribonucleic acid \\
\hline DNase & deoxyribonuclease \\
\hline dNTP & 2'-deoxyribonucleotide-5'-triphosphate \\
\hline DPBS & Dulbecco's phosphate buffered saline \\
\hline EB & embryoid body \\
\hline EDTA & ethylenediaminetetraacetic acid \\
\hline $\mathrm{EHT}$ & engineered heart tissue \\
\hline EHM & engineered heart muscle \\
\hline ESCs & embryonic stem cells \\
\hline $\mathrm{EtBr}$ & ethidium bromide \\
\hline FACS & fluorescence activated cell sorting \\
\hline FBS & fetal bovine serum \\
\hline g & gravitational force \\
\hline G418 & geneticin \\
\hline GAPDH & glyceraldehyde-3-phosphate-dehydrogenase \\
\hline hbFGF & human basic fibroblast growth factor \\
\hline hESCs & human embryonic stem cells \\
\hline hiPSCs & human induced pluripotent stem cells \\
\hline IGF-1 & insulin-like growth factor 1 \\
\hline
\end{tabular}




$\begin{array}{ll}\text { IgG } & \text { immunoglobulin G } \\ \text { IF } & \text { immunofluorescence analysis } \\ \text { IMDM } & \text { Iscove's modified Dulbecco's medium } \\ \text { iPSCs } & \text { induced pluripotent stem cells } \\ \text { M } & \text { molar (mol/L) } \\ \text { MAPK } & \text { mitogen-activated protein kinase } \\ \text { MOI } & \text { multiplicity of infection } \\ \text { MSCs } & \text { mesenchymal stem cells } \\ \text { NEAA } & \text { non-essential amino acids } \\ \text { OCT4 } & \text { octamer binding transcription factor 4 } \\ \text { PAGE } & \text { polyacrylamide gel electrophoresis } \\ \text { PBS } & \text { phosphate buffered saline } \\ \text { PCR } & \text { polymerase chain reaction } \\ \text { PFA } & \text { paraformaldehyde } \\ \text { PLB } & \text { phospholamban } \\ \text { P/S } & \text { penicillin/streptomycin } \\ \text { RNA } & \text { ribonucleic acid } \\ \text { RPMI } & \text { Rosewell Park Memorial Institute medium } \\ \text { RT } & \text { room temperature } \\ \text { RT-PCR } & \text { reverse transcription-PCR } \\ \text { RYR 2 } & \text { ryanodine receptor 2 } \\ \text { SDS } & \text { sodium dodecyl sulfate } \\ \text { SEM } & \text { standard error of mean } \\ \text { SERCA } & \text { sarco/endoplasmic reticulum Ca }{ }^{2+} \text {-ATPase } \\ \text { SSEA4 } & \text { Stage specific embryonic antigen 4 } \\ \text { Taq } & \text { Thermus aquaticus } \\ \text { T/E } & \text { Trypsin/EDTA } \\ \text { TRA-1-60 } & \text { Tumor rejection antigen 1-60 } \\ \text { U } & \text { Unit } \\ \text { V } & \text { Volt } \\ & \end{array}$




\section{$1.1 \quad$ Heart function and failure}

The human heart is a four-chambered pump capable of providing an optimal continuous blood flow to the rest of the body. It is mainly comprised of cardiomyocytes, fibroblasts, endothelial and smooth muscle cells of which cardiomyocytes are responsible for the contractility of the heart while fibroblasts synthesize and secrete extracellular matrix (ECM) to form the scaffold of the heart. In addition, growth factors are also secreted by fibroblasts, which promote growth, proliferation and maturation of cardiomyocytes in a paracrine manner. Cardiomyocytes are one of the least endogenously regenerative cell types in the human body (Mallory et al. 1939, Pasumarthi and Field 2002, Laflamme and Murry 2005, Rubart and Field 2006, Laflamme et al. 2007) with only $1 \%$ of cardiomyocytes in the human heart regenerating till the age of 25 and a subsequent gradual reduction to $0.5 \%$ till age of 75 (Bergmann et al. 2009). Hence, a loss of cardiomyocytes, for example as a consequence of myocardial ischemia, cannot be compensated effectively. Instead replacement fibrosis can be observed. This process also goes along with cardiomyocyte hypertrophy, which may partially compensate for the loss in cardiomyocytes, but will not suffice to restore proper function in most cases. Under these conditions, heart failure can develop.

Heart failure is the leading cause of mortality globally with higher incidence in developed nations. It is however projected by the WHO to affect more populations in the future and be the main cause of death worldwide in less 
then a decade (http://www.who.int/cardiovascular_diseases/en/). Unless promptly diagnosed and appropriate management strategies are implemented, heart failure progresses to severe forms where blood volume demands outstrip the ability of the heart to pump effectively. The only causal therapy for these patients is heart transplantation. Due to a shortage of organs many patients die before receiving a transplant. Hence, novel therapeutic modalities are needed urgently to bridge the time-to-transplant or re-muscularize the heart.

Alternative therapeutic approaches, either in clinical practice or still under development, have been proposed to reverse pathological remodeling and halt disease progression in heart failure (Figure 1):

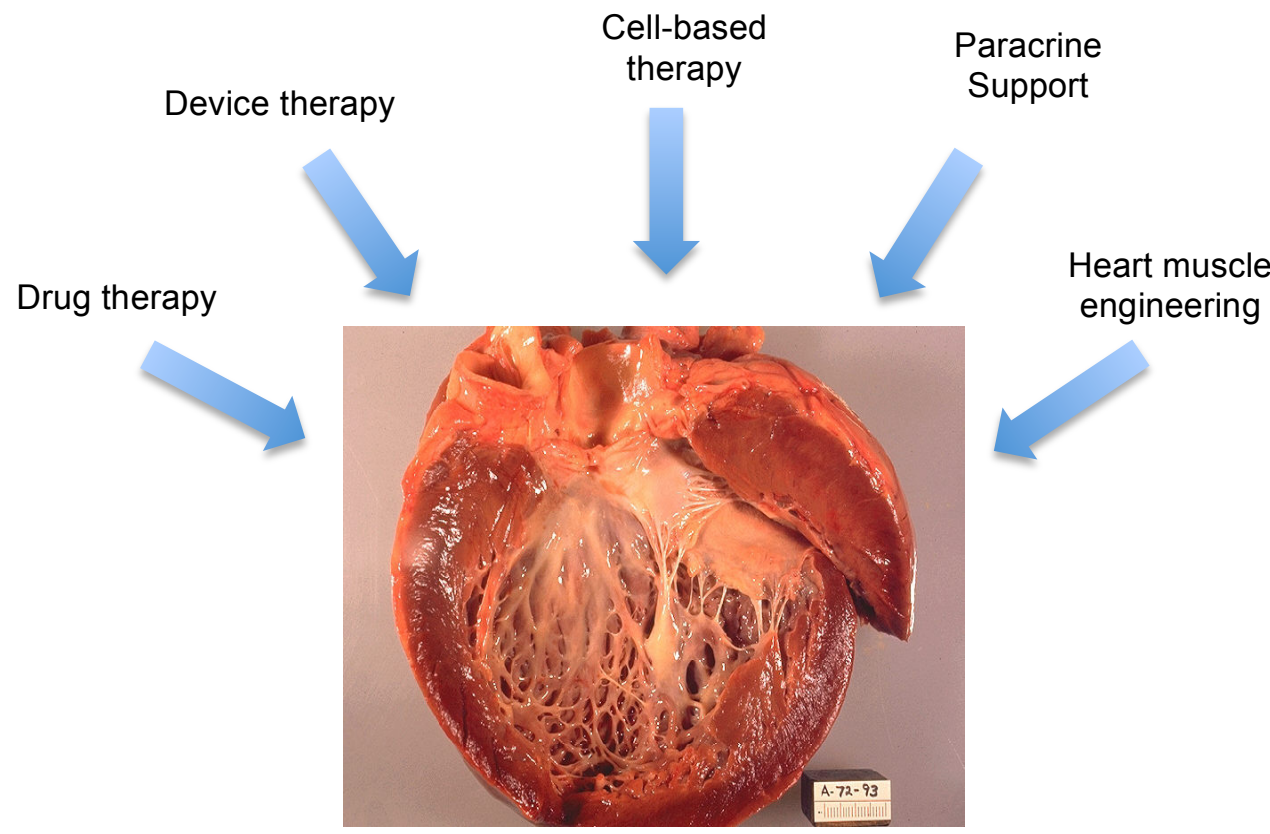

Figure 1. Summary of therapeutic strategies in heart failure.

Figure adapted from Dr. Edwin P. Ewing, CDC, USA. 


\section{$1.2 \quad$ Drug therapy}

Several classes of drugs have been shown to increase survival of heart failure patients. Beta-adrenergic receptor blockers, angiotensin-converting enzyme inhibitors / angiotensin II receptor 2 antagonists and aldosterone receptor antagonists have been demonstrated in clinical trials as individual or combinatorial drug therapy to lower total mortality and hospitalization by 30 $40 \%$ and also shown to improve left ventricular function in patients with class II through class IV heart failure (SOLVD-Investigators 1992, MERIT-HFInvestigators 1999, Pitt et al. 1999). These drugs have in common that they reduce neurohormonal activity and here in particular the stimulatory effects of endogenous catecholamines and the renin-angiotensin-aldosterone-system. Despite their success in clinical practice they do not stimulate cardiomyocyte proliferation and regeneration, and thus typically delay, but do not prevent the onset of late stage heart failure.

\subsection{Device therapy}

Throughout the progression of heart failure, the biophysical changes occurring in the cardiomyocytes lead to ventricle remodeling such as dilation of the myocardium, resulting in reduced left ventricular ejection fraction (LVEF); a critical index measured by amount of blood volume ejected from the left ventricle to the aorta and thus a widely used indicator of myocardium function. In end stage heart failure decrease of LVEF results in limited blood supply to the peripheral organs. To assist the failing heart cope with its pumping function, left ventricular assist devices (LVADs) can be implanted. LVADs are portable battery driven mechanical pumps which re-route blood supply from 
the left ventricle and pumps it into the aorta at an adjustable flow-rate. Recent developments in LVAD technologies have resulted in $2^{\text {nd }}$ and $3^{\text {rd }}$ generation non-pulsatile continuous-flow VADs yielding higher survival rates, better quality of life and longer device durability (Slaughter et al. 2009). However, while LVADs are able to reduce the overload of the heart and in some cases even appear to reverse heart failure progression, they do not represent a long-term solution, because of high unwanted side-effect rates; typically minor and major strokes in $70 \%$ of the patients in one year (Moazami et al. 1997, Lazar et al. 2004, Thoennissen et al. 2006).

An alternative "device" strategy was introduced with the Acorn Cor Cap Cardiac Support Device (ACSD; Acorn Cardiovascular Inc.; St Paul, MN, USA). ACSDs resemble knitted polyethylene terephthalate (PET) "bags" designed to be placed over the dilated heart as mesh wrap to restrict further dilation (Walsh 2005). In canine studies, restraint of left ventricle dilation was observed after ACSD placement (Sabbah 2005). Similar observations were made in a clinical study (Oz et al. 2003). However constriction of the heart was also observed in some patients, further compromising heart function. Finally, the ACSD was disapproved by the FDA primarily due to safety concerns (www.fda.gov/ohrms/dockets/ac/06/briefing/20064269b1_09_sponsor.pdf).

Taken together, neither LVADs nor ACSDs are capable of assisting in heart re-muscularization. 
As an ultimate device therapy the concept of building a complete artificial heart was introduced (Morrissey 2012). Following a successful preclinical attempt in a canine model by Kolff and colleagues in 1958 (Norman 1975, Cooley 2003), the first clinical artificial heart was successfully implanted in a man suffering acute coronary arterial occlusion and complete heart block (Cooley et al. 1969). Since then, continuous research led to several improvements for example by introducing novel materials and advanced design principles (Copeland et al. 2001, Gray and Selzman 2006). While these heart replacement devices extend life in patients with end-stage heart failure, they can only serve as a temporary solution while the patients await total heart transplantation, also because of procedure related side effects i.e. thrombosis, embolism, infections and device failure.

\section{$1.4 \quad$ Cell-based therapy}

Given the obvious limitations of drug and device therapy, novel cell-based approaches to achieve biological replacement of damaged myocardium have been introduced (Dimmeler et al. 2005, Murry et al. 2005). Skeletal myoblasts were tested first in animal models of myocardial infarction and demonstrated some therapeutic effects, despite their inability to trans differentiate into cardiomyocytes (Koh et al. 1993, Taylor et al. 1998, Atkins et al. 1999, Chedrawy et al. 2002, Reinecke et al. 2002). A first clinical trial was conducted and involved the implantation of autologous myoblasts directly into the infarcted scar tissue (Menasche et al. 2008). However, while the majority of patients demonstrated enhanced systolic function, 4 patients developed arrhythmias within 2 weeks of cell injections (Menasché 2009). Interestingly, 
there was no evidence for proper myoblasts integration into the host myocardium.

Other groups experimented with intravenous application of bone marrow derived mesenchymal stem cells (BM-MSCs) into a large infarcted region of the hearts from rats, mice and pigs (Tomita et al. 1999, Shake et al. 2002, Nagaya et al. 2005). Nagaya and co-workers injected MSCs directly into dilated hearts of a rat DCM model and demonstrated that surviving transplanted MSCs expressed connexin-43 at junctions between MSCs as well as with native cardiomyocytes suggesting that autologous MSCs are capable of survival and integration when heterotopically transplanted. The MSCs also secrete high levels of angiogenic and antiapoptotic factors such as insulin like growth factor 1 (IGF1), vascular endothelial growth factor (VEGF) and hepatocyte growth factor (HGF). Subsequently, clinical trials have been conducted demonstrating that autologous bone marrow cell transplantation can improve cardiac function likely by the inhibition of myocardial fibrosis as well as secretory growth factors that support myogenesis and angiogenesis (Murry, et al. 2005, Guarita-Souza et al. 2008, Strauer and Steinhoff 2011). Here it is important to note that additional animal studies have demonstrated that bone marrow cells and MSCs possess the risks of ectopic calcifications and ossifications in the heart (Breitbach et al. 2007). Nevertheless, human clinical trials are ongoing to ultimately assess safety, tolerability, and efficacy of bone marrow cell and MSC-based therapies (Schachinger et al. 2006, Assmus et al. 2010, Hare 2011). All of these trials target primarily patients with acute or sub-acute heart syndromes. In this scenario protective rather 
than reparative approaches may suffice to offer a substantial therapeutic benefit to patients.

In scenarios of chronic heart failure with substantial scarring there is clearly a need for re-muscularization. This may be best achieved by implantation of cardiomyocytes. In support of this, several groups have documented survival and integration of cardiomyocyte grafts in the heart (Soonpaa et al. 1994). These fundamental observations have been made in different animal models, but cannot be easily translated to the human, unless a reliable source for human cardiomyocytes can be identified.

In light of this, the introduction of robust protocols to derive and maintain human embryonic stem cells (hESCs) in a self-renewing state with pluripotent differentiation potential was a major breakthrough (Thomson et al. 1998). More recently, alternative human pluripotent stem cells, including induced pluripotent stem cells (Takahashi et al. 2007) and parthenogenetic stem cells (Turovets et al. 2011), became available and may offer new perspectives to overcome the obvious ethical restraints associated with a potential use of hESC (Laflamme and Murry 2005, Zimmermann 2011).

Today hESCs remain the gold standard for pluripotency and any pluripotent cell-based technology will have to be compared to it. hESCs can give rise to derivatives of the 3 germ lines - ectoderm, mesoderm and endoderm. Ectodermal differentiation is apparently the default differentiation pathway in most hESC lines (Vallier et al. 2004). Spontaneous mesoderm and in 
particular cardiomyocyte differentiation are minimal in ESCs, but may be enhanced by stage specific differentiation protocols, adapted to simulate the paracrine milieu that governs embryonic heart development (Kattman et al. 2011, Hudson et al. 2012). Coupled with new technologies to scale up the quantity of differentiated cardiomyocytes (Zweigerdt et al. 2011), these approaches would theoretically provide enough cardiomyocytes to replace and replenish those that were lost during myocardial infarction in a human heart (approx. $1 \times 10^{9}$ cardiomyocytes) (Reinecke et al. 2008). Alternatively, cardiomyocytes may be isolated and enriched by manual dissection of spontaneously beating areas within differentiating embryoid bodies (EBs) (Kehat et al. 2001, Xu et al. 2002), Percoll gradient centrifugation (Laflamme, et al. 2007), genetic selection in transgenic hESC-lines (Xu et al. 2008), or immune-assisted cell sorting via unique cell surface markers (Dubois et al. 2011, Elliott et al. 2011). Direct implantations of hESC-derived cardiomyocytes into pigs with experimental atrial-ventricular conduction block and guinea pig models demonstrated that these cardiomyocytes were able to function as pacemaker cells (Kehat et al. 2004, Xue et al. 2005) and further experiments in rodent models and mice demonstrated that these cardiomyocytes are capable of survival, engraftment and maturation long term (Laflamme et al. 2005, Dai et al. 2007, van Laake et al. 2007). However, this direct approach has its limitations and conflicting reports. Most studies report that direct injection of the cardiomyocytes into a pulsing heart leads to massive cell loss by immediate ejection. The remaining cells that are lodged in the myocardium typically undergo cell death (Müller-Ehmsen 2002, MullerEhmsen et al. 2002, Reinecke and Murry 2002, Dow et al. 2005). Well 
controlled animal studies demonstrate that only $<10 \%$ of the injected cells are retained (Zhang et al. 2001, Dow, et al. 2005, Qiao et al. 2009). In addition, when hESC derived cardiomyocytes were transplanted into rodents hearts, most of the transplanted cells secrete their unique extracellular matrix components which prevents the cells from integrating and connecting to the host myocardium; such fibrotic areas could also potentiate the risk for arrhythmia induction (Passier et al. 2008). However, a very recent study demonstrated that hESC derived cardiomyocytes can electrically couple and also prevent arrhythmias in infarcted guinea pig hearts (Shiba et al. 2012).

Another recently discovered pool of cells - cardiac progenitor cells (CPCs) has raised the possibility of endogenous heart regeneration (Hierlihy et al. 2002, Beltrami et al. 2003). These progenitors can be isolated by flow cytometry either by making use of a Hoechst dye extrusion assay (Jackson et al. 2001) or by selection via surface markers such as c-kit (Beltrami et al. 2003) and Sca-1 (Oh et al. 2003). Preliminary studies with transplanted animal CPCs and also sheets of clonally expanded Sca- $1^{+}$cells into infarcted animals suggested that CPCs are able to home to the injured myocardium (Oh, et al. 2003) and improve cardiac functions post infarct through VCAM1/VLA-4 signaling (Matsuura et al. 2009). These endogenous cells were also able to respond to growth factor stimulation via mobilization to the injured areas (Bocchi et al. 2011, Ellison et al. 2011). In humans, CPCs were also identified (Messina et al. 2004) and could be genetically modified to proliferate, survive, engraft with enhanced improvement to the injured myocardium structure and function (Mohsin et al. 2011). In clinical trials, patients with 
ischemic cardiomyopathy were transplanted with human cardiac stem cells and preliminary results demonstrated that intracoronary infusion of autologous cardiac stem cells improved left ventricular systolic function and also reduced the infarcted size in patients with heart failure (Bolli et al. 2011). Similar results were obtained in another study from the Marban laboratory using the autologous CPC approach (Makkar et al. 2012). Both studies were not powered to draw any conclusions towards efficacy. This will have to be tested in follow-up trials. In addition, the mechanism of action of the cell grafts is not well understood.

\subsection{Paracrine Support - IGF-1}

A key observation from the many experimental and clinical cell-based studies is that irrespective of the cell entity employed, therapeutic effects could be observed. This raised the question whether a set of commonly secreted factors underlies the cell-based therapeutic effect rather than functional integration of contractile units into the heart, which was not observed in most of the tested cell types. Among the many paracrine factors released from cell grafts IGF-1 appears to exhibit strong "therapeutic" activities, i.e. enhanced cell survival, cardiomyocyte hypertrophy, and enhanced angiogenesis (Welch et al. 2002, Shyu et al. 2005, Dobrucki et al. 2010).

IGF-1 application has been introduced clinically in the treatment of patients with Rett Syndrome (ClinicalTrials.gov Identifier: NCT01253317), amyotrophic lateral sclerosis (ClinicalTrials.gov Identifier: NCT00035815) and Duchenne

muscular dystrophy (ClinicalTrials.gov Identifier: NCT00004646). In heart 
failure, IGF-1 was tested to induce physiological hypertrophy in dilated ventricular myocardium (Osterziel et al. 1998, Vasan et al. 2003); these investigators could, however, not identify a clear therapeutic benefit of systemically applied IGF-1. Presently, safety and efficacy of IGF-1 (Mecasermin; single dose, intracoronary injection) is tested in patients with ST-elevation Acute Myocardial Infarction (STEMI; ClinicalTrials.gov Identifier: NCT01438086).

Biologically active IGF-1 is a 70 amino acid protein that is encoded on 6 exons. It is mainly produced in the liver in response to growth hormone stimulation and circulates throughout the body bound to its binding protein (IGFBP3). There are 4 IGF-1 splice variants, which can be further grouped in 2 classes (Figure 2). The mature peptide is encoded in exons 3 and 4 . The definite roles of the IGF-1 splice variants are not fully understood, but most biological activities are affiliated to class 1 IGF-1 protein variants (Bloor et. al., 2001). 


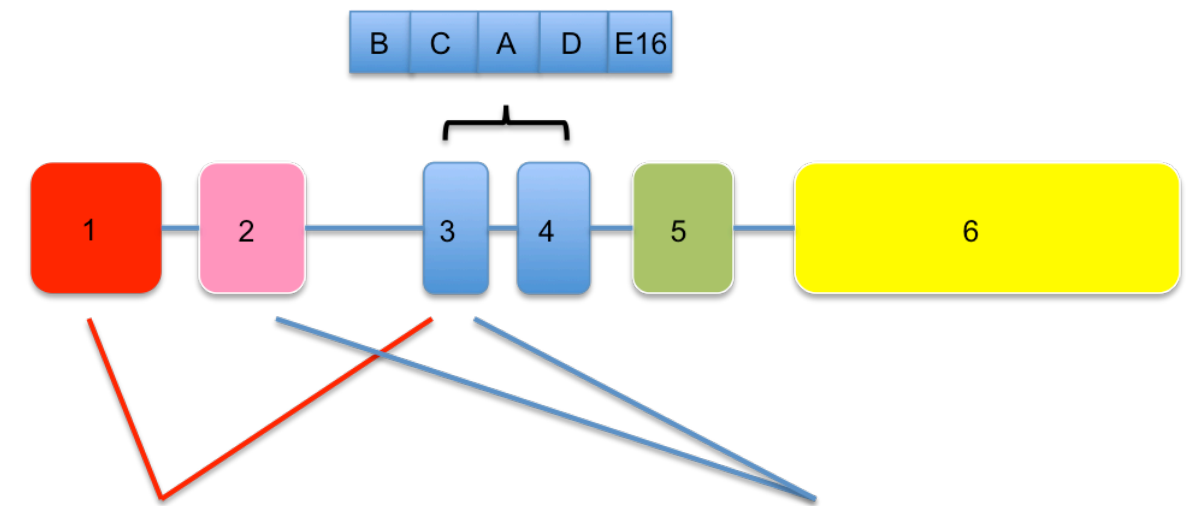

\section{Class 1}

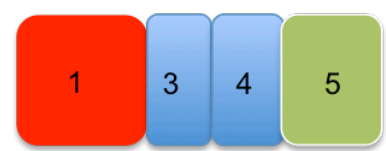

variant 3
Class 2

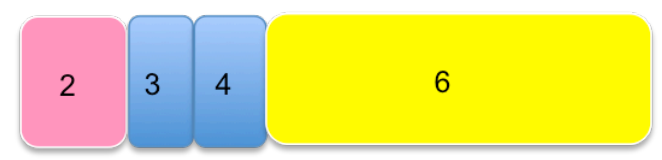

Variant 2 variant 4

6

Class 1

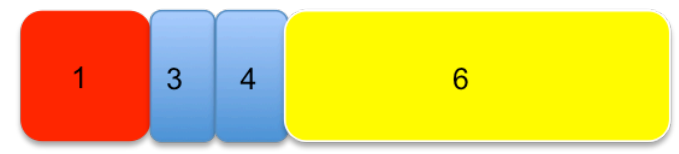

Class 2

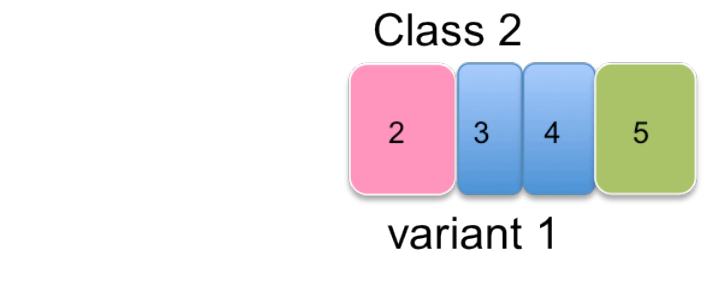

Figure 2: Schematic overview of IGF-1 splice variants. Numbers represents exons. The biologically active IGF-1 peptide is encoded on exons 3 and 4.

IGF-1 binds to a specific receptor (IGF-1R) and activates a variety of signaling cascades (Mourkioti and Rosenthal 2005), which include phosphatidylinositol3-kinase (PI3K)/Akt, mitogen-activated-protein-kinase (MAPK), and calmodulin dependent kinase (CaMK) signaling (Figure 3). Of particular therapeutic interest in heart failure may be its activation of pro-survival pathways and induction of physiological cardiomyocyte hypertrophy. Unwanted effects include the possibility to induce oncogenic cell growth. 


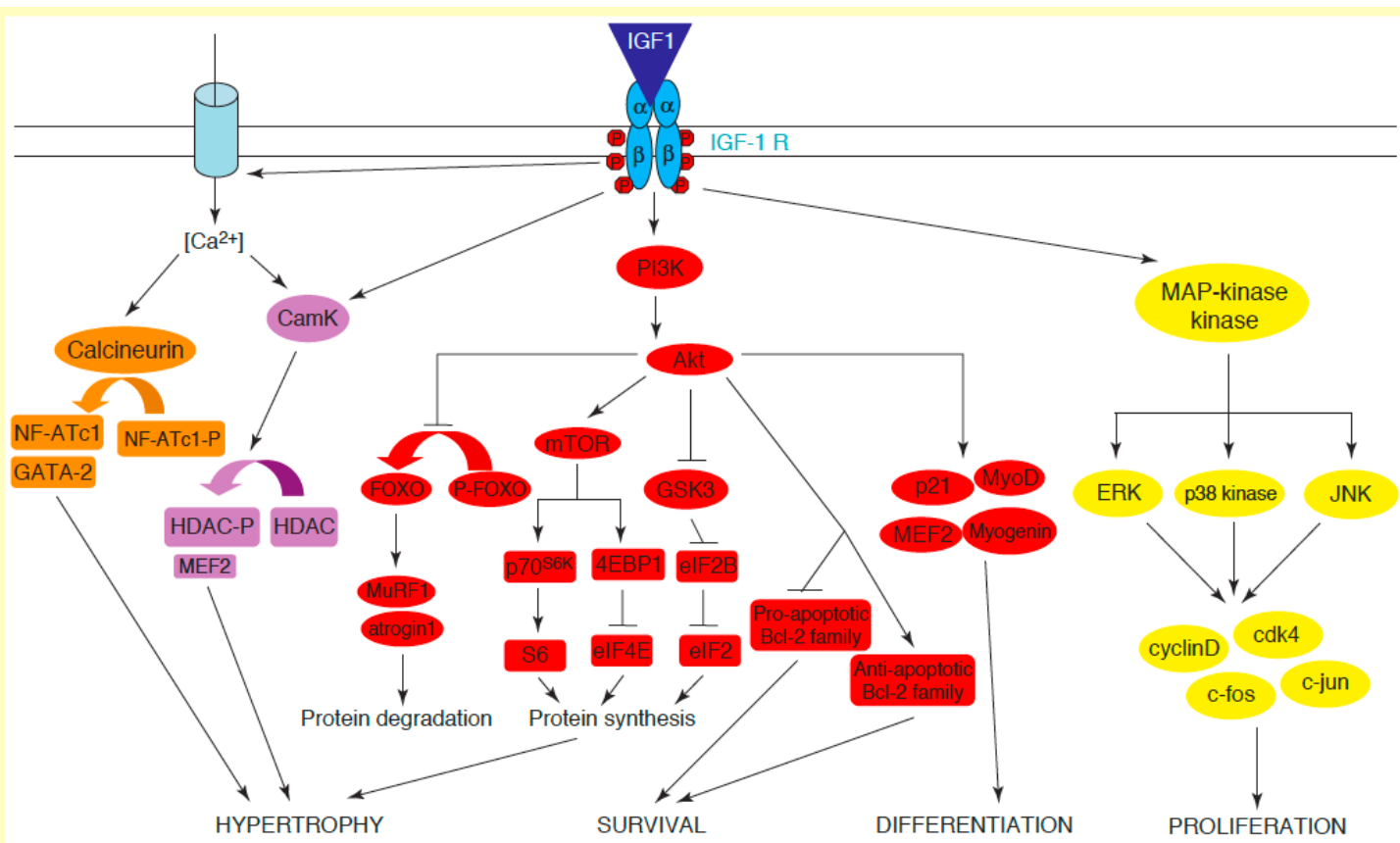

Figure 3. Schematic overview of IGF-1R signaling pathways.

Adapted from Moukioti and Rosenthal (2005).

\subsection{Heart muscle tissue engineering}

Tissue engineering has been developed to biophysically support the failing heart, but also to provide in vitro test-beds for drug development and studies of organogenesis (Eschenhagen and Zimmermann 2005). In heart muscle repair the main goals are to (1) add contractile elements to the failing heart for functional support and (2) provide restraint similar to the ACSD approach, but fully humanized. The most direct approach involves the use of scaffolds, either synthetic (Carrier et al. 1999) or biological (Li et al. 1996, Eschenhagen et al. 1997, Zimmermann et al. 2000, Zimmermann et al. 2002, Bursac et al. 2007, Tian and Morrisey 2012), and seeding of cardiomyocytes in or on these scaffold. The first macroscopic contractile three-dimensional heart-like tissue 
was engineered from embryonic chick cardiomyocytes as in vitro model for target validation (Eschenhagen, et al. 1997). This was followed by the advent of mammalian engineered heart tissues (EHTs) for drug screening and therapeutic applications (Zimmermann, et al. 2000, Zimmermann, et al. 2002, Zimmermann et al. 2004, Naito et al. 2006, Zimmermann et al. 2006) In contrast to other original tissue-engineered heart muscle models (Bursac et al. 1999, Carrier, et al. 1999, Li et al. 1999, Kelm and Fussenegger 2004, Leung and Sefton 2010), EHTs displayed coordinated beating with directed force development and heart muscle-like physiology (e.g., Frank-Starling mechanism) and pharmacological responses (e.g., beta-adrenergic and muscarinic modulation of contractile properties). Subsequently, alternative tissue engineering modalities with comparable functionality have been introduced (Radisic et al., 2004; Shimizu et al., 2002). Importantly, EHT cultures support anisotropic tissue organization and maturation of immature cardiomyocytes (Zimmermann, et al. 2002, Tiburcy et al. 2011). Based on this, it appeared straightforward to postulate that the EHT culture format would also support the assembly of immature hESC-derived cardiomyocytes into functional myocardium.

Despite the recent increased focus on developing advanced models of engineered tissues, several key clinical challenges remain to be addressed: engineered cardiac constructs should be of a clinically relevant size and thickness and consist of immunologically tolerable cell populations in collagen-based matrix similar to the host heart (Vunjak-Novakovic and Scadden 2011). These constructs must also be able to connect to the host 
blood supply, propagate electrical pulses which must be synchronized with the host myocardium, and subsequently generate sufficient contractile force to aid in blood circulation. First proof-of-concept for these in vivo functionalities stems from EHT engraftment in rats with myocardial infarction (Zimmermann, et al. 2006).

To address the size issue, attempts were made by up scaling the physical area and thickness of cardiac tissue constructs. Most of these involve the fusion or stacking of tissue constructs such as EHTs (Naito et al., 2006) or with cell sheets (Shimizu et al. 2006). To further extend the applications of the EHT technology, a different approach to provision of cardiac restraint with contractile elements was attempted. This involved the development of a continuous pouch-like EHT (Yildirim et al. 2007), which allowed the embracement of the heart ventricles with an anticipated function as biological ventricular assist device (BioVAD). The BioVADs were generated using neonatal rat cardiomyocytes mixed with collagen type 1 and placed over a spherical glass mold to allow tissue condensation within 7 days. BioVADs were observed to maintain spontaneous contractions throughout the casting and condensation stages, and force measurements demonstrated heart-like contractile properties. In addition, these BioVADs stably grafted onto the epicardial surface of rat hearts. Vascularization occurred rapidly in vivo. The study suggested that BioVADs could be engineered to provide a large tissue construct capable of therapeutically restraining the failing heart and adding contractile elements to aid in myocardial force generation. 


\section{$1.7 \quad$ Objectives}

The overarching aim of this dissertation was to advance the BioVAD concept to a human model with enhanced (paracrine) functionality. Following main objectives were defined and are summarized in Figure 4:

1) Implementation of robust protocols to direct cardiogenicity in human ESC cultures

2) Development of human engineered heart muscle (EHM) with properties of native myocardium

3) Construction of human BioVADs based on the knowledge gained from the human EHM and rat BioVAD models

4) Integration of paracrine IGF-1 activity into the human BioVAD approach.

5) Testing the feasibility of human BioVAD implantation in vivo.

1
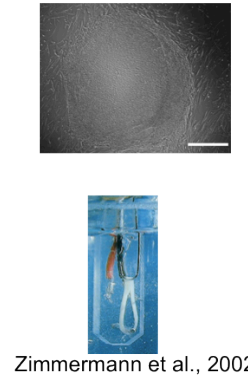

3

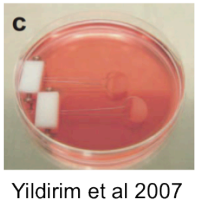

4

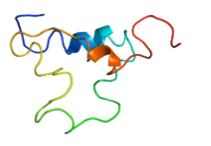

IGF-1
Graichen et al 2008

Hudson et al., 2012

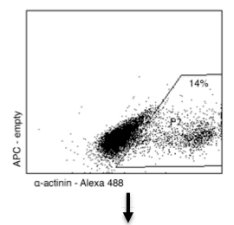

CM enrichment

$$
\underset{\substack{\text { Humanize EHM } \\ \text { Technology }}}{\longrightarrow}
$$
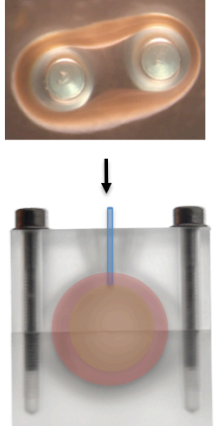

$$
\underset{\begin{array}{c}
\text { Scale BioVAD } \\
\text { Technology }
\end{array}}{\stackrel{\text { Humanize }}{\longrightarrow}}
$$
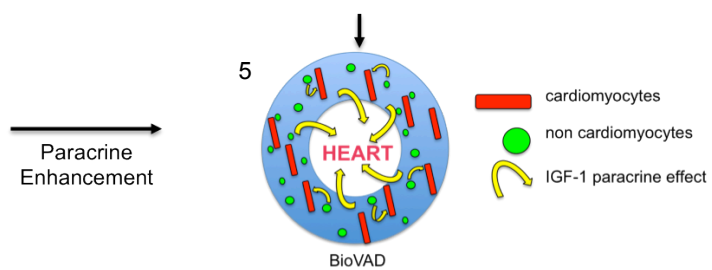

Figure 4: Experimental outline of the dissertation. 
All experiments were performed according to institutional regulations and good laboratory practice rules. Animal experiments were approved by LAVES (AZ 10.13, AZ 33.9-42502-04-12/0830). All substances were acquired at highest grade from SIGMA ALDRICH if not indicated otherwise.

\subsection{Human embryonic stem cell culture}

Import and experimentation with human embryonic stem cells were approved by the Robert-Koch-Institute (www.rki.de; approval \#12 from 13.09.2005 to W.H. Zimmermann according to $§ 11$ Stammzellgesetz).

\subsubsection{Human feeder cells preparation}

Human foreskin fibroblasts (HFFs) cells were purchased from the American Type Culture Collection (SCRC-1041; ATCC) and propagated in HFF-medium (Appendix) to passage 20 for cryopreservation at $-152^{\circ} \mathrm{C}$ in cryo-medium (Appendix) for controlled freezing rate of cells. Passage 21 and onwards HFF cells were subsequently used to support hESC culture. Briefly, $2 \times 10^{6} \mathrm{HFF}$ cells were harvested by trypsinization and exposed to 30 Gray $\mathrm{Y}$-irradiation (STS Biobeam 8000, Germany) to mitogenically arrest the cells. Subsequently, inactivated HFF cells were plated down on a cell culture dish. The culture dish was then incubated in a $37^{\circ} \mathrm{C}$ cell culture incubator for 24 hours. Thereafter, the cells were rinsed with PBS to remove the serum and 
fresh hESC medium (Appendix) was overlaid. Subsequently, hESC colonies can be plated on top of the irradiated HFF cells.

\subsubsection{Embryonic stem cell culture}

hESC lines, HES2 and HES3 (ES Cell International, Singapore), were obtained and adapted to culture on $y$-inactivated HFFs. hESC-medium was exchanged daily until colonies covered $80 \%$ of the culture dish. hESC cultures were tested to be free of mycoplasma using the MycoAlert ${ }^{\mathrm{TM}}$ Mycoplasma detection kit (Lonza).

\subsubsection{1 "Cut and Paste" passaging}

Undifferentiated hESCs were cultured as intact colonies and split at 1:9 ratio when confluent. The colonies were then enzymatically digested with collagenase IV working solution (Appendix) and either manually scored using a glass needles or by rolling with the StemPro ${ }^{\circledR}$ EZPassage ${ }^{\mathrm{TM}}$ Tool (Invitrogen) to obtain homogeneously sized cell rafts (Figure 5). These cell rafts were then either seeded onto another plate of irradiated HFFs for continual passage or subjected to embryoid bodies (EB) based cardiac differentiation protocols. 


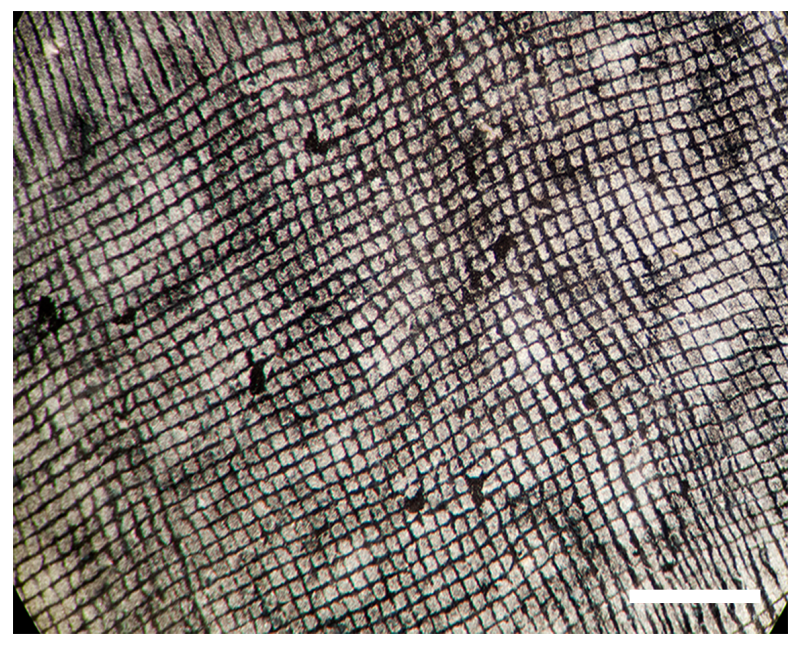

Figure 5: hESC colonies scored with the EZ Passage tool. Image displays a representative HES3 culture. Scale bar $1 \mathrm{~mm}$. Image from Soong et al., 2012.

\subsubsection{Monolayer passaging}

Undifferentiated hESC were first single cell adapted to a monolayer culture as outlined (Hudson, et al. 2012). Briefly, confluent hESC cultures were gently enzymatically dissociated with TrypLE (Invitrogen) and triturated with a $10 \mathrm{ml}$ serological pipette (Sarstedt) to obtain a homogenous suspension of single hESC with little contaminating fibroblast cells. The dissociated hESC were then plated onto $2.6 \times 10^{6} \mathrm{y}$-irradiated HFFs and allowed to expand for further 7 days in a $37^{\circ} \mathrm{C}$ humidified $5 \% \mathrm{CO}_{2}$ incubator. After at least 10 rounds of cell passaging, hESC were considered "single cell adapted" and suitable for monolayer cardiomyogenesis differentiation protocols. 


\subsubsection{Embryonic stem cell differentiation}

\subsubsection{Embryoid body differentiation}

HES 3 cell rafts were first adapted to serum free conditions in SF adaptation medium (Appendix) and incubated in a $100 \mathrm{~mm}$ Ultra-low ${ }^{\circledR}$ Petri dish (Corning) where EBs are spontaneously forming. These were then subjected to cardiomyocyte differentiation (Graichen et al. 2008) as follows. First a 40 $\mu \mathrm{m}$ cell strainer was inverted into an open $50 \mathrm{ml}$ centrifuge tube and placed carefully in a tube rack. Next, the Ultra Low ${ }^{\circledR}$ petri dishes containing the EBs were removed from the incubator. Then, the entire culture was passed through the inverted cell strainer rinsed with bSFS medium (Appendix). After the flow through was completed, the cell strainer was turned so that it sat properly inside the opening of a new sterile $50 \mathrm{ml}$ centrifuge tube. $10 \mathrm{ml}$ of bSFS containing $5 \mu \mathrm{mol} / \mathrm{L}$ of SB203580 (p38 MAPK inhibitor) was added in the dark and used to flush the EBs back into a centrifuge tube. Then they were transferred back into the source Ultra Low ${ }^{\circledR}$ Petri dish and incubated further (Figure 6). This was marked as Day 2 of differentiation. Medium change was performed every day until culture day 3 where it was then changed every 2 days. Spontaneously beating EBs can be observed from culture day 8 onwards. 


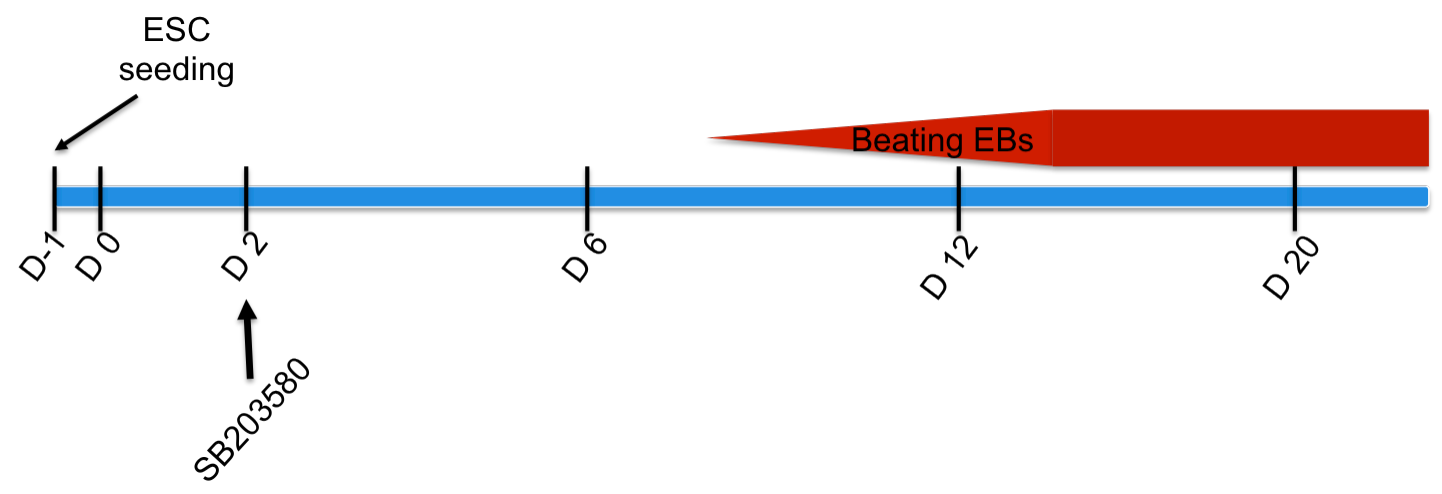

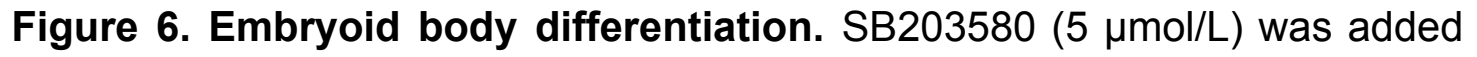
on day 2 (D2). Beating was observed to start on culture day 8 with increasing beating areas until culture day 14. D-1 denotes day of ESC seeding.

\subsubsection{Monolayer differentiation}

hESC colonies were first single cell adapted to form monolayers and then subjected to a modified cardiomyocyte differentiation protocol as outlined (Hudson, et al. 2012). Briefly, single cell adapted hESCs $\left(0.5 \times 10^{4}\right.$ cells per $\mathrm{cm}^{2}$ in a 24 well culture dish format) were exposed to a mesodermal induction protocol of 16 days (Figure 7 ). 


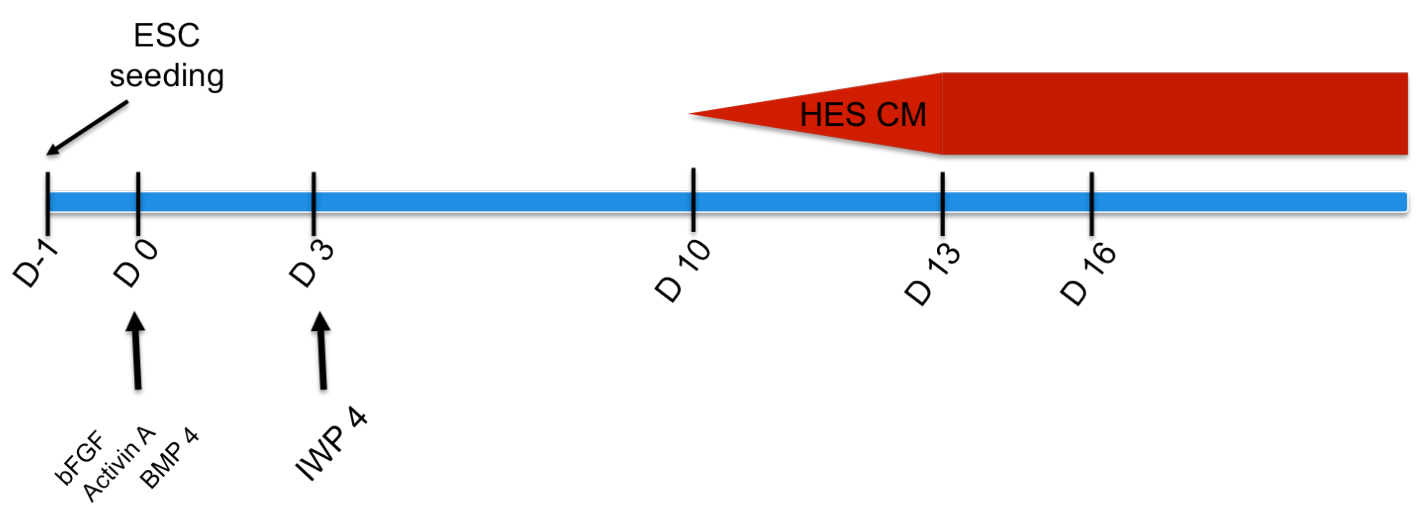

Figure 7. Monolayer differentiation. Activin and BMP were added for 3 days before Wnt signaling was inhibited with IWP4 (Wnt inhibitor) on culture day 3. First beating was observed on culture day 10 .

From days 0 - 2, hESCs were cultured in serum free basal monolayer differentiation medium (Appendix) supplemented with $9 \mathrm{ng} / \mathrm{ml}$ Activin A, 5 ng/ml BMP4 (both R\&D Systems), 5 ng/ml bFGF (Millipore). From Day 3 - 10, Activin A, BMP4 and bFGF were withdrawn. Culture medium was exchanged and supplemented with $5 \mu \mathrm{mol} / \mathrm{L}$ IWP4 (Stemgent) every $3^{\text {rd }}$ day until day 13 . From day 13 - 16, cardiomyocyte specification was enhanced withdrawal of IWP4 from basal monolayer differentiation medium. Typically, first beating areas in the cultures were observed between days $10-13$.

\subsubsection{Flow cytometry}

For analyzing pluripotency and cardiac differentiation efficiency cells were dissociated with trypsin and pelleted at $300 \times \mathrm{g}$ for 4 minutes. The supernatant was aspirated. The dissociated cells were fixed with $4 \%$ paraformaldehyde 
(Histofix, Roth) for 24 hours. Next, 2 wash steps with PBS were performed and samples were then permeabilized with Triton X-100 in a blocking buffer (Appendix) for 10 minutes at room temperature followed by the staining by primary antibodies against Tra1-60, Oct4, SSEA4 for 1 hour at $4{ }^{\circ} \mathrm{C}$. Following 3 additional wash steps with blocking buffer, secondary antibodies (goat antimouse IgG conjugated with Alexa Fluor ${ }^{\circledR} 488$, Invitrogen 1:1000) and nuclear label dye, DAPI $(1 \mu \mathrm{g} / \mathrm{ml}, 1: 1000)$ were then incubated with the cells for 30 minutes at $4{ }^{\circ} \mathrm{C}$ in the dark.

For ESC derived cardiomyocytes analysis, $70 \%$ ethanol fixed single cells were incubated in blocking buffer (Appendix) for 10 minutes followed by incubation with primary antibodies against alpha sarcomeric actinin (SigmaAldrich A7811, 1:4000) for 1 hour at $4{ }^{\circ} \mathrm{C}$. Following 3 additional wash steps with blocking buffer, secondary antibodies (goat anti-mouse, IgG conjugated with Alexa Fluor ${ }^{\circledR} 488$, Invitrogen 1:1000) and nuclear label dye, DAPI, were then added and the cardiomyocytes were incubated for 30 minutes at $4^{\circ} \mathrm{C}$ in the dark.

In parallel, cell populations incubated with IgG isotype control primary antibodies with appropriate secondary antibodies served as negative controls. Recordings were performed on a LSRII cytometer (BD) and analyzed using FACSDiva Software 6.0 (BD) or Cyflogic Software. The following gating strategy was applied. The population of interest was first displayed in FSC and SSC (Figure 8 A). A DNA stain was used to gate out dead cells (sub-G1 fraction, Figure $8 \mathrm{~B}$ ). The width of the DNA signal was then used exclude cell 
doublets (Figure $8 \mathrm{C}$ ). These gated cells were then displayed based on actinin fluorescence (Figure 8 D) to distinguish between cardiomyocytes (CM; actinin+) and non-myocytes (NM; actinin-).

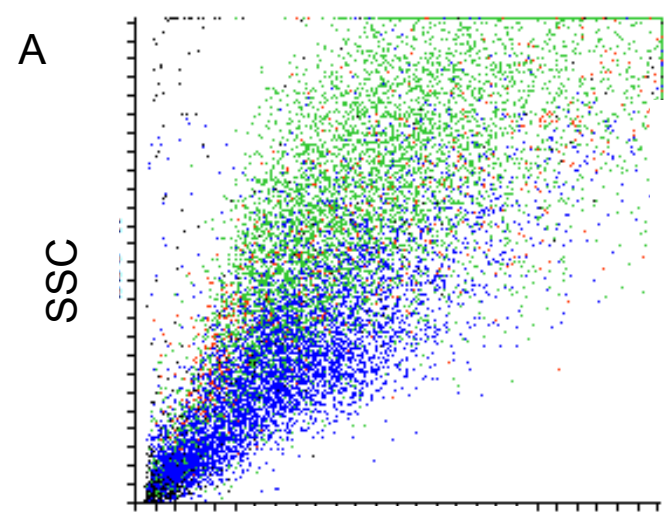

FSC

C

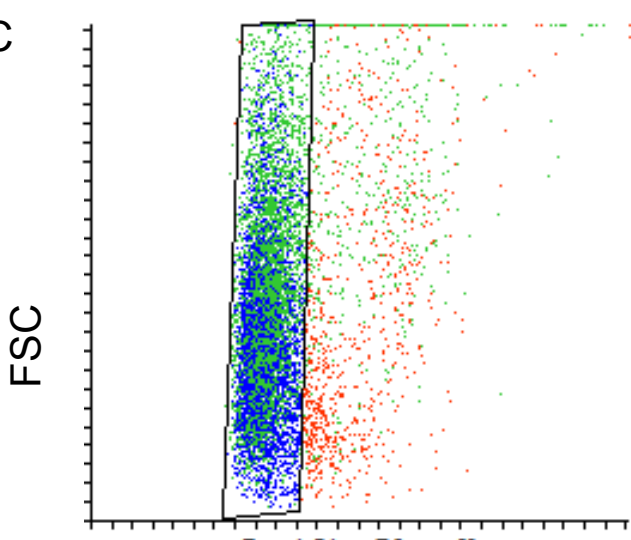

DAPI width

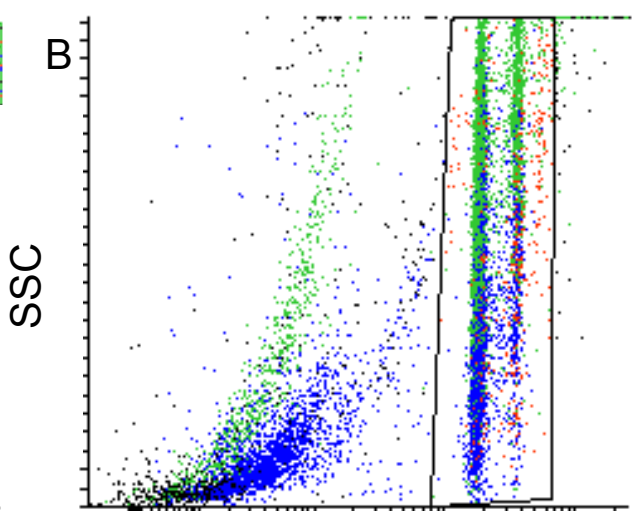

DAPI Amplitude/Intensity

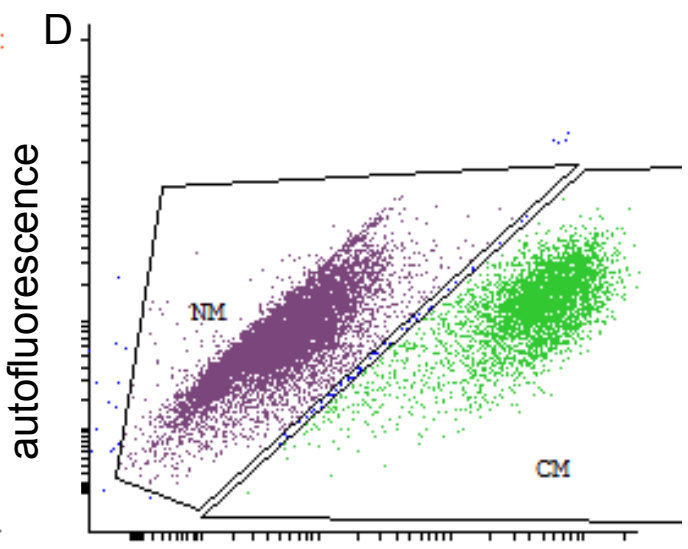

Actinin

Figure 8. Flow cytometry gating strategy. (A) Cells were displayed as scatter plot based on SSC + FSC. (B) Viable cells in G1 + G2 were selected based on DAPI signal intensity. (C) Doublets were excluded based on DAPI signal width. (D) Cardiomyocytes (CM) and non-myocytes (NM) were distinguished based on actinin positivity. Similar gating strategies were applied for detection of stem cell markers. 


\subsection{Generation and characterization of human Engineered Heart Muscle (EHM)}

\subsubsection{Preparation of casting molds}

To generate the casting molds for EHMs, 4 Teflon spacers of $11 \mathrm{~mm}$ diameter and $5 \mathrm{~mm}$ height were evenly spaced in a glass petri dish (Figure $9 \mathrm{~A}$ ). $9 \mathrm{ml}$ of Sylgard Silicone 184 (Dow Corning) and $1 \mathrm{ml}$ of curing agent were pipetted and mixed thoroughly in a $50 \mathrm{ml}$ centrifuge tube and spun at $300 \times \mathrm{g}$ for 3 minutes to remove air bubbles. The silicone mixture was then poured into the glass dish around the Teflon spacers, allowed to harden for 24 hours at room temperature. Next, the Teflon spacers were carefully removed with forceps and a droplet of premixed silicone was applied to each of the centers of the four recesses to attach a short silicone core upright (Figure $9 \mathrm{~A}$, ii) The assembled casting mold was allowed to cure at $55^{\circ} \mathrm{C}$ overnight.

To ensure the removal of toxic residuals from casting molds, they were placed in a glass beaker filled with distilled water, boiled and drained at least 4 times. Thereafter, silicone tubings (Figure $9 \mathrm{~A}$, iii) were slipped over the silicone cores and the fully assembled casting mold was wrapped in aluminum and autoclaved until ready for use. These casting molds can be reused indefinitely. 


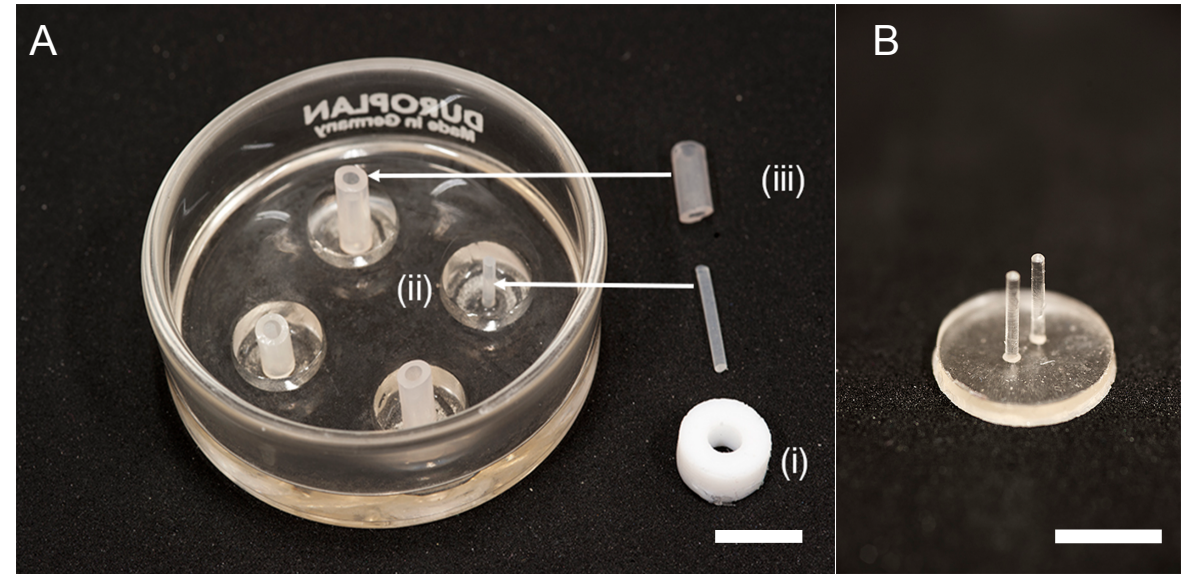

Figure 9: Casting mold and silicone holder for EHM culture. A: Glass culture dish filled with transparent silicone and 4 circular recesses with central spacers: (i) Teflon disc of $11 \mathrm{~mm}$ diameter and $5 \mathrm{~mm}$ height with central hole used as spacer during the silicone hardening process; (ii) recess with thin silicone core; (iii) silicone tubing used as inner spacer during the EHM formation process placed over a central silicon core. B: Flexible silicone poles for mechanical loading of EHM. Scale bars: $10 \mathrm{~mm}$. Image from Soong et al., 2012.

\subsubsection{Preparation of holding devices}

Flexible silicone poles (length: $11 \mathrm{~mm}$, thickness: $1.5 \mathrm{~mm}$, inner/outer distance: $3 / 6 \mathrm{~mm}$ ) with circular base (diameter: $20 \mathrm{~mm}$, thickness: $1.6 \mathrm{~mm}$ ) were made from Sylgard Silicone 184 (Dow Corning) as resilient holder (Figure 9 B) Before use they were boiled in distilled water, drained and autoclaved. 


\subsubsection{Preparations of cells}

Human EHM generation involves the casting of single cells, ESC-derived cardiomyocytes with or without non-myocytes such as fibroblasts, into a collagen-based hydrogel to form a 3 dimensional organoid.

\subsubsection{Embryonic stem cells}

To obtain single hESC derived cardiomyocytes from EBs or monolayer cells for human EHM generation, cells were first incubated with $0.2 \%$ collagenase type 1 (C0130, Sigma Aldrich) for 45 minutes at $37^{\circ} \mathrm{C}$ and then incubated with $0.25 \%$ trypsin (Invitrogen) for 5 minutes at room temperature. Trituration with micropipettes was performed to further dissociate cell clumps for 5 minutes at room temperature. Full neutralization with complete human EHM medium (Appendix) was next carried out and cells were centrifuged at $300 \times \mathrm{g}, 4$ minutes. Supernatant was aspirated and the cell pellet was resuspended in complete medium until a homogenous single cell suspension was obtained. Cells were counted with a Neubauer counting chamber.

\subsubsection{Human foreskin fibroblasts (HFF)}

To obtain single HFF cell suspensions, wild type or transgenically modified HFF cells were incubated with TrypLE Express (Invitrogen) for 3 minutes at $37^{\circ} \mathrm{C}$ and then triturated with a $10 \mathrm{ml}$ serological pipette to further dissociate cell clumps. Next, complete HFF medium (Appendix) was added to neutralize the enzymatic activity. Cells were then centrifuged at $300 \times \mathrm{g}, 4$ minutes and 
supernatant was aspirated. The required number of cells was counted in a Neubauer cell counting chamber.

\subsubsection{Construction and culture of EHM}

Single cells were mixed thoroughly with collagen type I, 2X DMEM (Appendix), $\mathrm{NaOH}$ and Matrigel in a prechilled $15 \mathrm{ml}$ centrifuge tube accordingly (Table 1). $\mathrm{NaOH}$ was added drop wise until Phenol red color indicator changes from yellow (acidic) to pink. Then, $450 \mu$ of the master mix was quickly distributed into individual casting mold recesses (Figure $9 \mathrm{~A}$ ) and placed in a $37^{\circ} \mathrm{C}$ humidified incubator with $5 \% \mathrm{CO}_{2}$ for 1 hour. Following that, $6 \mathrm{ml}$ of prewarmed complete EHM medium was overlaid until all EHMs were completely covered with medium and then incubated for a further 24 hours and medium was exchanged thereafter every other day. After the EHMs had progressively condensed, typically after 3 days, they were transferred onto resilient silicone holders (Figure $9 \mathrm{~B}$ ).

\begin{tabular}{|l|r|r|}
\hline Number of EHM & 4 & 20 \\
\hline Rat Collagen $(3.2 \mathrm{mg} / \mathrm{ml})$ & $440 \mu \mathrm{l}$ & $2,200 \mu \mathrm{l}$ \\
\hline $2 \mathrm{X}$ DMEM & $535 \mu \mathrm{l}$ & $2,675 \mu \mathrm{l}$ \\
\hline $\mathrm{NaOH} 0.1 \mathrm{~N}$ & $95 \mu \mathrm{l}$ & $475 \mu \mathrm{l}$ \\
\hline Matrigel $^{(}$ & $200 \mu \mathrm{l}$ & $1,000 \mu \mathrm{l}$ \\
\hline Cell Suspension $\left(1.5 \times 10^{6}\right.$ per EHM) & 829 & 4,145 \\
\hline TOTAL VOLUME & $2,100 \mu \mathrm{l}$ & $10,500 \mu \mathrm{l}$ \\
\hline
\end{tabular}

Table 1: EHM reconstitution mixture. 
Prior to the transfer of condensed EHMs, the necessary number of silicone holders was first placed into a tissue culture plate filled with EHM medium. Thereafter, the top of the removable silicone tubing of a casting mold dish was pinched gently with a pair of curved forceps and slowly removed from the casting dish. Next, the silicon tube was placed over one of the paired silicone poles of a silicone holder and the EHM was released by gentle shaking or nudging with a pipette tip. With the help of another sterile pipette tip, the other silicone pole was gently bent to suspend the EHM between the 2 poles. The contracting EHM will bend the silicone holders inducing dynamic load for the EHM to work against. Medium was exchanged every 2 days over the next 7 days of EHM maturation. EHMs were ready for end-point analyses on culture day 10.

\subsubsection{Isometric force measurements}

Force measurements of EHMs were performed in thermostatted organ baths (FMI GMbH) as previously described (Zimmermann, et al. 2000). Briefly, after day 7 of EHM culture on silicone stretchers, EHMs were carefully removed and placed over the hooks of a force transducer in an organ bath filled with Tyrode's solution (Appendix). EHMs were field stimulated via two platinum electrodes at $2 \mathrm{~Hz}$ (5 ms monophasic pulses, $200 \mathrm{~mA}$ ) and preloaded to the length of maximal force production (Lmax). Then the responses to increasing calcium concentrations ( 0.2 to $4 \mathrm{mmol} / \mathrm{L})$ data were acquired using BMON software and analyzed by AMON software (both Jäckel; Hanau, Germany). 


\subsubsection{Immunofluorescence imaging}

Whole mount immunofluorescence antibody staining was performed to visualize cardiac muscle formation within the EHM. EHMs were fixed in $4 \%$ formaldehyde solution (Histofix, Roth) overnight. EHMs were then incubated in a permeabilizing blocking buffer for 24 hours. Next, EHMs were incubated with primary antibodies against alpha sarcomeric actinin (Sigma-Aldrich A7811, 1:4,000) for 3 days at $4^{\circ} \mathrm{C}$ on a rotary microfuge holder. Thereafter, 3 thorough wash steps with blocking buffer (Appendix) were performed followed by the incubation with secondary antibodies (goat anti-mouse $2 \mathrm{mg} / \mathrm{ml}$, IgG conjugated with Alexa Fluor ${ }^{\circledR} 488$, Invitrogen 1:1,000), phalloidin (conjugated with Alexa Fluor ${ }^{\circledR} 546$, Mobitec 1:60) and nuclear label dye, DAPI (1 $\mu \mathrm{g} / \mathrm{ml}$, 1:1000) for 24 hours at $4^{\circ} \mathrm{C}$ in the dark. The EHMs were thoroughly washed with PBS and finally mounted on microscope slides for image capture and analysis. Images were taken with a Zeiss LSM710 confocal microscope.

\subsubsection{Dissociation of EHM for flow cytometry}

To obtain cells from EHMs for flow cytometry, each EHM was cut into half and incubated in $1 \mathrm{ml}$ of collagenase for 30 minutes at room temperature. Thereafter, the remaining large pieces were gently teased apart with two $27 \mathrm{G}$ needles to obtain smaller pieces in the cell culture well. Next, further enzymatic dissociation of the pieces was performed according to the procedures highlighted in section 2.2.3.1. After single cells were obtained from the dissociation of EHMs, the cells were fixed in $70 \% \mathrm{EtOH}$ and kept in 4 ${ }^{\circ} \mathrm{C}$ until flow cytometry. 


\subsection{Generation and characterization of BioVADs}

\subsubsection{Construction of BioVADs}

Modifications of the original rat BioVAD protocols (Yildirim et al., 2007) were required to create a scalable casting mold for the generation of large humanized BioVADs. In addition, to confer a biomimetic culture format with regular pulsatile action, an inflatable inner structure required to be designed.

A series of casting cubes from Makrolon ${ }^{\circledR}$ (Bayer MaterialScience) were spherically machine-hollowed out and aligned to generate $18 \mathrm{~mm}, 20 \mathrm{~mm}$ and $30 \mathrm{~mm}$ casting molds. $10 \%$ molten agarose was poured into the $18 \mathrm{~mm}$ casting mold and cooled to form a solidified spherical agarose ball and speared with a central wooden spine. Next, the ball and stick was removed, centrally placed in a $20 \mathrm{~mm}$ casting mold and liquid silicone (Silicone 2000 and curing agent 9:1 ratio) was poured around the $18 \mathrm{~mm}$ agarose ball and allowed to cure uniformly for 24 hours at room temperature. Thereafter, the solidified silicone coated ball and stick were removed and placed in boiling water until the inner agarose dissolved, yielding an inflatable sphere with 20 $\mathrm{mm}$ outer diameter and a wall thickness of $1 \mathrm{~mm}$. This $20 \mathrm{~mm}$ inflatable sphere was then placed in a $30 \mathrm{~mm}$ casting mold and connected to a $10 \mathrm{G}$ silicone urinary catheter (BARD, USA). 


\subsubsection{Preparation of casting molds for biomimetic support}

First, the silicone sphere was connected to a mechanical animal ventilator (FMI, GmbH) and inflated to check for surface tears so as to ensure proper pulsatile function. Next, the casting blocks with attached silicone spheres were boiled, drained and autoclaved to sterilize the whole apparatus prior to use. After cooling down to room temperature, the BioVAD casting mold could then be used for the seeding of cells to generate humanized BioVAD.

\subsubsection{Preparation of cells}

Initially, cardiomyocytes harvested from neonatal rat hearts were used to determine the feasibility of BioVAD formation. Thereafter, we attempted to generate human BioVADs with hESC derived cardiomyocytes.

\subsubsection{Rat model}

Rat myocytes were prepared by using a trypsin/DNase dissociation protocol (Zimmermann et al., 2002). $8 \mathrm{ml}$ reconstitution mixture containing $2.6 \times 10^{7}$ cells and rat-tail collagen $(4.2 \mathrm{mg})$ was poured into the mold and allowed to condense for 72 hours. After day 10, the rat BioVAD was harvested and analyzed. 


\subsubsection{Human model}

Single cells obtained from the dissociation of hESC-derived cardiomyocytes were used to generate the human BioVAD (hBioVAD)s as outlined in Table 2 and allowed to condense for 24 hours. From culture days 3 to 8 , uniform pulsatile stretch (10\% strain, 90 beats per minute) was initiated using a mechanical ventilator to inflate and deflate the central sphere. Non-pulsatile conditions served as control ( $0 \%$ strain).

\begin{tabular}{|l|r|}
\hline Human BioVAD & 1 \\
\hline Bovine collagen $(6.1 \mathrm{mg} / \mathrm{ml})$ & $1,030 \mu \mathrm{l}$ \\
\hline $2 x$ DMEM & $1,030 \mu \mathrm{l}$ \\
\hline $\mathrm{NaOH} 0.1 \mathrm{~N}$ & $200 \mu \mathrm{l}$ \\
\hline cells suspension & $6,140 \mu \mathrm{l}$ \\
\cline { 1 - 1 } cell number $\left(\times 10^{6}\right)$ & 26 \\
\cline { 1 - 1 } total & $8,400 \mu \mathrm{l}$ \\
\hline
\end{tabular}

Table 2: Components required to generate human BioVADs

\subsubsection{Immunofluorescence imaging}

Tissue samples from BioVADs were harvested and fixed in $4 \%$ formaldehyde (Histofix, Roth) overnight and then permeabilized with blocking buffer. Immunofluorescence labeling and imaging were performed as highlighted in section 2.2.6. 


\subsubsection{RNA preparation}

Total RNA was prepared using standard Trizol $^{\circledR}$ (Invitrogen) extraction protocols. BioVAD and EHM tissue samples were first rinsed with PBS prior to snap freezing in liquid nitrogen. $500 \mu$ of Trizol $^{\circledR}$ and $7 \mathrm{~mm}$ stainless steel beads (Qiagen) were added to each sample tube and homogenized with a Tissue Lyser II (Qiagen) at $25 \mathrm{~Hz}$ for 5 minutes. Next, $100 \mu \mathrm{l}$ of chloroform was added into the samples and the tubes were agitated vigorously for 1 minute and allowed to settle for 10 minutes at room temperature. The tubes were then spun at $12,000 \times \mathrm{g}$ for 20 minutes at $4^{\circ} \mathrm{C}$ centrifuge (Eppendorf 5417). The aqueous phase from the samples were transferred to individual RNAse free microfuge tubes and vigorously mixed with equal parts of isopropanol for 1 minute and allowed to settle for 5 minutes at room temperature. Next, the tubes were spun at $12,000 \times \mathrm{g}$ for 20 minutes to pellet the RNA and then rinsed with $70 \% \mathrm{EtOH}$. Following another centrifuge step of $12,000 \times \mathrm{g}$ for 5 minutes, the RNA tubes were allowed to air dry prior to suspension in RNAse free water. The amount of RNA was quantified and quality ensured (260 / 280nm OD. ratio $\geq 1.8)$ with the Nanodrop spectrophotometer (Thermo Scientific) and subsequently stored at $-80{ }^{\circ} \mathrm{C}$.

\subsubsection{Reverse transcription}

Extracted RNA samples were first treated with DNAse I (Roche) to remove contaminating DNA. A reaction mix consisting of $1 \mu \mathrm{g}$ RNA, $1 \mu \mathrm{L}$ DNAse I buffer (Roche), $0.2 \mu$ l DNAse I enzyme was incubated at $37{ }^{\circ} \mathrm{C}$ for 20 minutes followed by an addition of $0.2 \mu$ EDTA and incubation at $75^{\circ} \mathrm{C}$ for 10 minutes 
to inactivate DNAse I activity. For reverse transcription and quantitative RTPCR the High Capacity cDNA Reverse Transcription Kit (Applied Biosystems) was used according to manufacturer's instructions. $50 \mathrm{ng}$ cDNA was mixed with a mastermix of RT-PCR reactions consisting of 300 nM 5' primer and 3' primer each, $100 \mathrm{nM}$ Taqman probe and $2 \times$ Taq polymerase were assembled in a 384 well plate (Applied Biosystems).

\subsubsection{Quantitative RT-PCR}

Amplification was performed on an ABI PRISM 7900HT Fast Real-Time PCR system (Applied Biosystems) with the following parameters: $50^{\circ} \mathrm{C}$ for 2 minutes, denaturation at $95^{\circ} \mathrm{C}$ for 10 minutes and a cyclical amplification at $95^{\circ} \mathrm{C}$ for 15 seconds and $60^{\circ} \mathrm{C}$ for 1 minute for a total of 40 cycles. No template and no reverse transcriptase reactions served as controls to ensure product specificity. Results from the run were determined by using $\Delta \Delta C T$ method (Livak and Schmittgen 2001). Glyceraldehyde 3-phosphate dehydrogenase (GAPDH) served as housekeeping gene standard. Primer sequences are listed in the Appendix, page 127. 


\subsection{Development of a cell based IGF-1 secretion technology}

\subsubsection{Plasmids}

The plasmids pCMV-XL4 (SC119792; Origene), pLVx-Tight-Puro and pTetOn (both Lenti- $\mathrm{X}^{\mathrm{TM}}$ TetOn $^{\circledR}$ Advanced inducible expression system, 632162; Clontech) were purchased and used in the development of cell based IGF-1 secretion. $p C M V-X L 4$ consists of the full length human IGF-1 transcript; $p L V x-$ Tight-Puro is an expression response vector which consists of a modified CMV promoter $\left(P_{\text {Tight }}\right)$ with regulatory elements of the tetracycline operator sequences and includes a puromycin resistance gene; $p$ Tet-On-Advanced is the transactivator plasmid which contains an improved version of the reverse tetracycline controlled transactivator protein (rtTA), and also includes a neomycin resistance gene.

\subsubsection{Cells}

In this study, TSA cells (Giovarelli et al. 1995) were exploited to test the expression of human IGF-1 from pCMV-XL4 by transfection and as host cells for the packaging of genetically engineered lentivirus plasmids and lastly, to serve as production cells for transgenic lentivirus. HFF cells were used as target cells for transgenic lentivirus transduction to generate a stable inducible IGF-1 secreting cell line. Both TSA and HFF cells were cultured till $80 \%$ confluence prior to transfection or transduction respectively. 


\subsubsection{TSA cells}

TSA cells were cultured in TSA medium (Appendix) on $100 \mathrm{~mm}$ cell culture plates (Nunc).

\subsubsection{Human foreskin fibroblasts}

HFF cells were cultured in HFF medium (Appendix) as highlighted in 2.1.1 on $100 \mathrm{~mm}$ cell culture plates (Nunc).

\subsubsection{Lipofection of pCMV-XL4 into TSA cells}

TSA cells were transiently transfected with $3 \mu \mathrm{g}$ of $p C M V-X L 4$ plasmids using lipofection with Polyfect (Qiagen) according to manufacturer's protocol. The cell culture medium was exchanged after 16 hours and cells were incubated for another 48 hours.

\subsubsection{Analysis of IGF-1 expression and secretion}

Supernatants from transfected cells and untransfected cells were harvested and stored in $-20^{\circ} \mathrm{C}$ until further use. To obtain cell lysates from these cultures, cells were rinsed thoroughly with PBS to avoid supernatant contamination. Next, $400 \mu$ l CytoBuster protein extraction buffer (Novagen) was layered over the cells and allowed to incubate on ice for 30 minutes. Thereafter, with the help of a cell scraper, the lysates were collected individually in $1.5 \mathrm{ml}$ microfuge tubes and centrifuged at $12,000 \times \mathrm{g}$ for 30 minutes to pellet the cell 
debris. The supernatant above this cell debris was then collected into sterile microfuge tubes and designated as cell lysates and stored at $-20^{\circ} \mathrm{C}$ until further required.

\subsubsection{Western blot detection of IGF-1}

Cell lysates and supernatants were first quantified with standard Bradford protein assay to standardize loading protein concentrations and processed using standard western blot protocols. Briefly, proteins were resolved on a $10 \%$ SDS-polyacrylamide gel followed by $400 \mathrm{~mA}$ electrophoretic transfer to a $0.2-0.4 \mu \mathrm{m}$ nitrocellulose membrane (Protran, Whatman) at $400 \mathrm{~mA}$ for 1 hour. All membrane blots were blocked with blocking buffer ( $5 \%$ goat serum in PBS) for 1 hour followed by incubation with primary antibodies against hIGF-1 (abcam, 1:5,000) and GAPDH (Santa Cruz, 1:1,000) overnight at $4^{\circ} \mathrm{C}$. Thereafter, the membrane was washed with 1\% TBST buffer (Appendix) thoroughly and incubated with secondary antibodies (goat anti-mouse IgG, $1: 20,000)$ for 1 hour at room temperature. To visualize the protein bands, the membrane was incubated with horseradish peroxidase substrate (SuperSignal West Femto kit; Pearce, Thermo Scientific) and developed with

a membrane detection system (VersaDoc; BioRad) and analyzed with Quantity One software (BioRad). 


\subsubsection{ELISA detection of IGF-1}

IGF-1 concentration in cell culture supernatants was measured with a sandwich enzyme linked immunosorbent assay (ELISA) following the manufacturer's protocol (Quantikine ${ }^{\circledR}$ human IGF-1; R\&D systems). Results were recorded at $450 \mathrm{~nm}$ and analyzed with a microplate reader (FlexStation 3; Molecular Devices).

\subsubsection{IGF-1 PCR cloning}

The IGF-1 variant 4 sequence was PCR amplified from pCMV-XL4 with high fidelity hot start DNA polymerase (Platinum $^{\circledR}$ Taq; Invitrogen) and the following hIGF-1 primers with flanking restriction enzyme cutting sites: 5'GCGGCCGCATGGGAAAAATCAGCAGTCTTCC, TCTAGACTACATCCTGTAGTTCTTGTTTCC (5'-Notl and 3'-Xbal sites underlined respectively). The PCR mastermix had the following composition: $1 \mathrm{X}$ PCR buffer, $1.5 \mathrm{mM} \mathrm{MgCL}_{2}, 0.2 \mathrm{mM}$ dNTP mix, $0.2 \mu \mathrm{M}$ 5' forward primer , $0.2 \mu \mathrm{M}$ 3' reverse primer, $0.25 \mu \mathrm{g}$ plasmid DNA and $0.2 \mu \mathrm{l}$ of DNA Taq polymerase (1 unit) was subjected to 35 cycles in a thermal cycler (GeneAmp 9600, Applied Biosystems) using the following temperature profiles: denaturation at $94^{\circ} \mathrm{C}$ for $1 \mathrm{~min}$; annealing at $60^{\circ} \mathrm{C}$ for $1 \mathrm{~min}$; and extension at $72^{\circ} \mathrm{C}$ for $1 \mathrm{~min}$. The PCR product for IGF-1 was separated on $1 \%$ agarose gels, visualized by ethidium bromide $(\mathrm{EtBr})$ staining, excised and purified according to the manufacturer's protocol (QIAquick gel extraction kit; QIAGEN). The purified IGF-1 product was stored at $-20^{\circ} \mathrm{C}$ until required. Sequencing was performed to ensure the correct sequence of IGF-1 variant 4. 


\subsubsection{Construction of IGF-1 encoding lentivirus}

First, the plasmid pLVx-Tight-Puro was digested with restriction enzymes Notl and Xbal (both FastDigest ${ }^{\circledR}$, Fermentas) in a double digestion reaction to generate a linearized plasmid (linpLVx-Tight-Puro). The restriction reaction mix included: $1.0 \mu \mathrm{l}$ Notl, $1.0 \mu \mathrm{l}$ Xbal, $2 \mu \mathrm{l} \mathrm{FastDigest}{ }^{\circledR}$ Buffer, $1 \mu \mathrm{g} / \mu \mathrm{l}$ plasmid pLVx-Tight-Puro. This was incubated at $37^{\circ} \mathrm{C}$ for 4 hours and subsequently heat inactivated at $85^{\circ} \mathrm{C}$ for 5 minutes. The restriction digest product was separated on a $1 \%$ agarose gel, visualized by EtBr staining, excised and purified as described in 2.4.5. The purified linearized linpLVx-Tight-Puro vector was stored at $-20^{\circ} \mathrm{C}$ until required.

Next, a mastermix reaction containing 250 ng purified human IGF-1 amplified product, $100 \mathrm{ng}$ linpLVx-Tight-Puro, $4 \mu \mathrm{l}$ rapid ligation buffer (5X), $1 \mu \mathrm{l}$ T4 DNA ligase (5 units/ $\mu \mathrm{l}$ ) was assembled and incubated at room temperature for 10 minutes to generate the recombinant $\mathrm{pLVx}$-Tight-hIGF1-Puro plasmid.

Then, chemically competent DNA methylase negative (dam-) E. coli strain (One Shot ${ }^{\circledR}$ INV110; Invitrogen) was chemically transformed with $2 \mu \mathrm{l}$ pLVxTight-hIGF1-Puro plasmid according to the manufacturer's protocol. Positive colonies containing the ligated plasmid were selected for by ampicillin resistance and further confirmed by colony PCR with hIGF-1 primers listed above. Briefly, one colony of transformed E. coli was picked and inoculated into a tube containing the same PCR master mix outlined in 2.4.5. and PCR amplified. Amplification of a positively transformed E. coli colony containing the plasmid was then performed by sterile loop inoculation of a single colony 
into a $2 \mathrm{~L}$ glass conical flask containing $250 \mathrm{ml}$ of LB medium (Appendix) supplemented with $100 \mu \mathrm{g} / \mathrm{ml}$ ampicillin in a $37^{\circ} \mathrm{C}$ shaking incubator (Innova 4300) with constant 200 rpm agitation for 24 hours. Next, the amplified pLVxTight-hIGF1-Puro plasmid was extracted and purified according to the manufacturer's protocol for maximum pure plasmid recovery (NucleoBond ${ }^{\circledR}$ Xtra Maxi; Macherey-Nagel). The purified ligated plasmid was stored in $-20^{\circ} \mathrm{C}$ until required.

\subsubsection{Lentivirus production}

To generate IGF-1 encoding lentivirus, TSA cells were transfected with $3 \mu \mathrm{g}$ of $p L V x$-Tight-hIGF1-Puro, $2 \mu \mathrm{g}$ of pCMV2.1 and $3 \mu \mathrm{g}$ pMD2G plasmids (Trono Lab, EPFL, Switzerland) using lipofection with Polyfect (Qiagen). The cell culture medium was changed after 16 hours and medium containing recombinant IGF-1 lentiviral particles were harvested 48 hours later. The LentiX $^{\text {TM }}$ Go Stix ${ }^{\text {TM }}$ (Clontech) was used according to the manufacturer's protocol to determine the titer of $>5 \times 10^{6} \mathrm{IFU} / \mathrm{ml}$ of the lentiviral particles.

To generate the virus containing the Tet-On transactivator, TSA cells were also used as host cells and transfected with the same technique as described above. Again, cell culture medium was changed after 16 hours and medium containing recombinant Tet-On lentiviral particles were harvested 48 hours later. Both hIGF-1 and Tet-On lentivirus were then stored in $-80^{\circ} \mathrm{C}$ freezer until required. 


\subsubsection{Lentiviral transduction of human foreskin fibroblasts}

Prior to transduction of HFF with the lentivirus, fresh cell culture medium with 0.5\% FBS was exchanged and supplemented with $10 \mu \mathrm{g} / \mathrm{ml}$ hexadimethrine bromide (polybrene, Millipore) at $37^{\circ} \mathrm{C}$ for 10 minutes. Polybrene is a cationic polymer, which neutralizes cell membrane charges and increases the efficiency of transduction of viruses when added to cell culture medium. Thereafter, conditioned cell medium from TSA cells containing recombinant IGF-1 lentivirus was layered over HFF cells cultured in a $100 \mathrm{~mm}$ cell culture plate in a drop wise manner and then incubated in a $5 \% \mathrm{CO}_{2}, 37^{\circ} \mathrm{C}$ cell culture incubator for 72 hours. Thereafter, fresh HFF medium with 15\% FBS was exchanged and supplemented with $10 \mathrm{ng} / \mathrm{ml}$ basic Fibroblast Growth Factor (bFGF; Miltenyi) and $1 \mu \mathrm{g} / \mathrm{ml}$ Puromycin (Invitrogen). After 7 days, surviving cells were selected as HFF ${ }^{\mathrm{hIGF} 1+}$ cells.

To generate a stable inducible secretion of human IGF-1 from HFF cells, the HFF $^{\text {hIGF1+ }}$ cells were next transduced with pTet-On-Advanced lentivirus as outlined above followed by extended culture in medium containing $1 \mu \mathrm{g} / \mathrm{ml}$ puromycin and $800 \mu \mathrm{g} / \mathrm{ml}$ neomycin (Invitrogen) for 7 days. Cells that survived double antibiotic selection were deemed successfully transduced with both hIGF-1 and Tet-On viruses to generate the inducible human IGF-1 cell line: HFF $F^{\text {hIGF1+TetOn+ }}$. These cells were amplified till a desired quantity and frozen down as stock cell cultures in $-80^{\circ} \mathrm{C}$ until required. 


\subsubsection{Cell size measurement}

Cells were dispersed as outlined above in 2.2.3.2 and subjected to size measurements using a CASY counter (Roche).

2.5 In vivo testing of human BioVAD (hBioVAD) with paracrine activity

\subsubsection{Assembly of hBioVAD with paracrine activity}

To confer the paracrine modality to the hBioVAD, $18.2 \times 10^{6} \mathrm{hESC}$ derived cardiomyocytes and $7.8 \times 10^{6} \mathrm{HFF}^{\mathrm{hIGF} 1+\text { TetOn+ }}$ cells were mixed together to generate a BioVAD as highlighted in 2.3.2.2 and allowed to condense overnight. Thereafter, the hBioVAD was allowed to condense further for another 9 days prior to implantation.

\subsubsection{Implantation of hBioVAD in Wistar rat}

The hBioVAD was implanted into a $450 \mathrm{~g}$ male Wistar rat (Charles River). The implantation was performed under isoflurane (4\%) anesthesia. The heart was exposed after median sternotomy and careful refraction of pericardium. Next, the hBioVAD was slipped over the hearts, enveloping the apex, left and right ventricles and secured with 2 sutures (6-0 prolene, Ethicon). Following closure of sutures, cyclosporine A (5 mg/kg) and methylprednisolone (2 
$\mathrm{mg} / \mathrm{kg}$ ) were administered daily subcutaneously to suppress the immune response.

\section{$2.6 \quad$ Video capture}

Raw footages of spontaneously beating HES 2 cardiomyocytes and contracting BioVADs were captured with SONY HDR-HC9 1080p HD video camera and processed with Final Cut Pro software (Apple).

\section{$2.7 \quad$ Statistics}

GraphPad Prism software (GraphPad Software Inc; San Diego) was used to convert data sets into graphs (displayed as mean \pm SEM) and subjected to Student's t-test, one-way, or two-way ANOVA test where appropriate. $\mathrm{P}<$ 0.05 was considered to be significant. 


\subsection{Human embryonic stem cell culture}

The ability to maintain high quality hESC cultures was a precondition for the successful execution of the following experiments. Basic hESC cultures are generally maintained under serum (Thomson, et al. 1998). We prefer to induce cardiogenesis in serum-free conditions for optimal control of this highly sensitive process by making use of recently published protocols (Graichen, et al. 2008, Hudson, et al. 2012). Embryoid body (3D) differentiation was considered the standard for many years. Recently monolayer (2D) differentiation was introduced to further enhance and better control in vitro cardiogenesis in hESC (Kattman et al. 2011, Burridge et al. 2012).

\subsubsection{Human embryonic stem cell quality}

To assess whether hESCs would retain pluripotency characteristics after $2 \mathrm{D}$ monolayer adaptation, flow cytometry was performed and expression of pluripotency surrogate markers Oct4, Tra1-60 and SSEA4 (Andrews 1984, Badcock et al. 1999, Schopperle et al. 2003, Richards et al. 2004, Boyer et al. 2005) analyzed. This experiment demonstrated that typically $>99 \%$ cells expressed Oct4, Tra1-60 and SSEA4 in 2D cultured hESC (Figure 10). 


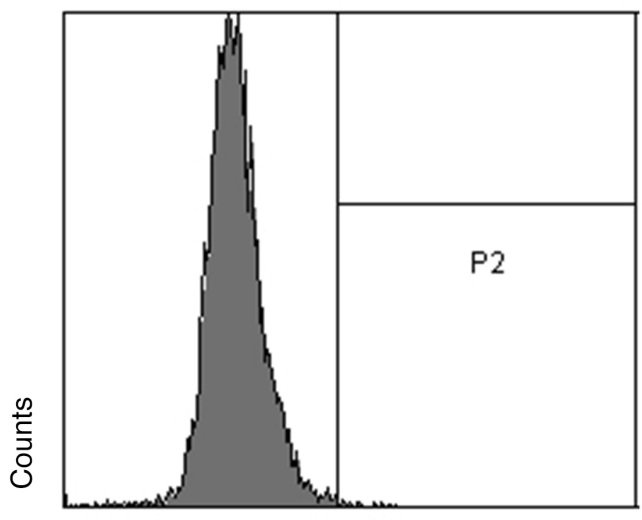

IgG Isotype control - Alexa 488

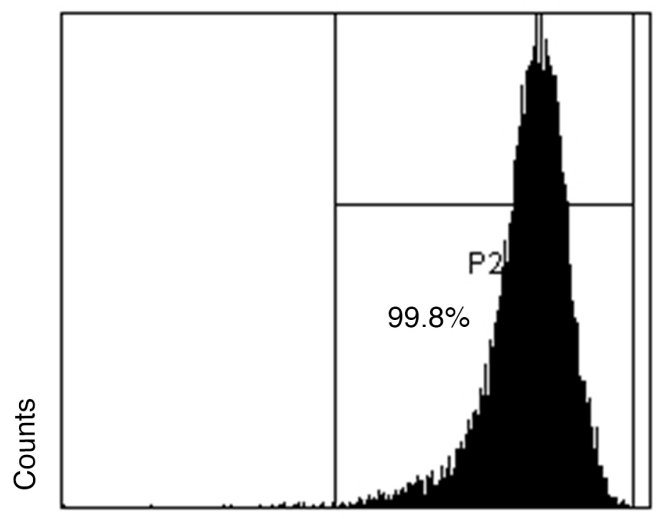

Tra 1-60
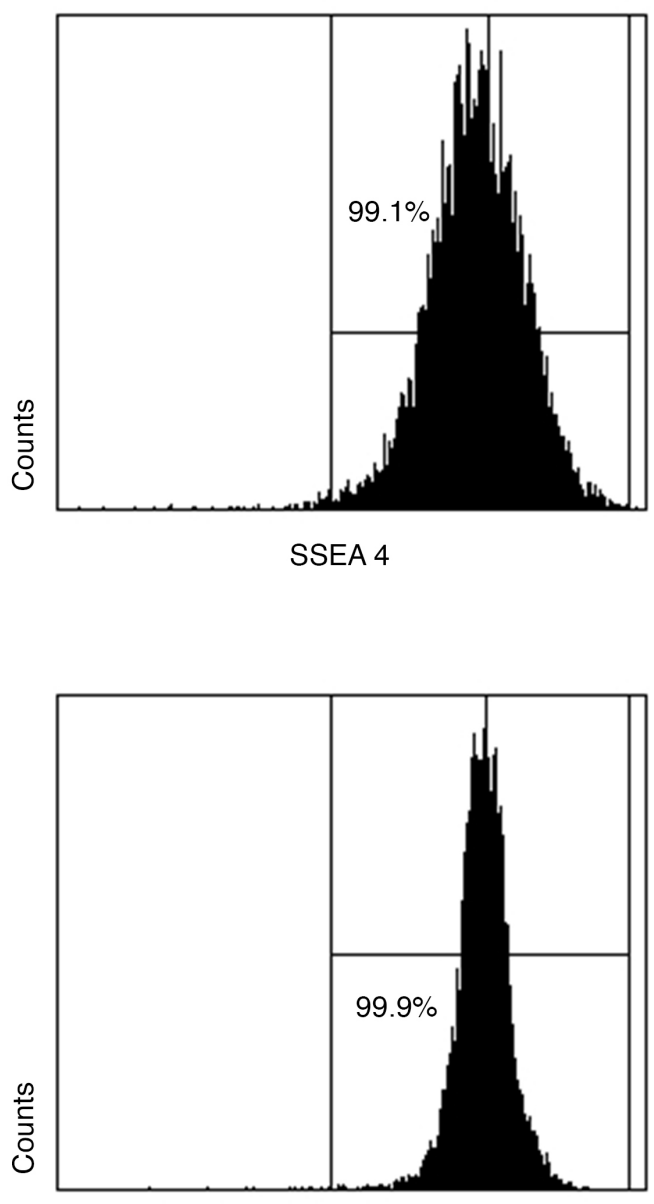

Oct 4

Figure 10: Detection of pluripotency surrogate markers in monolayer hESC cultures. Cells were analyses by flow cytometry after labeling of the indicated proteins; IgG isotype served as control. Representative experiment with HES2 cells.

\subsubsection{Cardiomyocyte differentiation}

To test the hypothesis that $2 \mathrm{D}$ adapted hESC cultures would respond better to directed differentiation protocols, a direct comparison of 3D vs. 2D culture was performed. In the "classical" 3D embryoid differentiation protocol, 
spontaneously beating EBs could typically be observed from culture day 8 onwards. In contrast, cardiomyocyte 2D differentiation developed beating cell clusters later, i.e. typically from culture day 10 onwards. For direct comparison of cardiogenic induction efficacy cells were harvested on culture days 12 and 16 from 3D and 2D cultures, respectively. These individual time-points were selected based on the observation that then steady-state beating activity was reached in the different culture protocols. Quantification of cardiomyocytes after specific labeling of the sarcomeric protein actinin by flow cytometry revealed $10-20 \%$ cardiomyocytes in $3 \mathrm{D}$ vs. $40-60 \%$ cardiomyocytes in $2 \mathrm{D}$ differentiation culture (Figure 11).

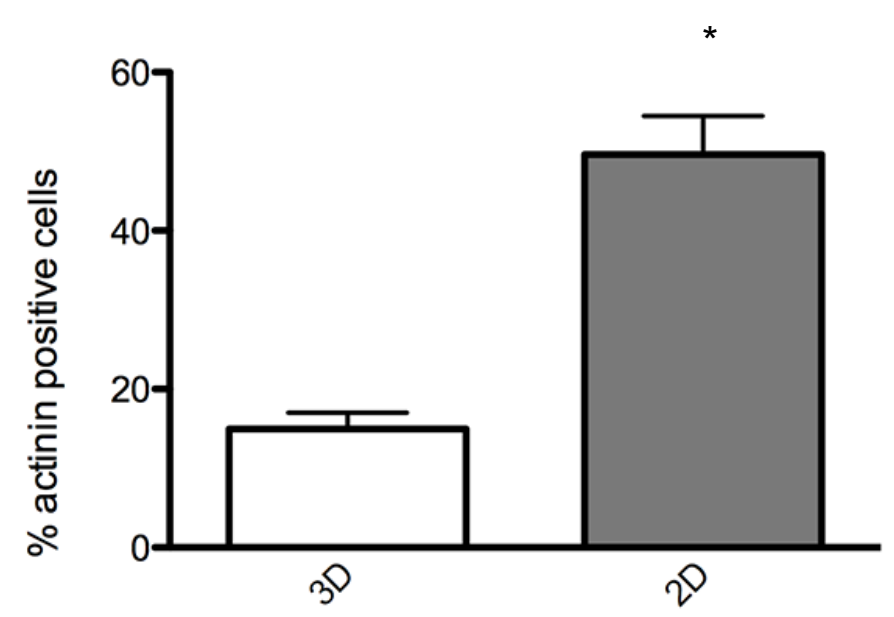

Figure 11: Enhanced cardiogenesis in $2 D$ vs. 3D cultures. $3 D$ and $2 D$ denotes embryoid body culture and monolayer culture, respectively ( $n=5$ per/group). The ordinate displays the percentage of cells labeled positively for actinin, assessed by flow cytometry. Experiments were performed with HES2 hESCs. * $p<0.05$ 3D vs. 2D (two-sided, unpaired Student's $t$-test). 


\subsection{Generation of human Engineered Heart Muscle}

\subsubsection{EHM exhibit heart like morphology and functionality}

EHM were generated from hESC after cardiogenic induction. Interestingly, EHM development, morphological and functional properties were similar in EHTs generated from $3 \mathrm{D}$ or $2 \mathrm{D}$ differentiation protocols. Beating was observed typically 48 hours after EHM generation. After 10 days EHMs were subjected to isometric force measurements or morphological studies. Immunolabelling of sarcomeric proteins (actinin and actin) revealed formation of anisotropically organized muscle bundles inside EHMs (Figure 12 A). EHMs responded to increasing extracellular calcium concentrations with a positive inotropic effect. Maximal contractile force was recorded at $2.8 \pm 0.4$ $\mathrm{mM}$ calcium (apparent $\mathrm{EC}_{50}: 0.7372 \pm 0.1770 \mathrm{mM} ; \mathrm{n}=4$ ). These human EHMs were then used as models to determine the impact of secreted human IGF-1 proteins on the functionality of the EHMs in the later part of this dissertation. 

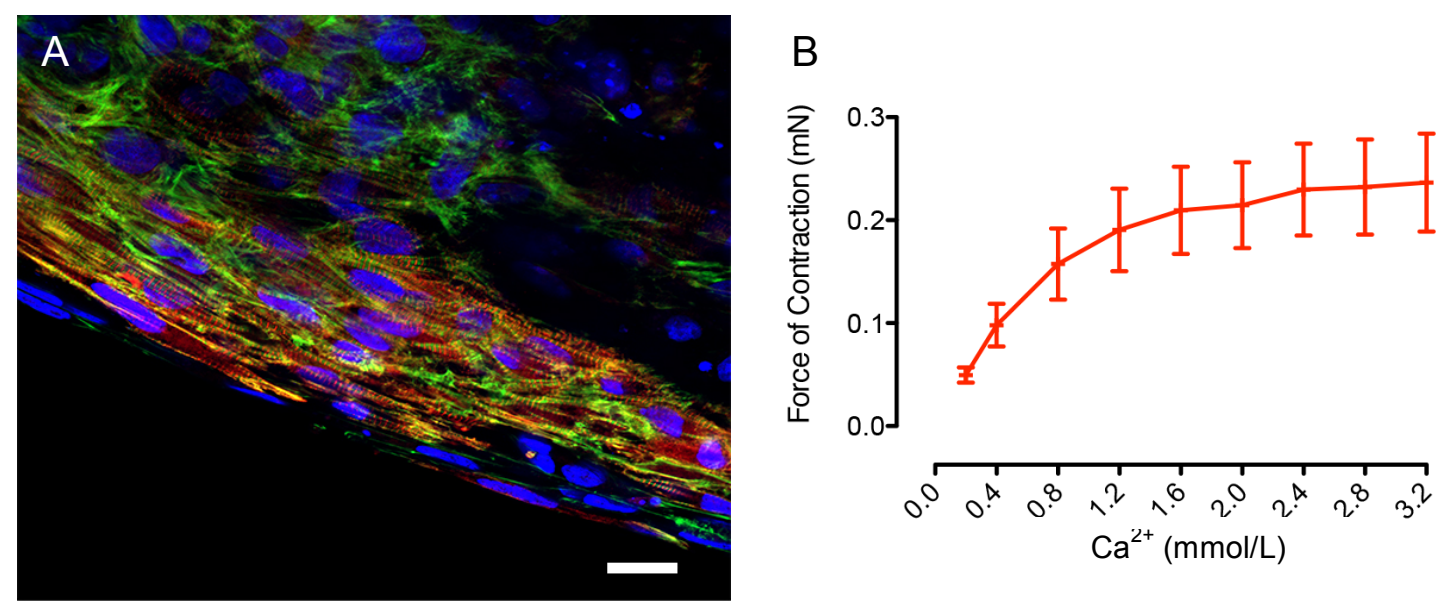

Figure 12. Morphological and functional parameters of human EHMs. (A) Anisotropically organized muscle bundle with characteristic sarcomeric crossstriation documented by confocal laser-scaning microscopy (red: a-actinin; green: f-actin; blue: DAPI stained nuclei). Scale bar: $20 \mu \mathrm{m}$. (B) Force of contraction measured under isometric conditions at $37^{\circ} \mathrm{C}$, electrical field stimulation at $2 \mathrm{~Hz}$, and increasing extracellular calcium $(\mathrm{n}=4)$.

\subsection{Generation of human BioVAD}

\subsubsection{Construction of novel casting molds}

The challenge was to develop a scalable BioVAD technology, suitable to envelope the ventricles of a rabbit heart. This required the construction of novel spherical casting molds of $18 \mathrm{~mm}, 20 \mathrm{~mm}$ and $30 \mathrm{~mm}$ diameter. To achieve this, cube blocks of Makrolon ${ }^{\circledR}$ (Bayer) (Figure $13 \mathrm{~A}$ ) were cut and hollowed using metal spherical bore drills respective to the diameters. Inflatable silicone spheres of $20 \mathrm{~mm}$ were also generated (section 2.3.1) (Figure 13 B) to enable "biomimetic" culture, i.e. culture under cyclic loading. 


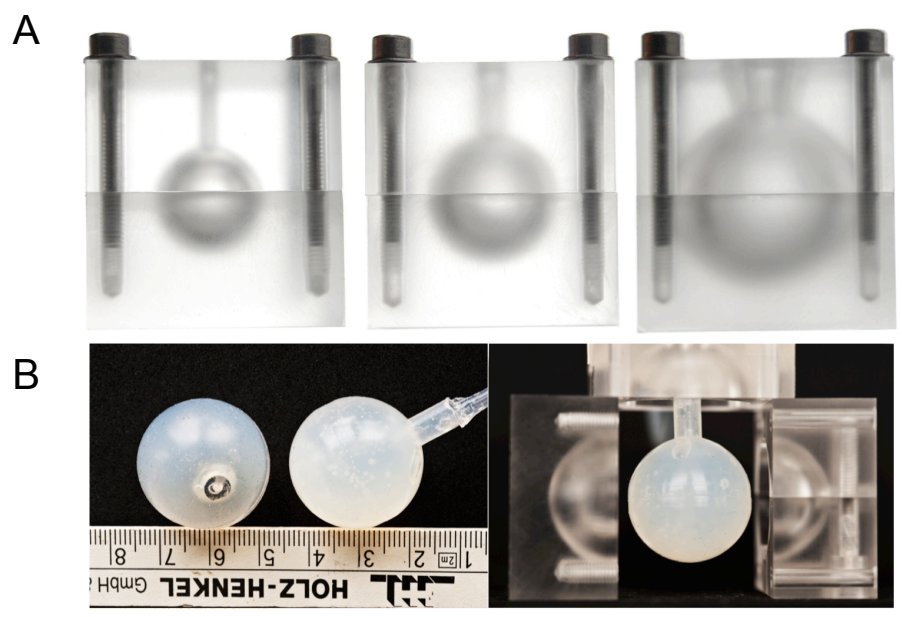

Figure 13. Casting molds construction for BioVAD technology. Components required to generate a BioVAD includes (A) scalable casting molds. (B) Inner inflatable silicone sphere.

\subsubsection{Cells tested to generate BioVAD}

The utility of the casting molds was first determined by making use of noncontractile fibroblasts and neonatal rat heart cells. Here the anticipated results were (1) formation of a tissue sphere at rabbit heart size and (2) contractile properties of native myocardium.

\subsubsection{BioVADs from fibroblasts}

To determine if the casting molds were feasible for cell seeding, we first mixed $16.8 \times 10^{6}$ naïve HFF cells with collagen 1 and pipetted the cell/collagen mixture into the interspace between the inflatable silicone sphere and inner 
wall of the casting mold. These cells were able to survive and formed a dense, albeit thin pouch like tissue within 72 hours (Figure 14).

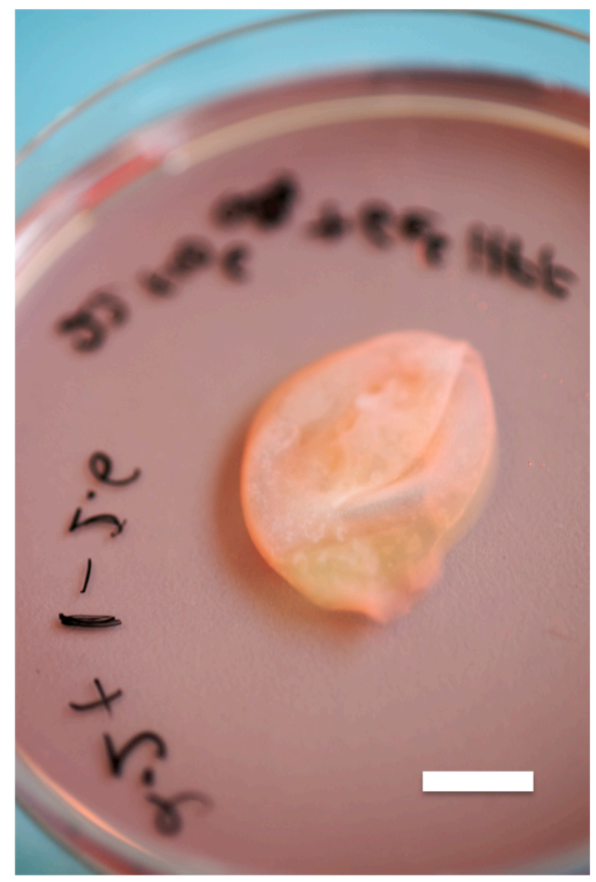

Figure 14. Pouch like tissue structure made from HFF. Scale bar: $10 \mathrm{~mm}$

\subsubsection{BioVADs from neonatal rat heart cells}

Next, we attempted to generate a similar BioVAD using whole heart cell preparations containing rat cardiomyocytes. $26 \times 10^{6}$ cells were seeded with collagen and after 24 hours, a dense tissue was observed (Figure 15) in agreement with a previous study (Yildirim et al., 2007). When released from the silicone sphere, the neonatal rat BioVAD was able to spontaneously contract in a synchronized manner. 


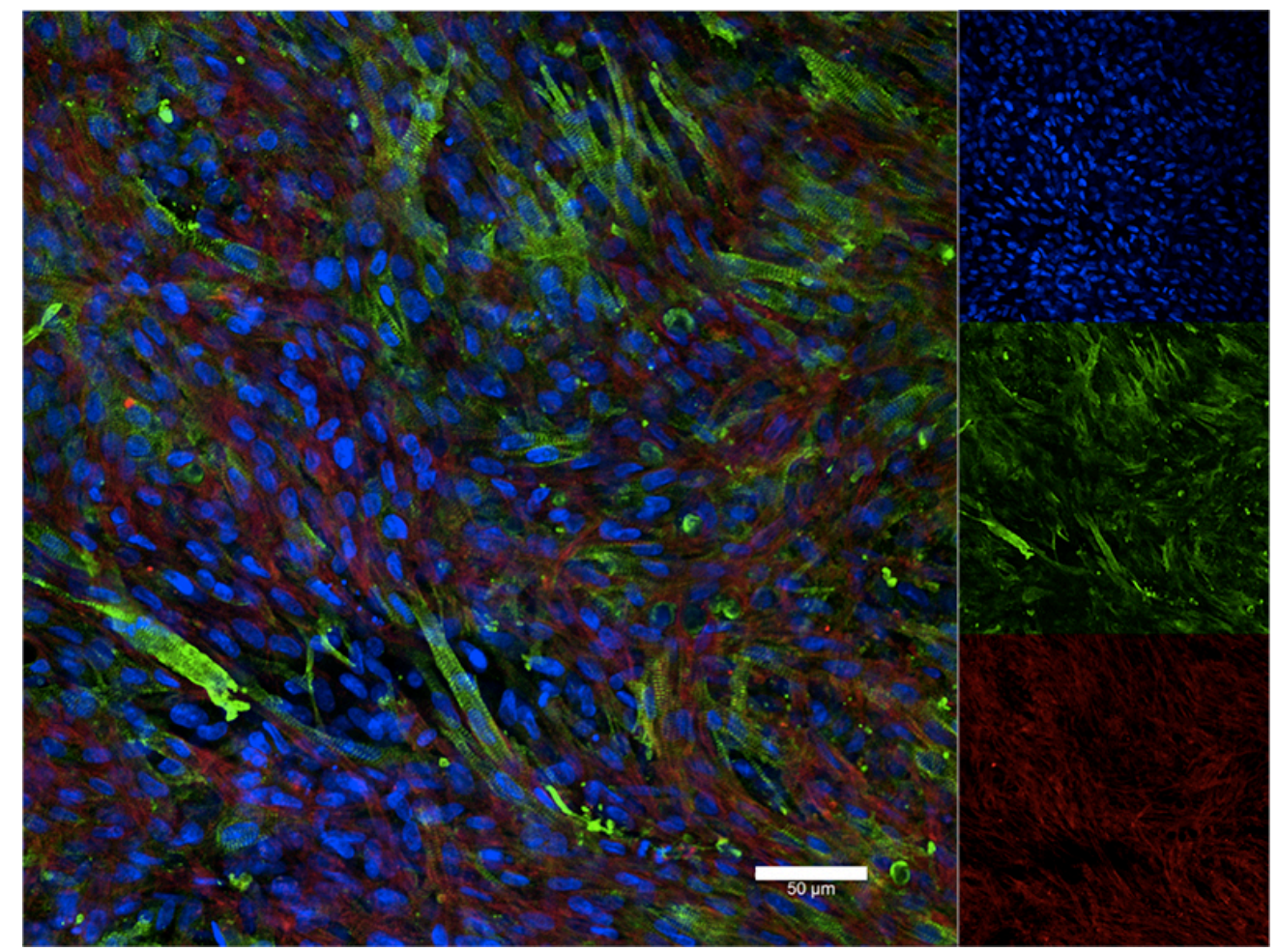

Figure 15: BioVAD from neonatal rat cardiomyocytes. After casting of the BioVAD reconstitution mix, formation of a tissue sphere could be observed within 24 hours. Beating was identified after additional 3 days. Images are from confocal laser scanning microscopy (red: f-actin; green: actinin; blue: DAPI stained nuclei). Scale bar: $50 \mu \mathrm{m}$.

\subsubsection{BioVAD from human embryonic stem cell derived cardiomyocytes}

Given the feasibility of the new molds to support BioVAD generation, we aimed at providing proof-of-concept for a humanized BioVAD approach. Enzymatically dissociated hESC-derived cardiomyocytes were obtained, mixed with bovine collagen (section 2.3.2.2) and poured into the BioVAD 
casting molds. The humanized BioVAD (hBioVAD) condensed within 24 hours to the size of a rabbit heart of approx. $35 \mathrm{~mm}$ in diameter (Figure 16).

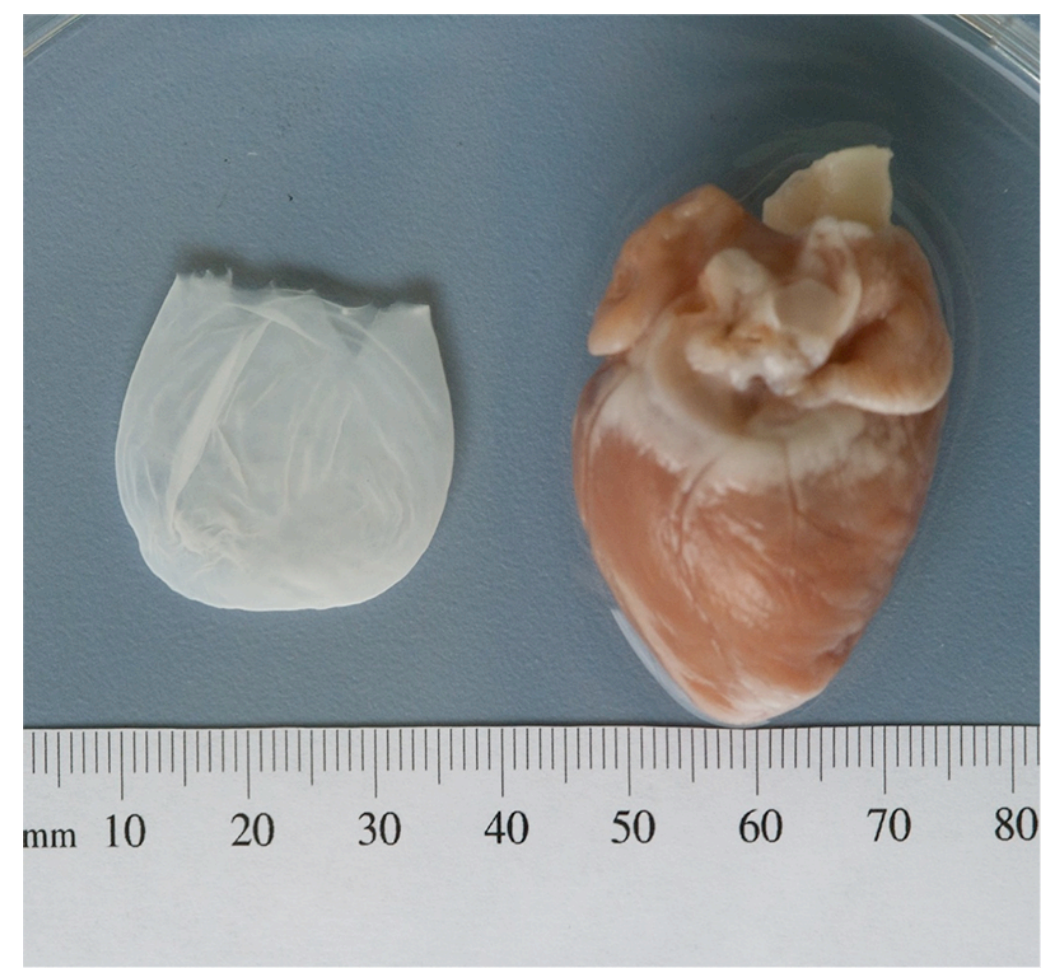

Figure 16: BioVAD from hESC derived cardiomyocytes. (left) hBioVAD after 10 days in culture; (right) adult rabbit heart.

Taken together, the data demonstrates that the mold design will enable larger scale tissues to be formed.

\subsubsection{Biomimetic pulsatile load on BioVAD}

We next asked if the BioVAD could be improved further by introducing pulsatile load. To achieve this, the central silicone sphere was connected to a rodent ventilator via a silicone tube catheter and pulsed via a series of inflation and deflation cycles. We then tested this hypothesis using HFF and 
adjusted the maxial strain to $110 \%$ of baseline at 90 inflation/deflation cycles per minute.

\subsubsection{Pulsatile load confers morphological rearrangements in fibroblasts}

To characterize the effects of the pulsatile loading immunofluorescence stainings for abundant cytoskeletal proteins (smooth muscle actin, vimentin and f-actin) were performed and identified superior elongation and alignment of HFFs in pulsed vs. unpulsed BioVADs (Figure 17).
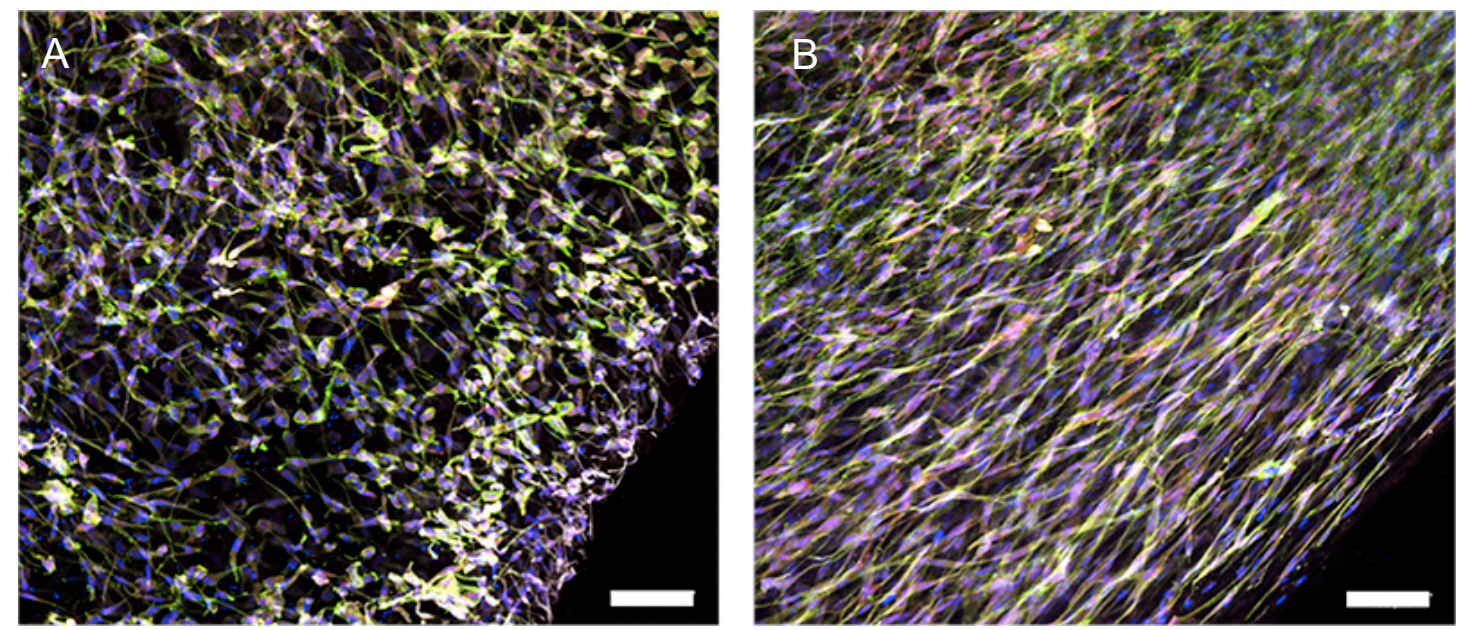

Figure 17. Mechanical load directs morphology in HFF-BioVADs. Unpulsed HFF-BioVAD (A) vs. pulsed BioVADs (B) stained for smooth muscle actin (red), vimentin (grey), actin (green) and nuclei staining with DAPI (blue). Images were recorded with a Zeiss LSM710 system. Scale bar: $100 \mu \mathrm{m}$. 
3.3.3.2 Pulsatile load confers morphological rearrangements in cardiomyocytes

When the pulsatile conditioning was applied to hESC-derived cardiomyocyte BioVADs cardiomyocyte elongation and enhanced sarcomere organization was observed (Figure 18 A, B). In contrast, unpulsed BioVADs showed mainly isotropic aggregation of cardiomyocytes (Figure $18 \mathrm{C}$ ).
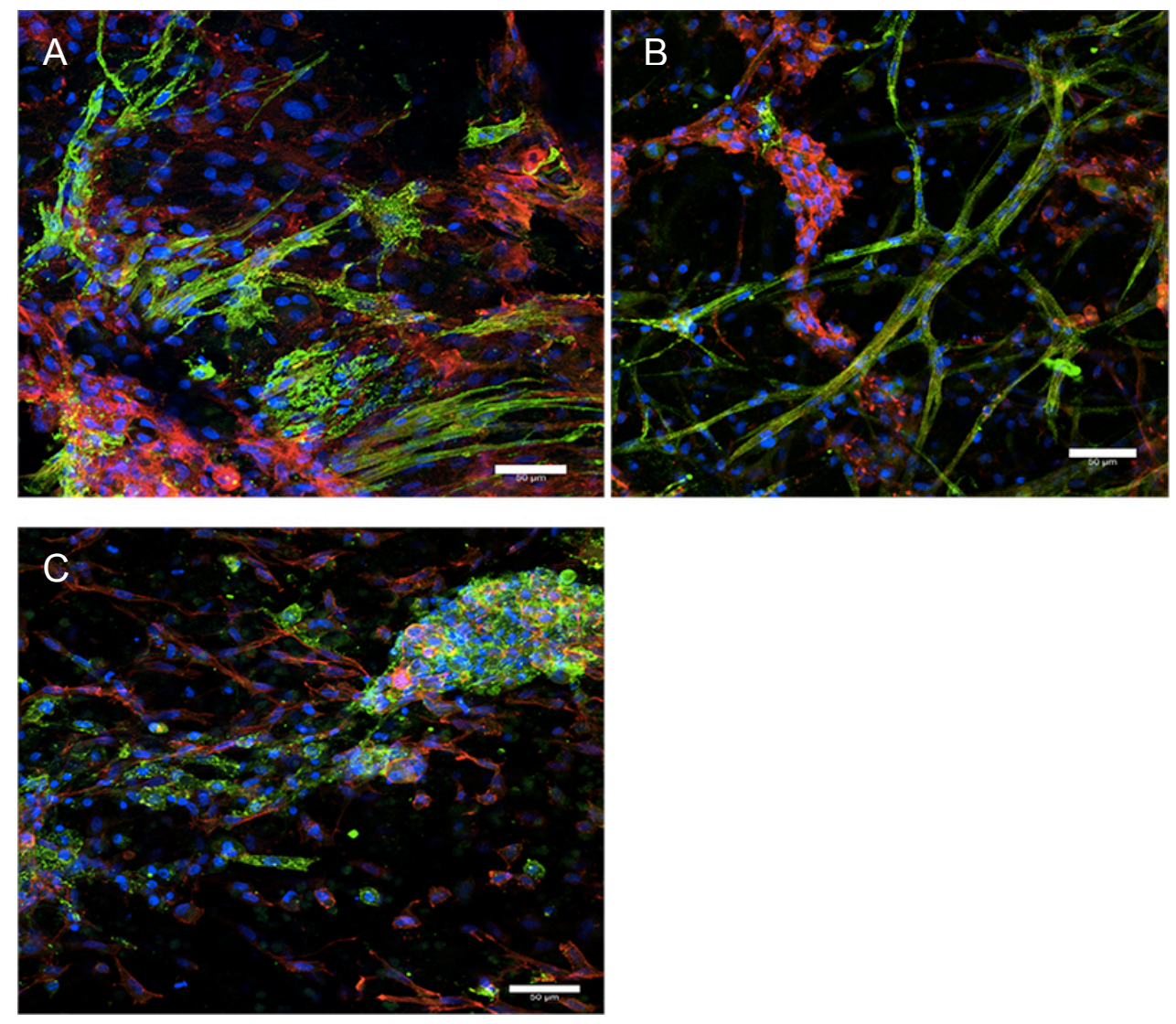

Figure 18: Mechanical pulsing improves morphology of hESC-BioVADs.

Pulsed (A, B) vs. unpulsed hBioVADs (C) stained for actinin (green), actin (red) and nuclei staining with DAPI (blue). Scale bar: $50 \mu \mathrm{m}$. 


\subsubsection{Pulsatile load leads to tissue maturation}

Based on the morphological enhancements in pulsed BioVAD constructs, we further investigated surrogates of maturation by qPCR. Pulsatile loading of BioVADs enhanced the expression of cardiac actin, skeletal actin, alpha- and beta-myosin heavy chain, ryanodine receptor 2 (RYR2) and calsequestrin 2 (CSQ2; Figure 19). In contrast, sarcoplasmic reticulum calcium-ATPase (SERCA2a) and phospholamban (PLB) transcript levels were unchanged compared to unpulsed BioVADs (Figure 19).

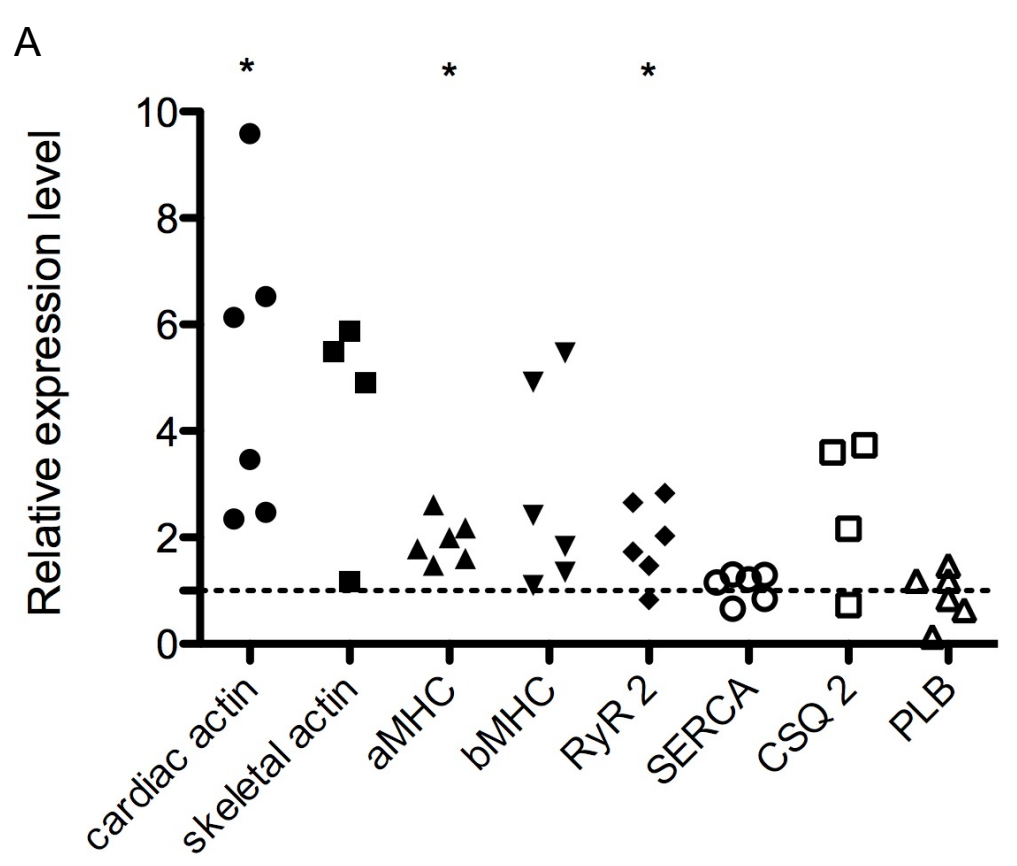

Figure 19. Pulsatile loading improves BioVAD maturation. Abundance of indicated transcripts was assessed by qPCR. The dotted line indicates the mean transcript abundance in unpulsed hBioVADs. The ordinate denotes the relative difference from this mean. ${ }^{*} p<0.05$ vs unpulsed; two-way ANOVA. 


\subsubsection{Pulsatile load enhances cell cycle activity}

Cell cycle activity was analyzed in isolated cells from BioVADs after DAPI labeling by flow cytometry. Pulsing increased the number of cells in G2/S phase in pulsed vs. unpulsed BioVADs (Figure 20), suggesting an increased cell cycle activity and/or DNA synthesis.

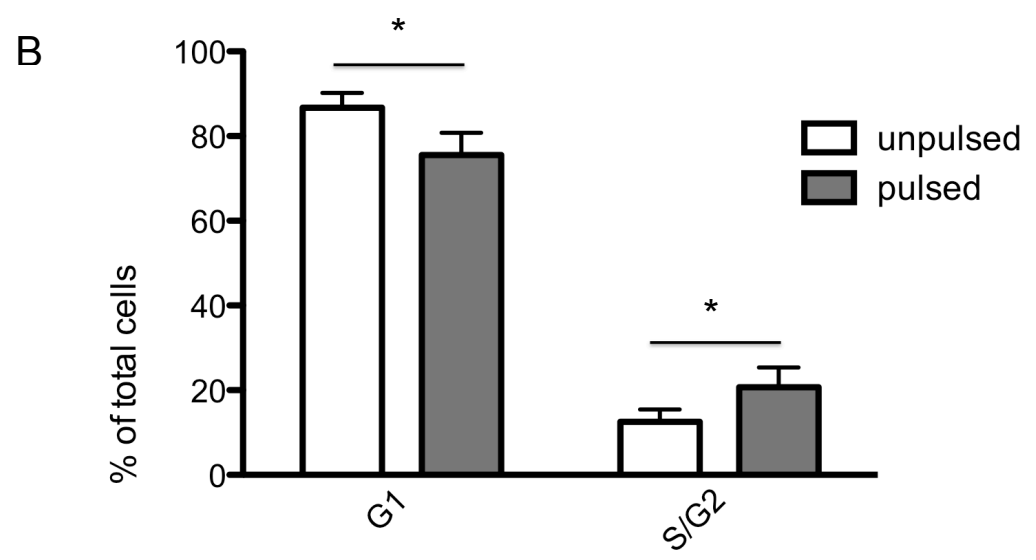

Figure 20. Pulsatile loading enhances cell cycle activity in BioVAD. Cell cycle phase was determined in isolated cells from BioVADs by flow cytometry after DNA labeling with DAPI. ${ }^{*} \mathrm{p}<0.05$ vs. unpulsed (two-sided, unpaired Student's t-test; $n=5$ for all groups).

\subsection{Pharmacological control of IGF-1 release from cells}

To further advance the functionality of the hBioVAD, supplementation of the system with inducible IGF-1 producing cells was proposed. The main goal of IGF-1 release in an EHM is to provide localized paracrine growth and survival support that can be controlled pharmacologically. One such system that allows 
the controlled release of IGF-1 is the Lenti-X ${ }^{\mathrm{TM}}$ TetOn ${ }^{\circledR}$ Advanced Expression system (Clontech). For this system to function, IGF-1 or any other gene of interest would need to be cloned into the Multiple Cloning Site (MCS), downstream of a modified CMV promoter which controls the expression of IGF-1. The promoter in turn is bound by Tet-controlled transactivators, which activates transcription in the presence of doxycycline. 


\subsubsection{PCR cloning of human IGF-1 gene}

The gene transcript for human IGF-1 variant 4 cDNA encoded on pCMV6-XL4 plasmid (SC119792, Origene) spans 7,260 bp . The mature IGF-1 peptide is encoded on exons 3 and exons 4 (Figure $21 \mathrm{~A}$ ). PCR amplification yielded an anticipated 462 bp fragment (Figure 21 B), which codes for the 153 amino acids of the secreted IGF-1 protein.

A

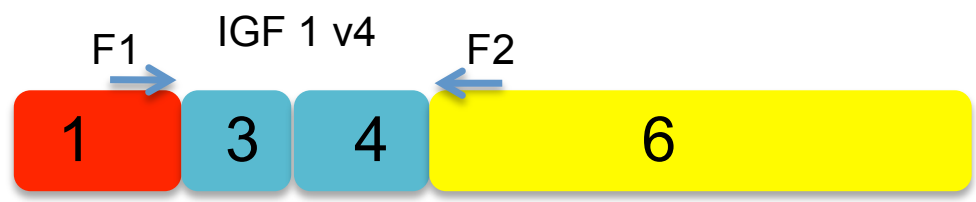

B

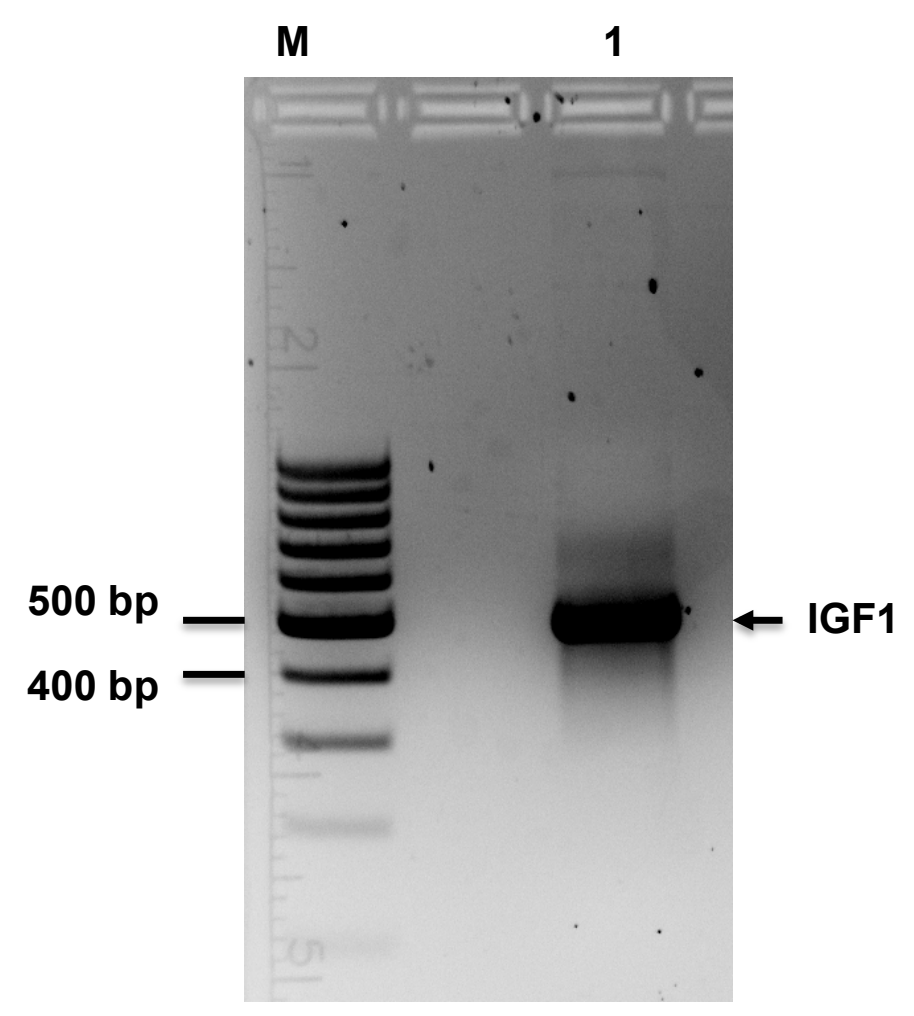

Figure 21: PCR cloning of IGF-1. (A) Schematic of exon arrangements in IGF-1 variant 4; PCR primer positions indicated by F1 and F2. (B) Lanes: (1) IGF-1 PCR amplified with F1 and F2. (M) DNA ladder (100 bp; Fermentas). 
Next, restriction enzyme digestion of $p L V x$-Tight-Puro plasmid at the MCS with Notl and Xbal generated a 7791 bp linearized plasmid for the insertion of the amplified IGF-1. Subsequent ligation to generate recombinant $p L V x$-TighthIGF1-Puro plasmid yielded 8253 bp (Figure 22, lanes 2)

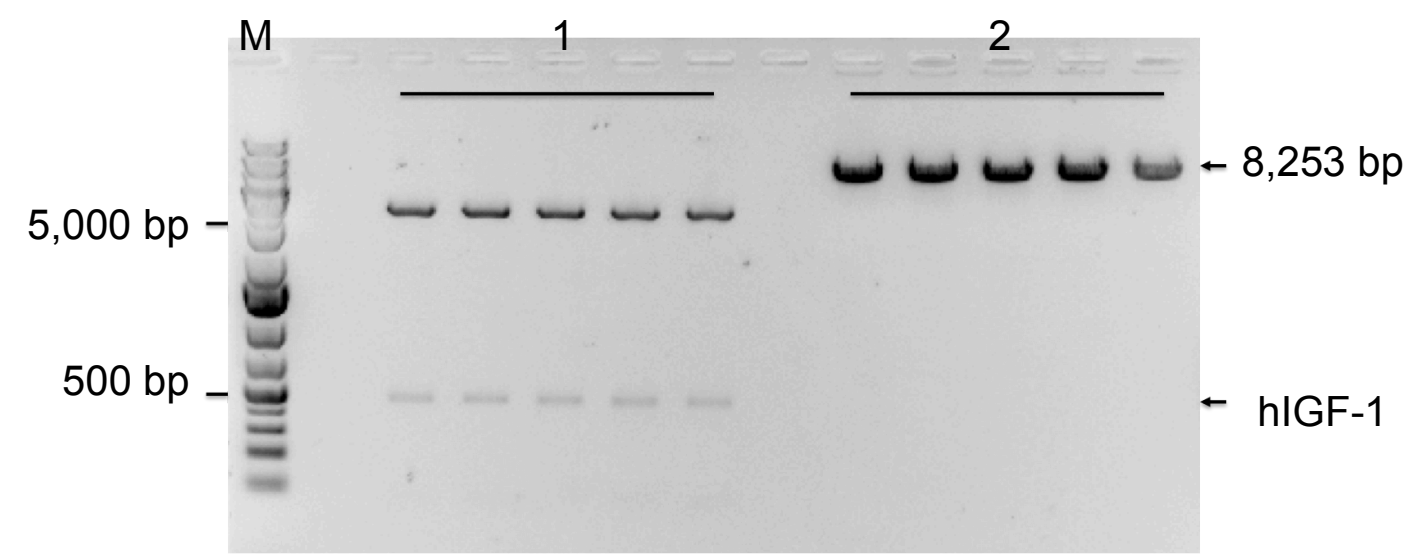

Figure 22: Construction of pLVx-IGF-1-Tight-Puro. Lanes: (1) Restriction enzyme digestion of hIGF-1 subcloned into TOPO TA plasmid with Notl and Xbal yields hIGF-1 (462 bp). (2) Linearized pLVx-hIGF1-Tight Puro with NotI only (8253 bp). (M) DNA ladder (1 kb plus, Fermentas).

\subsubsection{Transient expression of human IGF-1 in TSA cells}

To determine if IGF-1 could be transcribed, translated and secreted in human cells, TSA cells were first transiently transfected with $p C M V-X L 4$, encoding for full length human IGF-1. Cell lysates and supernatants were harvested and analyzed by Western blot after 24 hours. Supernatants of pCMV-XL4 
transfected but not EGFP transfected TSA cells contained human IGF-1 protein with similar apparent molecular weight as the recombinant human IGF-1 positive control (Figure 23).

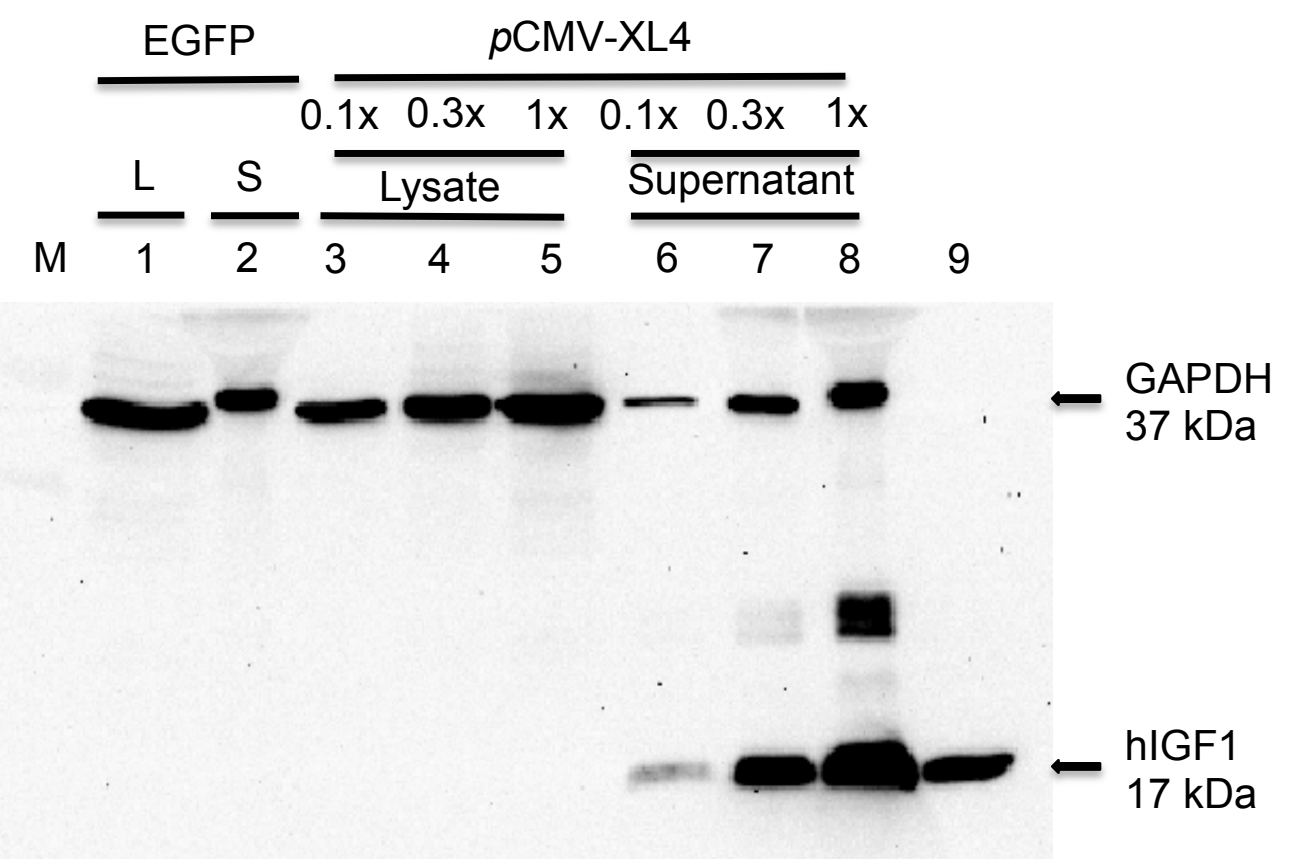

Figure 23. Secretion of IGF-1 from pCMV-XL4 transfected TSA cells Lanes: (1) Cell lysate from TSA cells transfected with EGFP plasmid. (2) Supernatant from TSA cells transfected with EGFP. (3-5) Cell lysates from TSA cells transfected with increasing concentrations of pCMV-XL4; (6-8) Supernatant from TSA cells transfected with increasing concentrations of pCMV-XL4 plasmid. Samples were run on a 10\% SDS PAGE at 120 Volts. (9) IGF-1 protein control (17 kDa) (Peprotech).

Thereafter, TSA cells were transfected with $p \mathrm{LVx}$-Tight-hIGF1-Puro and $p$ TetOn-Advanced plasmids together, only pLVx-Tight-hIGF1-Puro plasmid, only 
pCMV-XL4 plasmid as a positive control or with EGFP as a negative control plasmid. After 48 hours stimulation with $10 \mathrm{ng} / \mathrm{ml}$ doxycycline, cell lysates and supernatants were harvested. Western blot analyses of transfected cell supernatants demonstrated that human IGF-1 protein was secreted from $\mathrm{TSA}^{p \mathrm{LVx} \text {-Tight-hIGF1-Puro and } p \text { TetOn+ }}$ and $\mathrm{TSA}^{\text {pLVx-Tight-hlGF1-Puro only }}$ cells into the cell culture medium. In TSA ${ }^{\text {EGFP }}$ culture, no IGF-1 could be detected in the respective supernatant. In addition, the amount of secreted human IGF-1 protein is further increased when $10 \mathrm{ng} / \mathrm{ml}$ doxycycline was added to the cell culture (Figure 24).

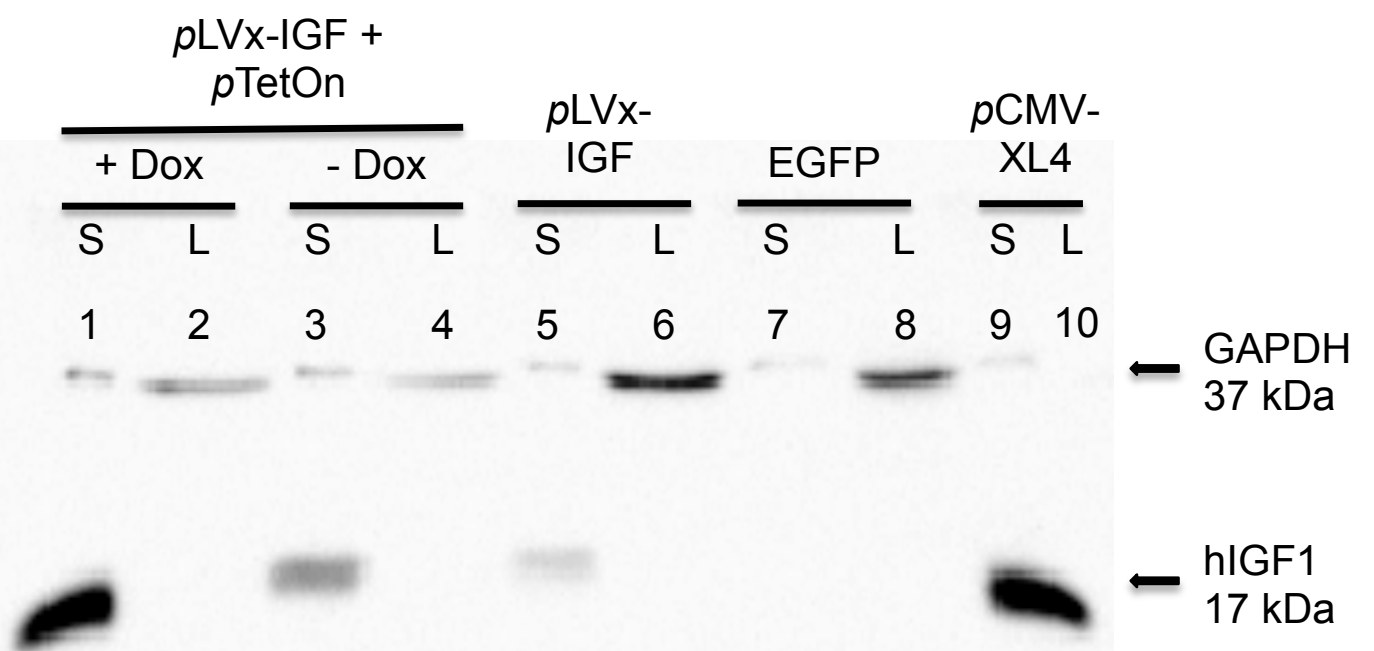

Figure 24: Expression of IGF-1 from $p L V x-I G F$ transfected TSA cells. Lanes: (1-2) TSA cells transfected with pLVxIGF1 and pTetOnAct supplemented with $10 \mathrm{ng} / \mathrm{ml}$ doxycycline. (3-4) TSA cells transfected with $p L V x I G F 1$ and pTetOnAct in the absence of doxycycline. (5-6) TSA cells transfected with pLVx-IGF1 only. (7-8) TSA cells transfected with EGFP plasmid as negative control. (9-10) TSA cells transfected with pCMV-XL4 
plasmid as positive control. (S) Represents supernatants. (L) Represents cell lysates.

Taken together, this data demonstrates that that the secretion of human IGF-1 can be induced in this system. Interestingly, no detectable amounts of human IGF-1 protein could be detected in cell lysates, suggesting that TSA cells are highly efficient host cells that are capable of processing and secreting the human IGF-1 protein.

\subsubsection{Quantification of IGF-1 release.}

In addition, ELISA analysis of supernatants from these TSA cell lines also revealed that human IGF-1 protein secretion was 11 times higher when induced by doxycycline (Figure 25). 
hIGF1 ELISA

Standard Curve

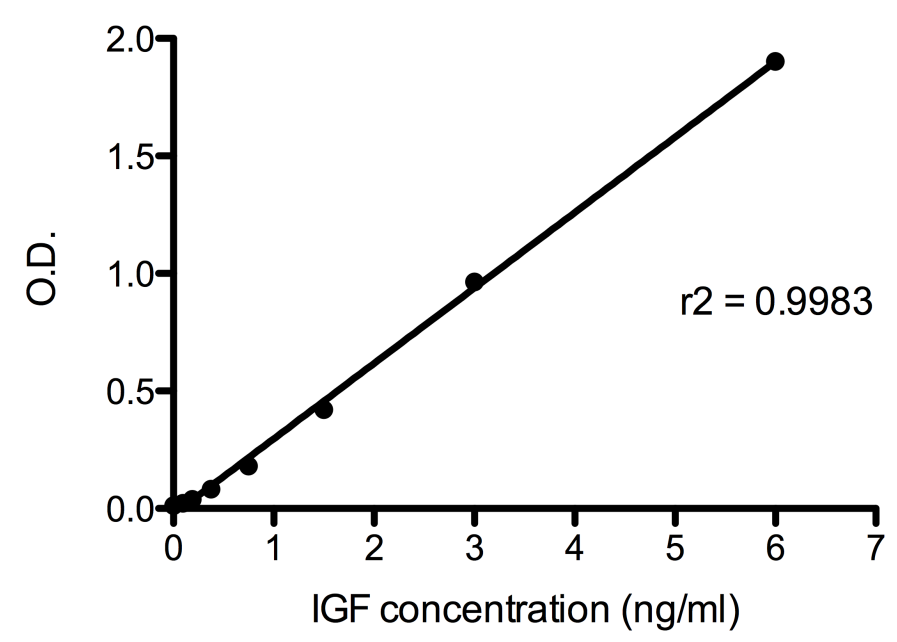

\begin{tabular}{|l|c|c|}
\hline & 0 ng Dox & 10 ng Dox \\
\hline -ve Ctrl (medium) & 0.164 & - \\
\hline Origene hIGF-1 & 11.697 & - \\
\hline$p L V x$ hIGF-1 & 0.884 & - \\
\hline$p L V x$ hIGF-1 + $p$ TetOn & 0.599 & 11.806 \\
\hline
\end{tabular}

Figure 25: Quantification of secreted IGF-1 from transfected TSA cells. The IGF-1 standard curve demonstrates linearity of the ELISA between 0 and $6 \mathrm{ng} / \mathrm{ml}$. IGF-1 release under baseline and doxycycline as displayed in table format. 


\subsubsection{Lentivirus transduction of IGF-1}

Given that IGF-1 could be secreted in TSA cells, lentiviruses were produced using pLVx-Tight-hIGF1-Puro and pTet-On in TSA cells as highlighted in 2.4.7.

\subsubsection{Antibiotic kill curves}

The recombinant plasmids contain antibiotic resistance genes. To determine the effective concentrations of antibiotics to select for positively transduced cells, we performed a toxicity killing assay on non transgenic HFF cells with the following concentrations of antibiotics; puromycin: $0,0.01,0.03,0.1,0.3$ and $1 \mu \mathrm{g} / \mathrm{ml}$, neomycin: 0, 10, 30, 100, 300 and $1000 \mu \mathrm{g} / \mathrm{ml}$. Surviving cells were counted for each concentration.

This revealed that $1 \mathrm{mg} / \mathrm{ml}$ neomycin (Figure $26 \mathrm{~A}$ ) and $1 \mu \mathrm{g} / \mathrm{ml}$ puromycin (Figure 26 B) were the effective concentrations required to inhibit naïve $\left(\mathrm{HFF}^{\mathrm{wt}}\right)$ cell growth. These concentrations were then selected for transgenic HFF cell growth. 

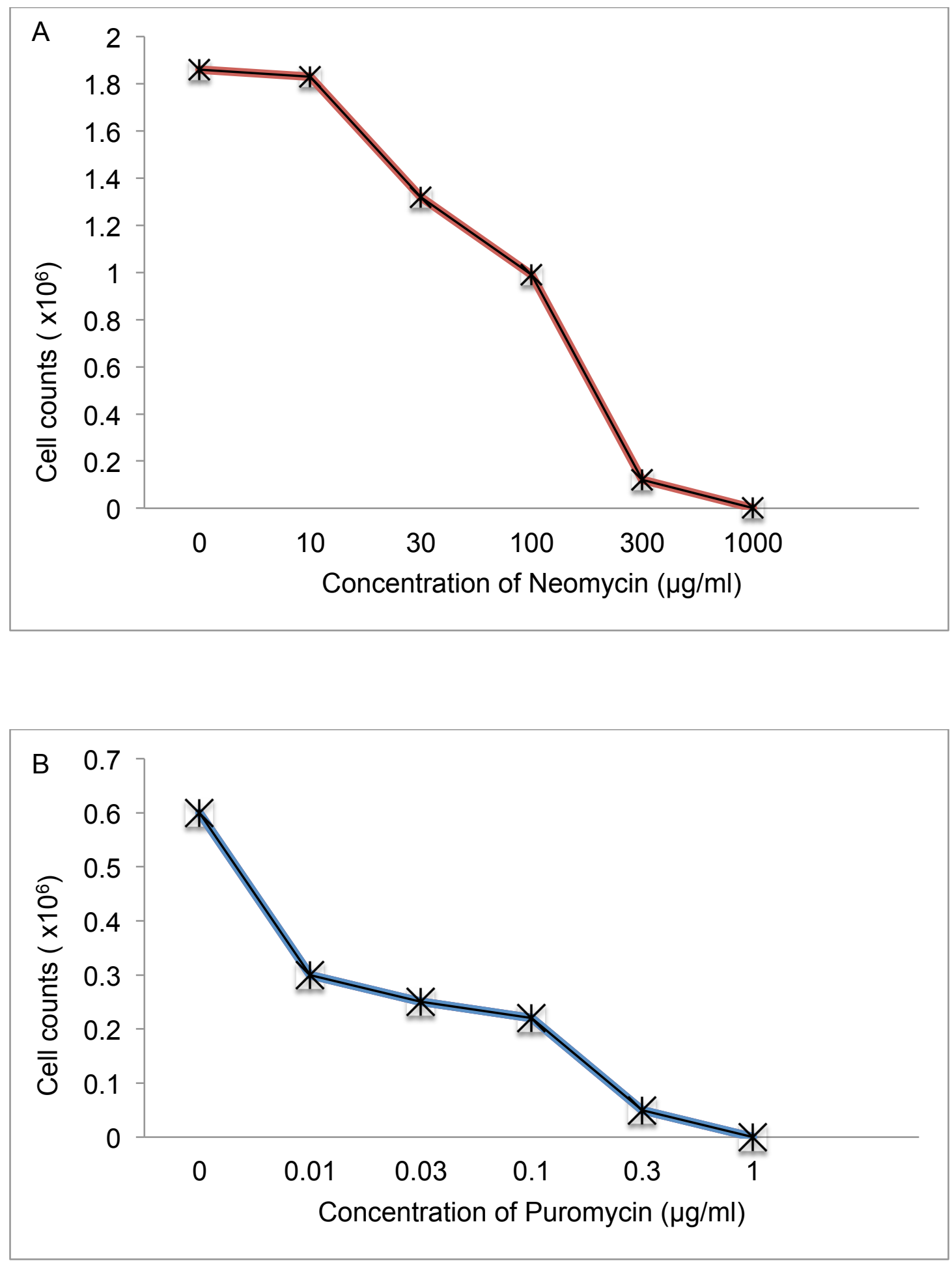

Figure 26: Antibiotic kill curves. (A) Effective killing concentration of neomycin at $1000 \mu \mathrm{g} / \mathrm{ml}$ (B) Effective killing concentration of puromycin at 1 $\mu \mathrm{g} / \mathrm{ml} . \mathrm{n}=1$. 


\subsubsection{Generation of IGF-1 transgenic cell line}

After confirming the inducible expression of hIGF-1 from transfected TSA cells and the effective antibiotic concentration to kill non transgenic HFF, we generated hIGF-1 lentivirus and/or $p$ TetOn transactivator virus by transiently transfecting TSA cells with the recombinant $p$ LVx-Tight-hIGF1-Puro plasmid or $p$ Tet-On-Advanced plasmid together with packaging $p C M V$ and $p M D G$ plasmids. Supernatant samples obtained were tested by the LentiX GoStix ${ }^{\circledR}$ rapid lentiviral p24 indicative test. More than $5 \times 10^{5} \mathrm{IFU} / \mathrm{ml}$ (infectious units / $\mathrm{ml}$ ) of $p \mathrm{LVx}$-Tight-hIGF1-Puro and $p$ Tet-On-Advanced viruses were obtained.

Viruses from $p L V x$-Tight-hIGF1-Puro and $p$ Tet-On-Advanced were used to transduce HFF cells as outlined in 2.4.8. Effective integration was tested by stringent antibiotic selection. Double transduced transgenic HFF $\left(\mathrm{HFF}^{\mathrm{IGF1+TetOn}}\right)$ cells proliferated in the antibiotic supplemented cell culture medium while control HFF ${ }^{\mathrm{wt}}$ cells were killed.

\subsubsection{Expression of IGF-1 from lentiviral transduced fibroblasts}

After successful generation of the HFF ${ }^{\text {IGF1+TetOn }}$ line, the expression of IGF-1 was tested by quantitative ELISA assay and immunostaining. 


\subsubsection{Detection of IGF-1 in transgenic fibroblasts}

We first examined whether IGF-1 would be enriched in HFF ${ }^{\text {IGF1+TetOn }}$ compared to $\mathrm{HFF}^{\mathrm{wt}}$ by immunofluorescence labeling of respective cultures. As anticipated, IGF-1 could be detected particularly in HFF ${ }^{I G F 1+T e t O n}$ in the endoplasmic reticulum (Figure 27).
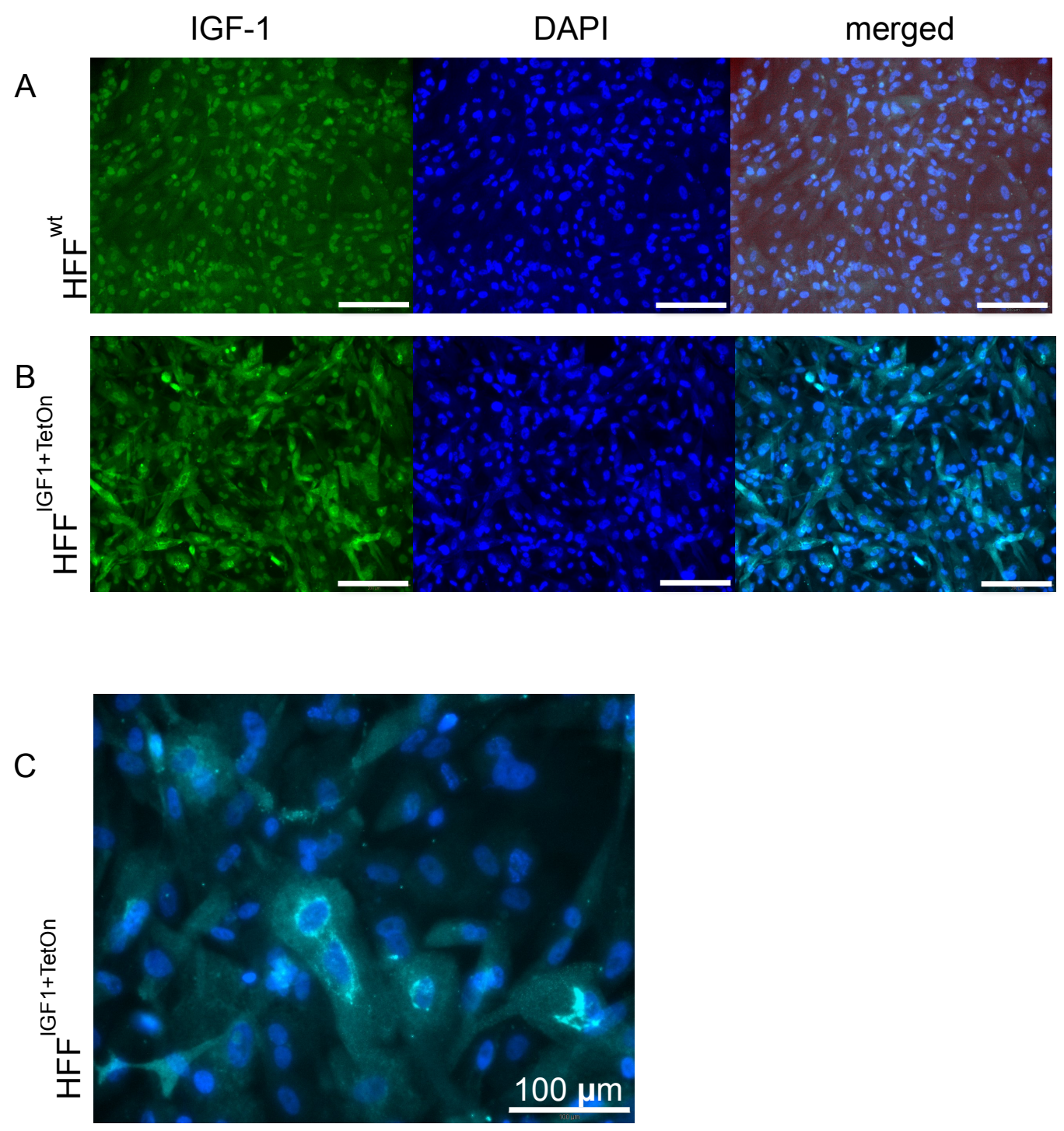

Figure 27. Increased expression of IGF-1 in $\operatorname{HFF}^{\mathrm{IGF1+TetOn}}$. HFF ${ }^{\mathrm{wt}}(\mathrm{A})$ and HFF $^{\text {IGF1+TetOn }}$ (B) labeled for IGF-1 (green). (C) Magnification identifies IGF-1 primarily in the endoplasmic reticulum, Golgi of HFF ${ }^{\mid G F 1+T e t O n}$. 


\subsubsection{Quantification of IGF-1 release}

To demonstrate the reliability and functionality following transduction of HFF cells with this Tet-On lentiviral transduction system, we quantified the levels of human IGF-1 protein in the 72 hour conditioned supernatants and cell lysates harvested from $\mathrm{HFF}^{\mathrm{wt}}$ and transduced $\mathrm{HFF}^{\mathrm{hlGF} 1+\mathrm{TetO}}$ with and without doxycycline exposure. Different concentrations of doxycycline were tested (10 - $1000 \mathrm{ng} / \mathrm{ml})$. We observed that in the supernatants of non-stimulated HFF ${ }^{\text {hIGF1+TetOn }}$ cells, human IGF-1 protein levels were secreted at approximately $2.8 \mathrm{ng} / \mathrm{ml}$ of medium while $\mathrm{HFF}^{\mathrm{wt}}$ cells secreted only $0.4 \mathrm{ng} / \mathrm{ml}$ IGF-1 protein. In cell lysates from $\mathrm{HFF}^{\mathrm{wt}}$ and HFF ${ }^{\mathrm{hIGF} 1}$ cells, minimal human IGF-1 protein was detected $(0.16 \mathrm{ng} / \mathrm{ml}$ and $0.23 \mathrm{ng} / \mathrm{ml}$ respectively). Exposure to doxycycline stimulation led to a 10 fold increase of human IGF-1 protein in the supernatants and cell lysates of HFF ${ }^{\text {hIGF1+TetOn }}$ cells, while minimal IGF-1 protein was detected from HFF ${ }^{\mathrm{wt}}$ cells (Figure 28). Increasing the doxycycline concentrations did not significantly increase IGF-1 protein production.

Taken together, this result suggested that, the HFFs were successfully transduced with the inducible Tet-On lentivirus and both production and secretion of human IGF-1 proteins can be induced by pharmacological concentrations of doxycycline, demonstrating a proof of concept that growth factor production and expression can be controllable with pharmacological drug stimulation. On the other hand, leaky expression was observed in unstimulated HFF IFF1, however, at 10-fold lower levels compared to doxycycline induced cells. 


\section{hIGF1 ELISA}

Standard Curve

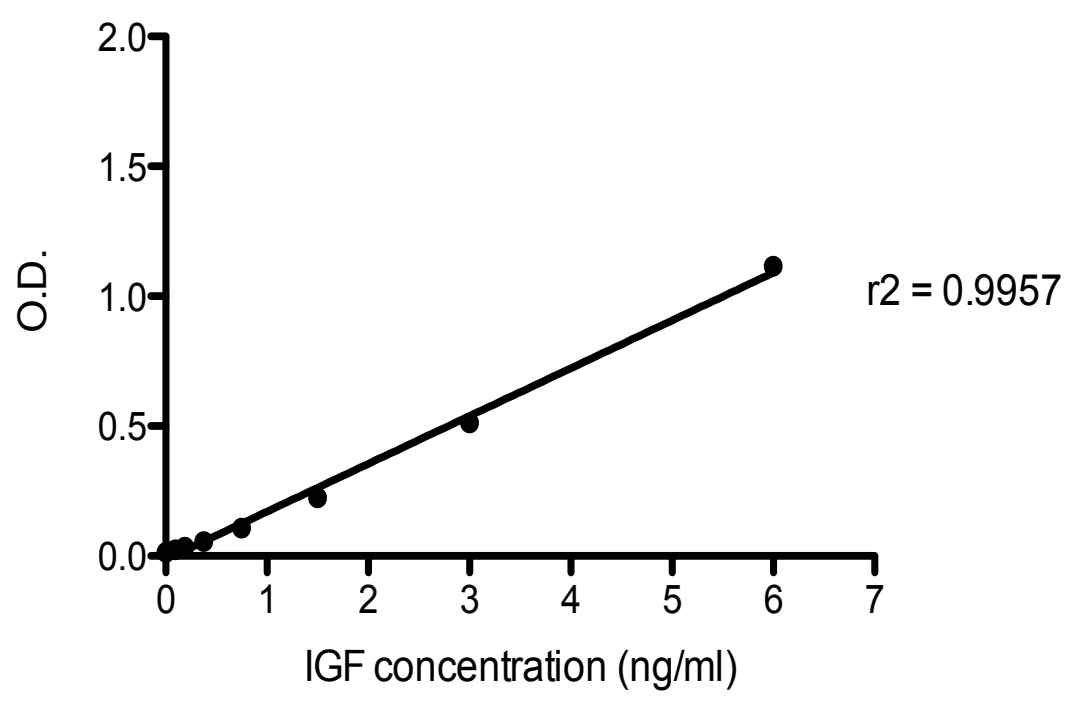

\begin{tabular}{|c|c|c|c|c|c|}
\multicolumn{2}{c|}{$\begin{array}{c}\text { Doxycycline } \\
(\mathrm{ng} / \mathrm{ml})\end{array}$} & 0 & 10 & 30 & 100 \\
\hline \multirow{2}{*}{ HFF $^{\text {wt }}$} & Supernatant & 0.394346 & 0.3970632 & 0.3889115 & 0.3780425 \\
\hline & Cell Lysate & 0.1633805 & 0.1633805 & 0.168815 & 0.1606633 \\
\hline \multirow{2}{*}{ HFF IGF+TetOn $^{*}$} & Supernatant & 2.774649 & 20.28998 & 19.57807 & 20.06717 \\
\cline { 2 - 6 } & Cell Lysate & 0.2313115 & 20.34704 & 20.37693 & 20.03728 \\
\hline
\end{tabular}

Figure 28. Human IGF-1 protein secretion from inducible HFFs. $10 \mathrm{ng} / \mathrm{ml}$ doxycycline was sufficient to induce 10 fold higher level of IGF-1 expression in HFF $^{\text {IGF1+TetOn }}$ cells and also secretion into the supernatants. Naïve HFF ${ }^{\text {wt }}$ cells were investigated as negative controls. 


\subsubsection{Biological activity of human IGF-1}

\subsubsection{Hypertrophy in IGF-1 transgenic fibroblasts}

Next we asked if the secreted hIGF from generated transgenic cell line confers biological activity in vitro. We observed that transduced HFF ${ }^{\text {hIGF1+TetOn }}$ cells appeared larger in size compared to $\mathrm{HFF}^{\mathrm{wt}}$ cells during routine cell culture passaging (Figure 29).
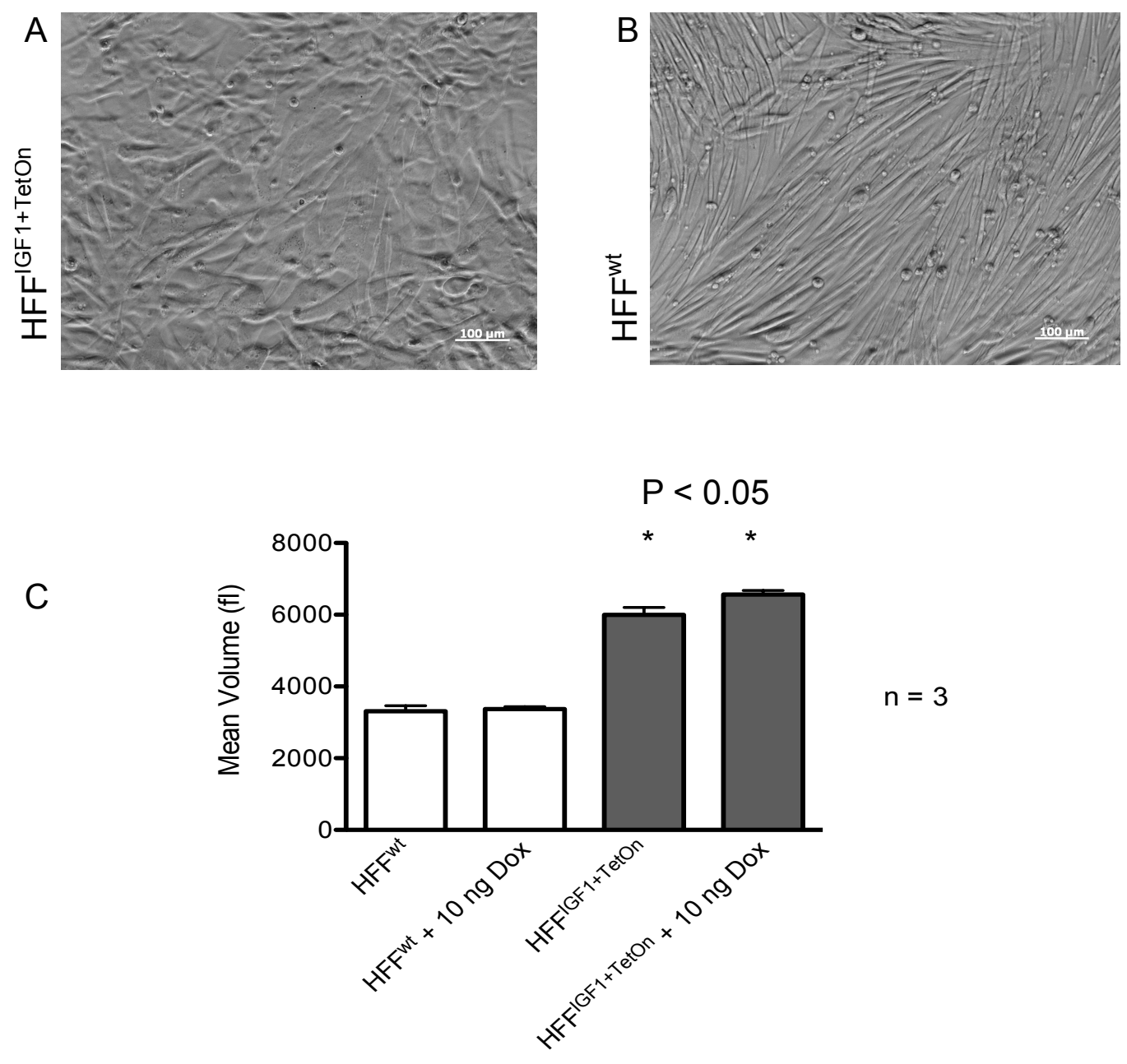

Figure 29. Hypertrophy in IGF-1 transduced HFFs. Brightfield image of $\operatorname{HFFIGF}^{1+\text { TetOn }}(\mathrm{A})$ and $\mathrm{HFF}^{\mathrm{wt}}(\mathrm{B}) .(\mathrm{C})$ Cell volumes in $\mathrm{HFF}^{\mathrm{wt}}$ and HFFIGF${ }^{1+\text { TetOn }}$ in the presence and absence of $10 \mathrm{ng} / \mathrm{ml}$ doxycycline. 


\subsubsection{Paracrine action of IGF-1 activates Akt in cardiomyocytes}

As our overall goal of this study was to induce a beneficial effect in the human heart we next examined the downstream mediators of paracrine action of secreted IGF-1 on hypertrophy signaling pathway in hESC-derived cardiomyocytes. 72 hour serum-free conditioned medium from unstimulated and doxycycline stimulated $\mathrm{HFF}^{\mathrm{wt}}$ and $\mathrm{HFF}^{\mathrm{hlGF} 1+\text { TetOn }}$ cells were harvested and layered over day $16 \mathrm{hESC}$-derived cardiomyocytes for 30 minutes. The cardiomyocytes were then harvested and lysed. Western blot of the hESC cardiomyocytes lysates revealed that phosphorylated Akt (pAkt) proteins were higher in unstimulated and stimulated HFF ${ }^{\text {hlGF1+TetOn }}$ cells compared to HFF ${ }^{\text {wt }}$ cells (Figure $30 \mathrm{~A}$ ). 


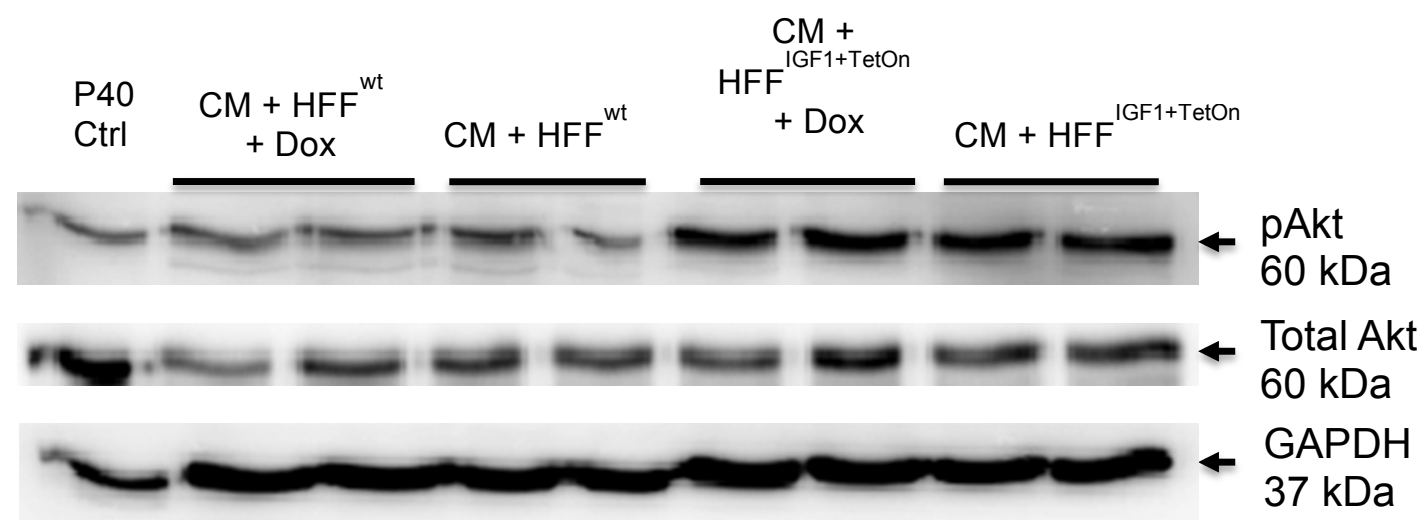

B

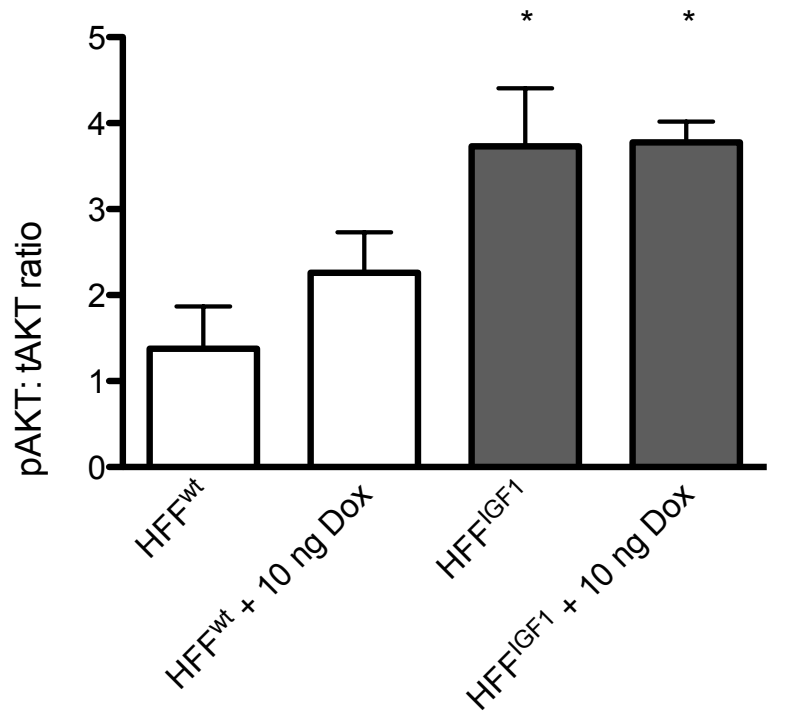

Figure 30. IGF-1 conditioned medium induces Akt phosphorylation in cardiomyocytes. Western blot analyses of pAkt, Akt and GAPDH in hESCderived cardiomyocytes exposed to supernatant from HFF ${ }^{\text {wt }}$ and HFF ${ }^{\text {IGF1+TetOn }}$ ( \pm doxycycline stimulation). (B) Summary of Western blot ( $\mathrm{n}=3$ per group). * p< 0.05 vs HFF ${ }^{\mathrm{wt}}$ ( \pm doxycycline; two-sided, unpaired Student's t-test) 


\subsubsection{IGF-1 enhances force generation of human EHMs}

We supplemented EHMs with $20 \%$ of either $\mathrm{HFF}^{\mathrm{wt}}$ or HFF ${ }^{\text {IGF-1TetOn }}$ cells. Subsequently, EHMs were transferred onto flexible silicone poles on culture day 3 . On culture day $7,10 \mathrm{ng} / \mathrm{ml}$ doxycycline was added to the EHMs medium to induce hIGF-1 secretion from HFF cells. Control EHMs were left without doxycycline. EHMs were subjected to force measurements 72 hours later. Analyses of the forces revealed that, despite no doxycycline stimulation, EHMs generated with HFF ${ }^{\mid \mathrm{GF} 1+\text { TetOn }}$ cells developed stronger contraction forces compared to EHMs generated with HFF ${ }^{\mathrm{wt}}$ cells. However, doxycycline supplemented EHM with HFF hIGF1+TetOn cells developed highest forces compared to all other EHM groups (Figure 31) across varying calcium concentrations, with maximum force at $3.2 \mathrm{mmol} / \mathrm{L} \mathrm{Ca}^{2+}$.

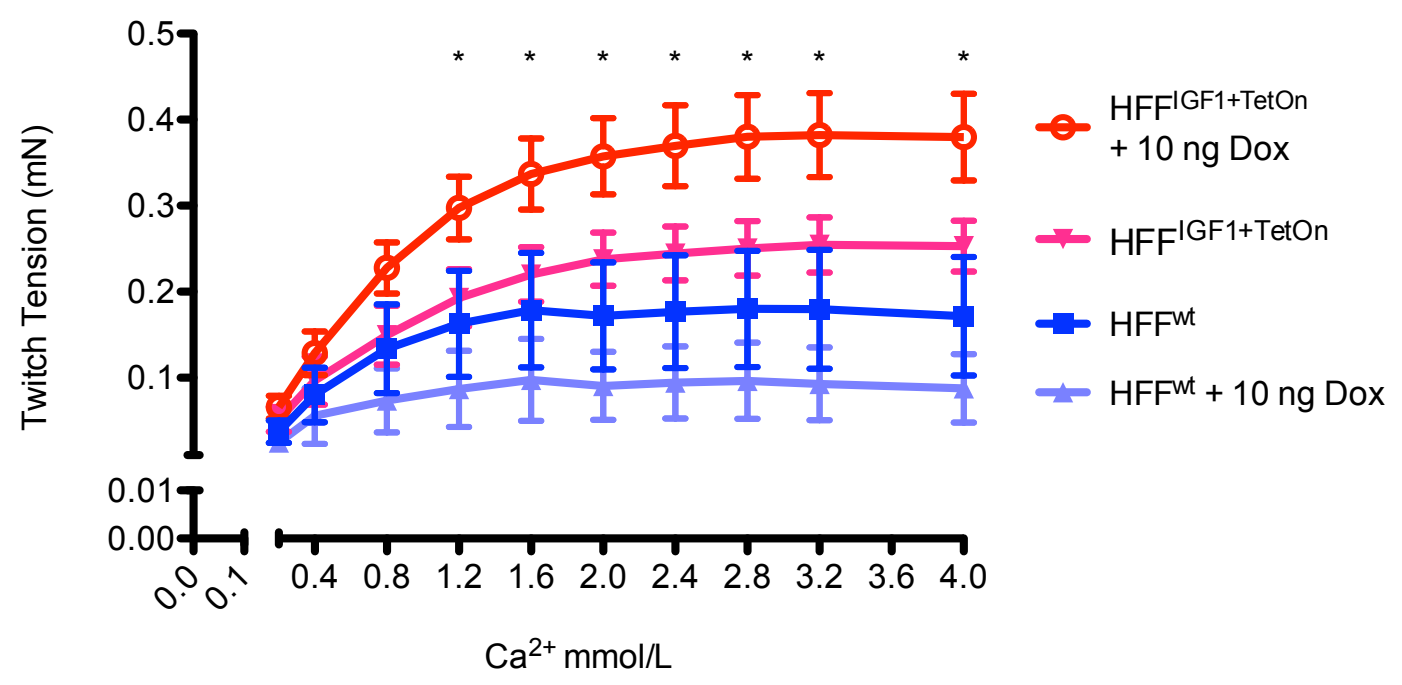

Figure 31. Force generation of EHMs is enhanced by doxycycline activiation of HFF ${ }^{\text {IGF1+TetOn }}$. The ordinate display twitch tension in $\mathrm{mN}$. The abscissa denotes extracellular calcium concentrations. ${ }^{*} p<0.05$ vs HFF ${ }^{\text {wt }}$ EHM; two way ANOVA. 


\subsubsection{IGF-1 induces cell hypertrophy in human EHMs}

We then enzymatically digested these human EHMs, isolated single cells and analyzed the cell sizes from each group using flow cytometry and observed that cells were larger in the presence of human IGF-1 (Figure 32). Enhanced size of non-myocytes may be due to the addition of "large" HFFIGF" ${ }^{1+T e t O n}$. In contrast, cardiomyocyte hypertrophy seems to be stimulated by the HFFs paracrine activity. 
A

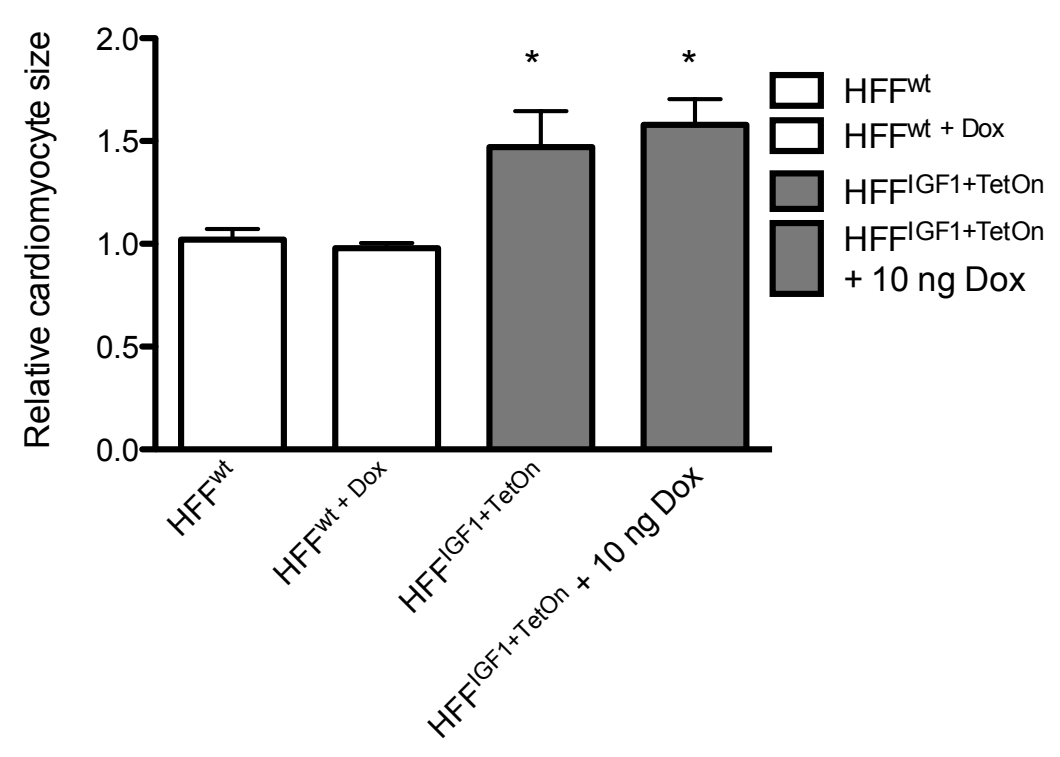

B

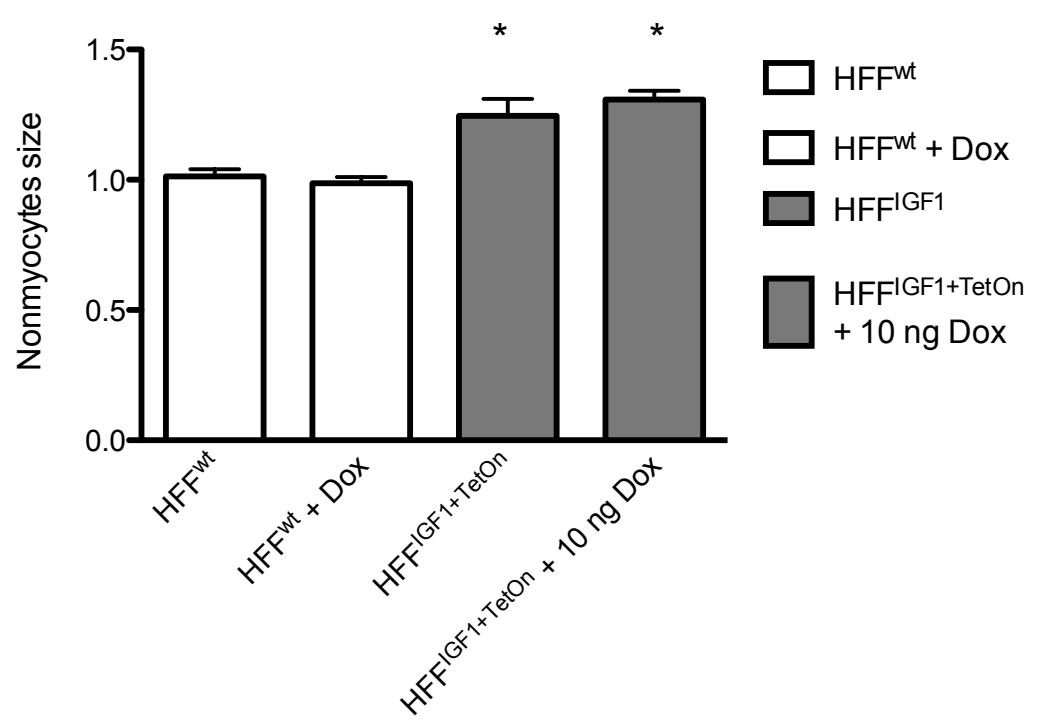

Figure 32. IGF-1 induces cardiomyocytes hypertrophy in EHMs.

Cardiomyocyte (A) and (B) non-myocyte size measured by flow cytometry. ${ }^{*} \mathrm{p}<0.05$ vs HFF ${ }^{\mathrm{wt}}$. 


\subsubsection{IGF-1 improves morphology of human EHMs}

We performed whole mount immunofluorescence staining on both groups of EHMs and observed that cardiomyocytes were generally elongated and anisotropically aligned and form cardiac bundles (Figure 33 A). However, EHMs generated from cardiomyocytes mixed with HFF ${ }^{\mid G F 1+T e t O n}$ appear to contain thicker muscle bundles and enlarged cardiomyocytes (Figure $33 \mathrm{~B}$ ).
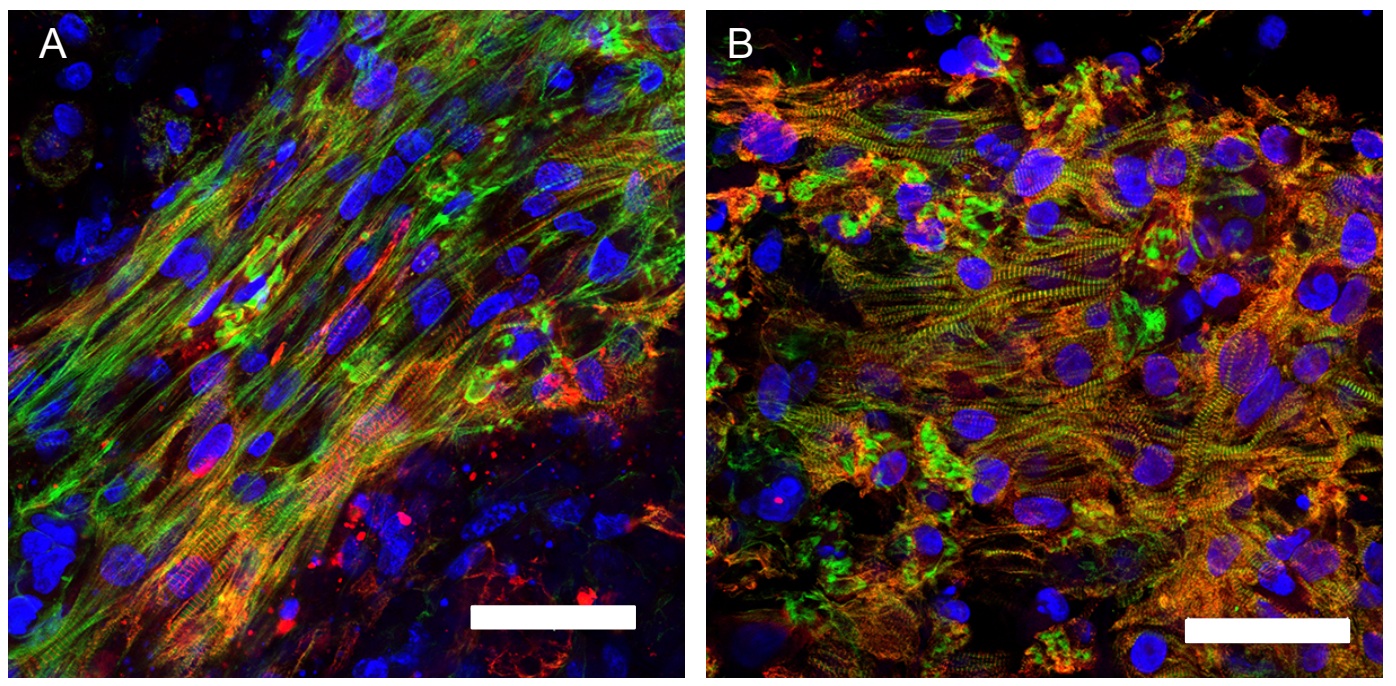

Figure 33: Wholemount stainings of EHMs. (A) EHMs cultured with HFF" (B) EHMs cultured with HFF ${ }^{\mid G F 1+T e t O n}$ cells. EHMs stained for actinin (red), actin (green) and nuclei staining with DAPI (blue). Scale bar: $50 \mu \mathrm{m}$.

\section{5 "paraBioVAD" generation}

To finally prepare the BioVAD with paracrine IGF-1 release, 20\% HFF HFF1+TetOn $^{\text {I }}$ were added to the BioVAD reconstitution mixture. This yielded "paraBioVAD" with similar appearance as the "simple" BioVAD (Figure 34). 


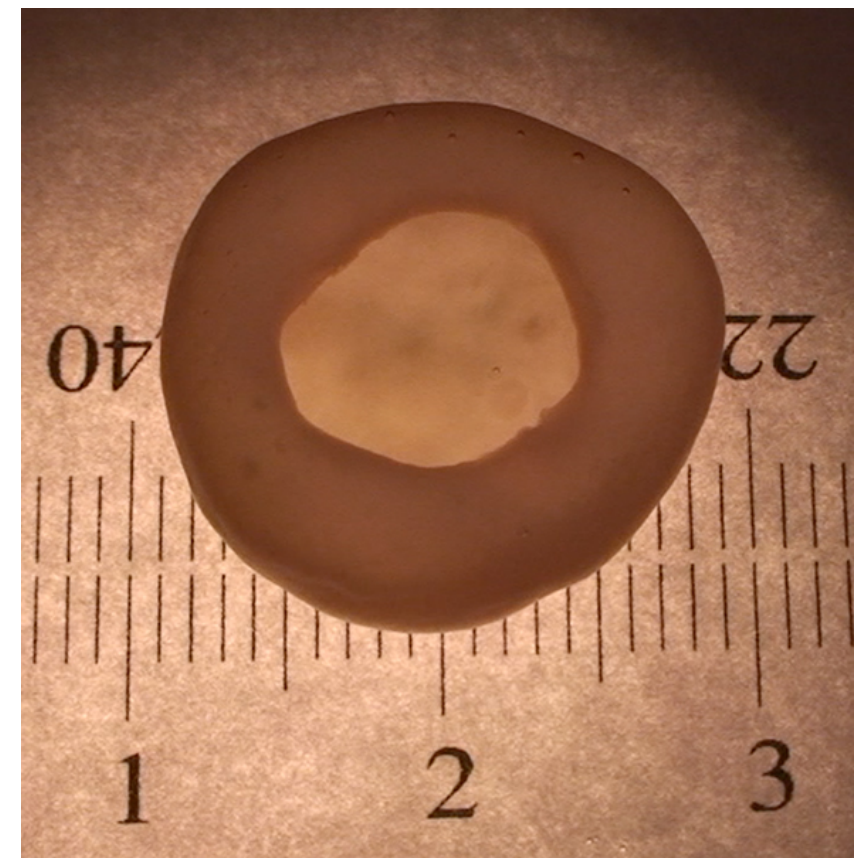

Figure 34. Human "paraBioVAD". Diameter of $20 \mathrm{~mm}$.

\subsubsection{Implantation of "paraBioVAD"}

A single "paraBioVAD" was implanted in an immunosuppressed Wistar rat and harvested after 3 weeks (Figure 35 ). The explant was observed to have contracted towards the apex but remain attached and still encompassed the ventricles. 


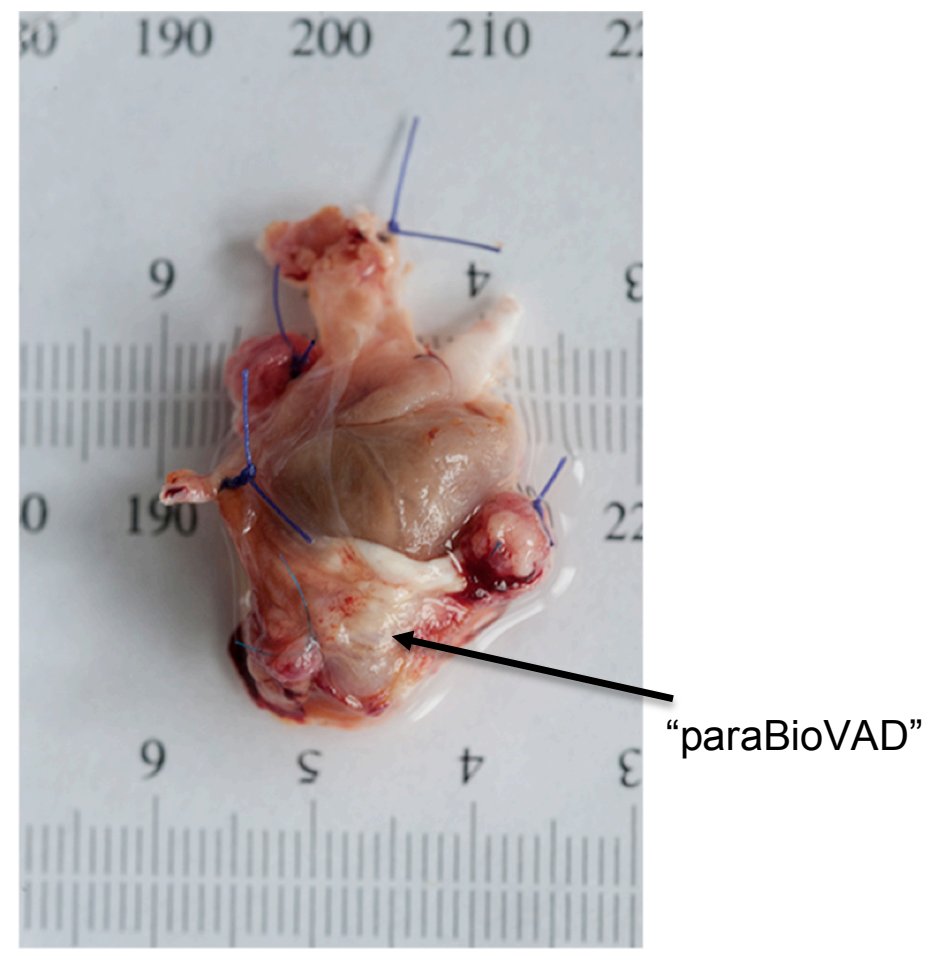

Figure 35. Explant of human "paraBioVAD". Explanted "paraBioVAD" remains attached to rat heart 3 weeks post implantation.

\subsubsection{Histological observations of explanted "paraBioVAD"}

We then performed routine Haematoxylin \& Eosin (H\&E) and Sirius Red stainings to study the morphology of the explanted "paraBioVAD" relative to the rat heart and observed that the "paraBioVAD" generally remained intact over the rat heart.

A clear border zone between the heart and the "paraBioVAD" was observed (Figure 36). Generally, a gap of 50-100 $\mu \mathrm{m}$ distinguishes the heart from the "paraBioVAD". However, in several areas, there were clear "contact zones" between the "paraBioVAD" and recipient myocardium (Figure $36 \mathrm{~A}, \mathrm{~B}, \mathrm{C}$ ). 
"Myocardial-like" elongated cells were also observed (Figure 36 C). Interestingly, several areas showed developing vascular structures (Figure 36 $D, E, F)$, suggesting early vascularization.
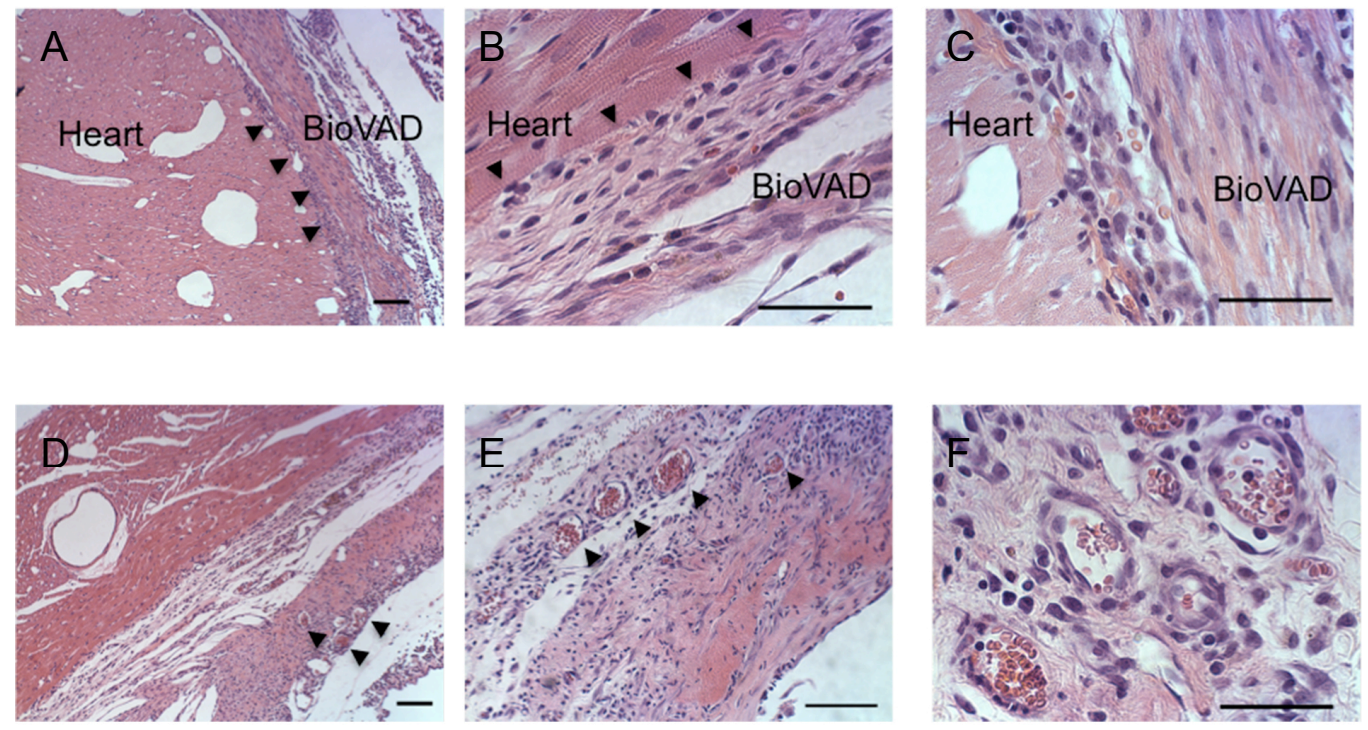

Figure 36. Histological sections of "paraBioVAD" on rat heart. (A) Grafting areas of "paraBioVAD" to the rat heart (arrows). Scale bar $100 \mu \mathrm{m}$ (B) Magnified area of engraftment with rat myocardium. Scale bar $50 \mu \mathrm{m}$. (C) Elongated muscle like strands engrafted to rat heart. Scale bar $50 \mu \mathrm{m}$. (D-F) Vascularization of "paraBioVAD". (D) arrows indicate developing vasculature structures. Scale bar $100 \mu \mathrm{m}$. (E) Magnified image of vessels (arrows). Scale bar $100 \mu \mathrm{m}$. (F) Developing vascular structures in the "paraBioVAD" showing vessels containing blood. Scale $50 \mu \mathrm{m}$. 
In Sirius red stained sections, we observed clear demarcation of collagen (stained red) stemming from the "paraBioVAD" matrix. Collagen was also observed at several points where the "paraBioVAD" engrafted onto the rat heart (Figure 37). Vascular structures were also observed in several areas of the "paraBioVAD" (Figure 36).

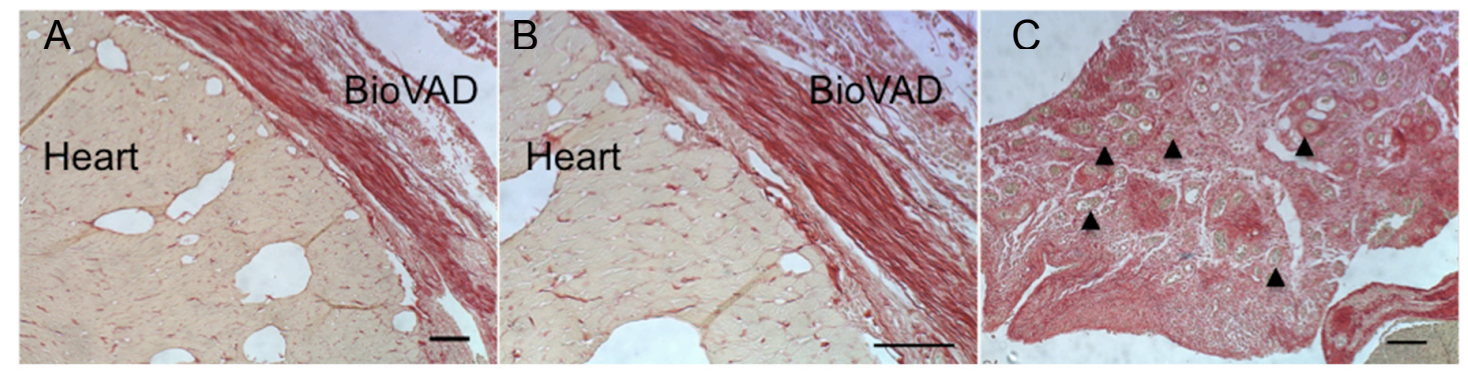

Figure 37. Morphology of "paraBioVAD" stained with Sirius red. $(A-C)$ Red staining indicates collagen. (A) Scale bar $100 \mu \mathrm{m}$ (B) Scale bar $100 \mu \mathrm{m}$. (C) Vascular structures containing blood (arrows). Scale bar $100 \mu \mathrm{m}$. 
Heart failure develops typically after myocardial infarction or chronic hypertension. However, not all patients with these conditions develop endstage heart failure and the mechanisms underlying its disease progression and conversion into severe heart failure are not well understood. Given the limitations in drug and device therapy today, cell therapy has been proposed as an alternative with the potential to replenish the disease heart with cardiomyocytes. Yet, until recently, direct cell replacement approaches have not yielded favorable results consistently (Schachinger, et al. 2006, Lunde and Aakhus 2008, Perin et al. 2012). In particular in chronic heart failure, where seeding of cardiomyocytes would likely elicit an optimal therapeutic effect, little advance has been made. This is partly due to a lack of suitable cells (cardiomyocytes) and low cell retention rates following transplantations. The discovery of ESCs and subsequent establishment of stem cell lines have rekindled the possibility of obtaining unlimited amounts of cardiomyocytes (Thomson, et al. 1998). However, ethical and safety concerns have prevented the wide use and application of ESC as a therapy. Only the recent establishment of induced pluripotent stem cells (iPSC) circumvented this issue and allowed the use of virtually any adult cell to be transformed to an "ESC-like" state (Takahashi and Yamanaka 2006). This also led to a surge in up scaling technologies to rapidly increase the quantities and availability of naïve stem cells (Nie et al. 2009, Singh et al. 2010, Chen et al. 2011, Zweigerdt, et al. 2011). Despite these advances, differentiation of stem cells to obtain pure cardiomyocytes remains challenging, let alone obtaining large 
quantities and quality. This is also due in part to the lack of understanding of the underlying mechanisms for proper cardiomyocyte differentiation.

In recent years, the paradigm to replace the defective myocardium has shifted from direct cell replacement strategies to tissue-based approaches ( $\mathrm{Li}$, et al. 1999, Shimizu et al. 2002, Zimmermann and Eschenhagen 2003, Zimmermann, et al. 2006). Applications of these engineered cardiac tissues in animal models have been encouraging, albeit insufficient to fully repair diseased heart muscle. The next phase of bioengineering advancements was to scale the tissue engineering concepts (Naito et al. 2006, Yildirim et al. 2007). Based on this previous work, it was hypothesized that a large continuous human "pouch-like" tissue construct (BioVAD) can be generated with additional protective paracrine activity.

The following results were achieved:

- Robust cardiomyocyte derivation from hESCs.

- Generation of human EHM from hESC-derived cardiomyocytes

- Creation of a biomimetic culture platform to scale and mature BioVADs.

- Development of a drug-inducible IGF-1 release cell line.

- Proof-of-concept for tissue engineered paracrine support BioVAD 


\section{1 hESC differentiation to generate cardiomyocytes for tissue engineering}

In this study, two different protocols to generate cardiomyocytes from hESC cell lines were used. The first protocol involved the generation of spontaneously beating 3D embryoid bodies, which resulted in $10-20 \%$ cardiomyocytes being generated. This differentiation protocol required hESC cell "rafts"; small pieces of uniformly cut HES colonies to be generated as starting material (Soong et al. 2012). This technique, while easily mastered is laborious and variable with respect to total cardiomyocyte yield. On day 2 of differentiation, cardiomyogenesis was initiated with the addition of a small molecule, SB203580, which is a specific inhibitor of the p38 - Mitogen Activated Protein Kinase (MAPK) pathway. This has been demonstrated to greatly enhance cardiomyogenesis in hESCs within a narrow range of $1-10$ $\mu \mathrm{M}$ concentrations (Graichen, et al. 2008) and marked dephosphorylation of p38 at $5 \mu \mathrm{M}$ (Kempf et al. 2011). However, the inhibition of p38 MAPK has also been reported to inhibit ERK and JNK kinases and PKB (Henklova et. al., 2008, Muniyappa et. al., 2008) and also inducing differentiation in human myeloid leukemia cells (Ishii et. al., 2001), suggesting that the inhibitory action also has widespread downstream effects on other important cell signaling pathways and hence is not an ideal small molecule to direct differentiation of HES cells into cardiomyocytes.

Although the 3D EB formation approach may have been developed to mimic the environment during embryo development in the blastocyst stage and also as a method to initiate spontaneous differentiation into the 3 germ lineages, 
directed cardiomyogenesis to yield large amounts of cardiomyocytes with such a model remains challenging. Embryoid bodies possess a layer of epithelial like cells which secretes extracellular matrix containing collagen and forms a thin barrier which limits uniform diffusion across the layer and also creates gradients of nutrients and metabolites reaching the cells within the (Sachlos and Auguste 2008, Carpenedo et al. 2009, Kinney et al. 2011, Van Winkle et al. 2012). This suggests that the cells within the EB which receives optimal concentrations of growth factors will undergo differentiation while others do not, leading to heterogeneous decreased efficiency in an EB and suboptimal numbers of cardiomyocytes. However, recent reports suggest that the 3D EB culture method may yield more physiologically similar and matured cardiac phenotype cells with decreased fetal genes expression and respond more rapidly to $T_{3}$ hormonal stimulation than parallel $2 \mathrm{D}$ cultures (Akins et al. 2010).

The second differentiation protocol involves the generation of cardiomyocytes from 2D monolayer hESCs and is based on the differentiation protocol from Hudson et. al. 2012. First, heterogeneity of undifferentiated hESCs were reduced by single cell adaptation of hESCs and then cultured in a monolayer of $0.5 \times 10^{5}$ cells per $\mathrm{cm}^{2}$ in a tissue culture well of a 24 well plate. This cell number is critical to prevent overgrowth of cells during mesodermal cell type proliferation and is optimal for primitive streak cell specification with Activin A and BMP 4 supplementation and also allows even diffusion of the growth factors and oxygen concentrations into the culture, thus exposing a monolayer of cells to undergo uniform temporal differentiation in the well. The result is a 
high yield of 40-60 \% differentiated cardiomyocytes. In addition, supplementation of IWP4 inhibits Wnt/ß-catenin signaling; a signaling pathway implicated in hESC cardiogenesis (Klaus et al. 2007, Tzahor 2007, Paige et al. 2010, Hudson and Zimmermann 2011). Inhibition of the Wnt signaling pathway at day 3 was critical as BMP4 was withdrawn from the differentiation medium. This was done to prevent the continual activation and accumulation of Wnt, which then drives the expression of hematopoietic/vascular markers in the cells, and reduce cardiomyogenesis.

Taking the results from both protocols, one can conclude that generation of cardiomyocytes from human ESCs involves the inhibition of key signaling pathways such as the p38-MAPK and Wnt regardless of human ESC lines. This can be accomplished by the antagonistic action of small molecules at critical concentrations. However, specific inhibition of the Wnt/ß-catenin signaling pathway offers the most effective way to achieve high yields of cardiomyocytes in an in vitro system compared to that of p38-MAPK pathway. Hence, a 2D direct differentiation protocol may be more suited in situations where large quantities of cardiomyocytes are required such as generating large cardiac constructs for application in humans.

\subsection{Generation of human EHM from ESC derived cardiomyocytes}

To engineer cardiac constructs capable of synchronous contraction and force generation, a finely balanced environment similar in composition to the native heart had to be recapitulated. Previous rodent EHT models generated with hydrogels containing collagen type 1 and Matrigel have been demonstrated to 
be highly reproducible (Zimmermann, et al. 2000, Tiburcy, et al. 2011). The constructs also demonstrated enhanced maturity when subjected to strain (Fink et al. 2000, Zimmermann, et al. 2000, Zimmermann, et al. 2006). In this study, similar concepts were exploited to demonstrate the feasibility of human EHM construction with hESC-derived cardiomyocytes. The term Engineered Heart Muscle (EHM) was introduced instead of Engineered Heart Tissue (EHT) because it better describes the identity of the engineered construct and clearly distinguishes it from heart valve and vessel engineering. EHMs contracted spontaneously, generated appreciable forces, and responded to inotropic interventions (i.e. increase in extracellular calcium concentration) as expected for heart muscle, albeit with a higher calcium sensitivity. Morphologically, EHMs contained elongated and anisotropically aligned cardiomyocytes with highly ordered sarcomere arrangements. This is in clear contrast to monolayer cardiomyocyte cultures, where cell morphology does typically not resemble the in vivo situation (Kehat, et al. 2001, Mummery et al. 2003). Hence, the human EHM platform may also for in vitro studies be considered more suitable than monolayer cultures.

\subsection{Generation of a large humanized BioVAD}

To overcome the limitations of restraint medical devices and the size of hEHMs, we rationalized that large functional human cardiac constructs can be generated by combining the large quantities of cardiomyocytes obtained from the 2D differentiation protocol of hESC together with an improvement of casting stages of the construct. It was of particular importance to fabricate "perfectly" spherical casting molds and spacers to ensure homogenous tissue 
formation. This not only allowed the advancement of the previously developed BioVAD concept (Yildirim et al. 2007) from the rat to the human model, but also scaling of the BioVADs towards human heart applications.

A further improvement was this implementation of biomimetic pulsatile mechanical stretch by making use of an inflatable inner "spacer". Our results demonstrated that with conditioning by pulsatile stretch, we could obtained a rabbit heart sized human BioVAD that contained more cells undergoing DNA synthesis than unpulsed constructs, consistent with reports that mechanical stretching regulates DNA synthesis (Iwasaki et al. 2000, Adam et al. 2004), and activates stress activated protein kinases (Komuro et al. 1996). Whether this was in cardiomyocytes or non-myocytes remains to be clarified.

Transcript analysis demonstrated higher abundance of sarcomeric protein and some, but not all, analyzed calcium handling protein encoding mRNAs in pulsed vs. unpulsed BioVADs. This is in agreement with previous studies demonstrating high maturity in tissue engineered heart muscle developed under mechanical load (Tiburcy, et al. 2011). Whether additional biophysical stimuli such as electrical stimulation would further facilitate tissue maturation remains to be studied.

\subsection{Drug-inducible IGF-1 release for paracrine heart support}

We reasoned that pharmacologically controlled paracrine secretion of IGF-1 could confer an additional therapeutic benefit to the BioVAD technology. To achieve this, a fibroblast cell line with stable IGF-1 secretion was under the 
control of the Tet-On activator domain was generated. However, already under unstimulated conditions IGF-1 release was enhanced, but could be further enhanced by doxycycline supplementation. In these cells IGF-1 secretion reached maximum concentration already under $10 \mathrm{ng}$ doxycycline. This was unexpected and either argues for an all-or-nothing activation, the need to test even lower doxycycline concentrations or insufficient linearity of the IGF-1 ELISA. Finally, alternative drug-inducible systems may need to be exploited to enable full control of IGF-1 release.

Half-maximal activation $\left(\mathrm{EC}_{50}\right)$ of the IGF-1 receptor is at $2 \mathrm{ng} / \mathrm{ml}$ IGF-1. IGF1 transduced cells supplemented the culture medium with $20.3 \mathrm{ng} / \mathrm{ml} \mathrm{IGF-1} \mathrm{in}$ 30 minutes. We also observed hypertrophy in IGF-1 expressing fibroblasts, which could be either an indirect effect of the transgenic approach or due to autocrine stimulation.

IGF-1 has been studied extensively in skeletal muscle biology and its effects on aging (Renganathan et al. 1998, Musaro et al. 2001, Rommel et al. 2001, Rabinovsky et al. 2003, Musarò et al. 2004, Musarò et al. 2004, Song 2005, Perrini et al. 2010, Taekema et al. 2011). Circulating IGF-1 produced from the liver typically activates PI3K/Akt/mTOR and MAPK pathways (Mourkioti et. al., 2005). Its effects on cardiomyocytes are mainly enhanced survival (Katjstura et. al., 2001) and hypertrophy (Kinugawa et al. 1999, Iwanaga et al. 2000, Kajstura et al. 2001, Yamashita et al. 2001, Welch, et al. 2002, McDevitt et al. 2005, Millis et al. 2012); both are likely in response to AKT-activation. Different IGF-1 isoforms have been implicated in cardiomyocyte biology 
(Vinciguerra et. al., 2009). In this study, IGF-1 variant 4 (Figure 3) was overexpressed to activate prosurvival and physiological hypertrophy in EHMs. Conditioned medium from human IGF-1 secreting fibroblasts increased Akt phosphorylation in hESC-derived cardiomyocytes in a paracrine manner. These cardiomyocytes were also significantly bigger than those not exposed to IGF-1 suggesting hypertrophic gene activation program.

In three dimensional human cardiac tissue constructs, our results demonstrated that IGF-1-enriched EHMs developed enhanced contractile forces compared to non IGF-1-enriched EHTs. Here doxycycline addition to enhance IGF-1 release did indeed further improve contractile force. Whether this is due to better enrichment of the paracrine micro milieu in the EHM as compared to medium supernatant remains to be clarified.

Given that IGF-1 plays a key role in many signaling pathways including proliferation, differentiation and hypertrophy (Figure 4), it would not be surprising that IGF-1 levels may be responsible for the regulation of contraction forces. Indeed, several studies have demonstrated that IGF-1 binds to receptor tyrosine kinase and activates Akt via PI3K, and enhances Ltype $\mathrm{Ca}^{2+}$ current channels (Kamp and Chiamvimonvat 2006). Moreover, Akt overexpression studies in the myocardium also suggest an increased calcium channel activity in ventricular myocytes (Macrez et al. 2001, Quignard et al. 2001, Kim et al. 2003). 


\subsection{Feasibility of "para BioVAD" generation and implantation}

Finally, we integrated the IGF-1 releasing fibroblasts into the human BioVAD system. The "paraBioVADs" were generated with $20 \% \mathrm{HFF}^{\mathrm{IGF1+TetOn}}$ cells. So far, only one attempt of implantation of a humanized "paraBioVAD" has been carried out. Importantly, the recipient rat survived the operation with no evidence of pericardial constriction or other complications. Teratoma formations were not detected despite the administration of cyclosporine. Longer observational studies are necessary to rule out this risk typically associated with pluripotent stem cell-derivatives. On the other hand, the relatively low numbers of undifferentiated hESCs after $2 \mathrm{D}$ differentiation (Hudson, et al. 2012) may not pose a risk for teratoma formation.

Following explantation of the rat heart, histological stainings revealed areas of "paraBioVAD" that resemble "myocardial" structures. There was clear survival of cells within the graft which are elongated and aligned at the border zone, confirming that such engineered cardiac constructs can survive after transplantations in agreement with other studies (Zimmermann, et al. 2006, Yildirim, et al. 2007, Shiba, et al. 2012).

We were encouraged by the observation of vascularization in several areas within the "paraBioVAD". Indeed, vascularization is a critical point in attempts to generate humanized cardiac tissue constructs. In the human heart, vascular networks consisting of smaller arteries and capillaries are present to deliver oxygen and also transport growth factors to the contracting cardiomyocytes. This complicated network stems from the endothelial 
mesenchymal lineage precursor cells (Martens et al. 2006) that is regulated by the extracellular cell matrix secreted by stromal cells (Kreutziger et al. 2011). Any tissue engraftments then will need to develop connections to the host vascular system to obtain oxygen and important growth factors to allow the survival and further maturation of such tissues. Several cardiac constructs such as stacked cell sheets (Shimizu, et al. 2006), overlapping looped EHTs to form fused multiloops (Zimmermann, et al. 2006) and the neonatal rat BioVAD (Yildirim, et al. 2007) have also demonstrated some form of angiogenesis following engraftment of the construct. One major caveat is the potential hypoxia arising from the thickness of the BioVAD. Data from the cell sheet stacks demonstrated that the maximum thickness for tissues to survive with angiogenesis was 4 cell sheet layers amounting to $\sim 45 \mu \mathrm{m}$ (Shimizu, et al. 2002). This limitation could be circumvented by allowing the first blocks of cell sheet stacks to develop vasculature followed by polysurgery to further stack other cell sheet layers till a thick tissue is formed (Shimizu, et al. 2006). However, the "paraBioVAD" was generated to form a thick myocardial tissue of at least $1 \mathrm{~mm}$ and was also designed to prevent multiple surgical interventions during therapy. In light of this, we believe that the human "paraBioVAD" with enhanced survival will be able to obtain nutrients and oxygen via its developing vascularization network. However, further studies will have to characterize oxygen and nutrient supply in BioVAD grafts.

The outlook of generating large viable and clinically applicable engineered cardiac constructs seems promising. Owing to the advancement and understanding of key signaling pathways and role of growth factors in hESC 
development, improvements made in hESC cardiac differentiation protocols have significantly increased and enriched the amount of human cardiomyocytes that can be derived in vitro (Kattman et al. 2006, Hudson and Zimmermann 2011, Kattman et al. 2011, Hudson, et al. 2012). Coupled with mass scaling approaches with bioreactors (Zweigerdt, et al. 2011), the amount ( 1 billion) of cardiomyocytes required to repair a myocardial infarcted region may soon be attained.

Despite this advancement, further developments pertaining to the application of these cardiomyocytes have to be understood and addressed. Small models of engineered heart tissues using hESC-derived cardiomyocytes and nonmyocytes have only been recently established. Results gleaned from previous studies using similar animal EHT models have demonstrated that tissues engineered with only cardiomyocytes will not be sufficient to generate sufficient force and are structurally inferior to those generated with an equal composition of non myocytes and cardiomyocytes (Naito, et al. 2006, Yildirim, et al. 2007), suggesting a more complex mix of cell types would be required to engineer tissues that are deemed faithful to a healthy myocardium. In addition, these cells mix within the tissue must also demonstrate maturity of the tissue by responding to various stimuli (positive inotropic response to extracellular calcium and isoprenaline) through the generation of strong contractile forces and non-myocytes within such tissues must also secrete beneficial paracrine factors to the cardiomyocytes. Currently, we have addressed these issues in our human EHM model and are investigating the application to larger human engineered cardiac constructs such as the BioVAD. 
For any contracting bioengineered cardiac construct to deliver an effective and improved function to the heart, the tissue must be able to integrate and electrically couple with the native heart. In addition, such constructs must also propagate the electrical impulses throughout the entire construct. We were encouraged to see areas of engraftments of the BioVAD to the rat heart in our study as well as possible microvasculature within the implant. This could potentially be derived from the surrounding pericard, however, further investigations would have to be performed to confirm the origins of such vascular structures. Concerns with electrical conduction issues pertaining to synchronization of tissue beating rate to host heart leading to arrhythmic events can be rectified by transient integrating pacemakers during early transplantation of the BioVAD. 
A new technology to "build" scalable BioVADs from hESCs under "biomimetic" pulsatile stretching was developed. In addition, the concept of pharmacological inducible paracrine support in tissue engineered myocardium was established. First proof-of-concept for a BioVAD technology with paracrine activity was provided. This will further be exploited to investigate the hypothesis that BioVADs with paracrine activity can support a failing heart via (1) mechanical restraint, (2) contractile support, and (3) and paracrine activity. Currently, a doxorubicin induced dilated cardiomyopathy rat model is being established for first tests in a disease model. Further optimization of the BioVAD approach will likely be necessary to offer the necessary bio-artificial muscle mass to elicit a direct therapeutic effect and to identify optimal timing and "dosing" of its paracrine activity. Moreover, IGF-1 may turn out to not be the best choice to support a failing heart, requiring tests of other factors and combinations thereof. Given the use of potentially tumorigenic cells on the one hand and electrically excitable and conducting cells on the other hand it will be essential to define the risks associated with the proposed biological support approach. This will have to involve long-term large animal studies and "clinical" surveillance. Whether alternatives to the hESC approach will become available will depend on the implementation of robust methods to control cardiogenicity in vitro and on further advances in stem cell immunology and banking to facilitate allogeneic or autologous stem cell applications. 
[1] Adam RM, Eaton SH, Estrada C, Nimgaonkar A, Shih SC, Smith LE, Kohane IS, Bagli D and Freeman MR. 2004. Mechanical stretch is a highly selective regulator of gene expression in human bladder smooth muscle cells. Physiol Genomics. 20 (1):36-44

[2] Akins RE, Jr., Rockwood D, Robinson KG, Sandusky D, Rabolt J and Pizarro C. 2010. Three-dimensional culture alters primary cardiac cell phenotype. Tissue Eng Part A. 16 (2):629-41

[3] Andrews PW. 1984. Retinoic acid induces neuronal differentiation of a cloned human embryonal carcinoma cell line in vitro. Dev Biol. 103 (2):285-93

[4] Assmus B, Rolf A, Erbs S, Elsasser A, Haberbosch W, Hambrecht R, Tillmanns H, Yu J, Corti R, Mathey DG, Hamm CW, Suselbeck T, Tonn T, Dimmeler S, Dill T, Zeiher AM and Schachinger V. 2010. Clinical outcome 2 years after intracoronary administration of bone marrowderived progenitor cells in acute myocardial infarction. Circ Heart Fail. $3(1): 89-96$

[5] Atkins BZ, Lewis CW, Kraus WE, Hutcheson KA, Glower DD and Taylor DA. 1999. Intracardiac transplantation of skeletal myoblasts yields two populations of striated cells in situ. Ann Thorac Surg. 67 (1):124-9

[6] Badcock G, Pigott C, Goepel J and Andrews PW. 1999. The Human Embryonal Carcinoma Marker Antigen TRA-1-60 is a Sialylated Keratan Sulfate Proteoglycan. Cancer Research. 59 (18):4715-4719

[7] Beltrami AP, Barlucchi L, Torella D, Baker M, Limana F, Chimenti S, Kasahara H, Rota M, Musso E, Urbanek K, Leri A, Kajstura J, NadalGinard B and Anversa P. 2003. Adult cardiac stem cells are multipotent and support myocardial regeneration. Cell. 114 (6):763-76

[8] Bergmann O, Bhardwaj RD, Bernard S, Zdunek S, Barnabe-Heider F, Walsh S, Zupicich J, Alkass K, Buchholz BA, Druid $H$, Jovinge $S$ and Frisen J. 2009. Evidence for cardiomyocyte renewal in humans. Science. 324 (5923):98-102

[9] Bocchi L, Savi M, Graiani G, Rossi S, Agnetti A, Stillitano F, Lagrasta C, Baruffi S, Berni R, Frati C, Vassalle M, Squarcia U, Cerbai E, Macchi E, Stilli D, Quaini F and Musso E. 2011. Growth factor-induced mobilization of cardiac progenitor cells reduces the risk of arrhythmias, in a rat model of chronic myocardial infarction. PLoS One. 6 (3):e17750

[10] Bolli R, Chugh AR, D'Amario D, Loughran JH, Stoddard MF, Ikram S, Beache GM, Wagner SG, Leri A, Hosoda T, Sanada F, Elmore JB, 
Goichberg P, Cappetta D, Solankhi NK, Fahsah I, Rokosh DG, Slaughter MS, Kajstura J and Anversa P. 2011. Cardiac stem cells in patients with ischaemic cardiomyopathy (SCIPIO): initial results of a randomised phase 1 trial. The Lancet. 378 (9806):1847-1857

[11] Boyer LA, Lee TI, Cole MF, Johnstone SE, Levine SS, Zucker JP, Guenther MG, Kumar RM, Murray HL, Jenner RG, Gifford DK, Melton DA, Jaenisch $R$ and Young RA. 2005. Core transcriptional regulatory circuitry in human embryonic stem cells. Cell. 122 (6):947-56

[12] Breitbach M, Bostani T, Roell W, Xia Y, Dewald O, Nygren JM, Fries JWU, Tiemann K, Bohlen H, Hescheler J, Welz A, Bloch W, Jacobsen SEW and Fleischmann BK. 2007. Potential risks of bone marrow cell transplantation into infarcted hearts. Blood. 110 (4):1362-1369

[13] Burridge PW, Keller G, Gold JD and Wu JC. 2012. Production of de novo cardiomyocytes: human pluripotent stem cell differentiation and direct reprogramming. Cell Stem Cell. 10 (1):16-28

[14] Bursac N, Loo Y, Leong K and Tung L. 2007. Novel anisotropic engineered cardiac tissues: studies of electrical propagation. Biochem Biophys Res Commun. 361 (4):847-53

[15] Bursac N, Papadaki M, Cohen RJ, Schoen FJ, Eisenberg SR, Carrier R, Vunjak-Novakovic $G$ and Freed LE. 1999. Cardiac muscle tissue engineering: toward an in vitro model for electrophysiological studies. Am J Physiol. 277 (2 Pt 2):H433-44

[16] Carpenedo RL, Bratt-Leal AM, Marklein RA, Seaman SA, Bowen NJ, McDonald JF and McDevitt TC. 2009. Homogeneous and organized differentiation within embryoid bodies induced by microspheremediated delivery of small molecules. Biomaterials. 30 (13):2507-2515

[17] Carrier RL, Papadaki M, Rupnick M, Schoen FJ, Bursac N, Langer R, Freed LE and Vunjak-Novakovic G. 1999. Cardiac tissue engineering: cell seeding, cultivation parameters, and tissue construct characterization. Biotechnol Bioeng. 64 (5):580-9

[18] Chedrawy EG, Wang J-S, Nguyen DM, Shum-Tim D and Chiu RCJ. 2002. Incorporation and integration of implanted myogenic and stem cells into native myocardial fibers: Anatomic basis for functional improvements. The Journal of Thoracic and Cardiovascular Surgery. $124(3): 584-590$

[19] Chen AK, Chen X, Choo AB, Reuveny S and Oh SK. 2011. Critical microcarrier properties affecting the expansion of undifferentiated human embryonic stem cells. Stem Cell Res. 7 (2):97-111

[20] Cooley DA. 2003. The total artificial heart. Nat Med. 9 (1):108-11 
[21] Cooley DA, Liotta D, Hallman GL, Bloodwell RD, Leachman RD and Milam JD. 1969. Orthotopic cardiac prosthesis for two-staged cardiac replacement. Am J Cardiol. 24 (5):723-30

[22] Copeland JG, 3rd, Smith RG, Arabia FA, Nolan PE, Mehta VK, McCarthy MS and Chisholm KA. 2001. Comparison of the CardioWest total artificial heart, the novacor left ventricular assist system and the thoratec ventricular assist system in bridge to transplantation. Ann Thorac Surg. 71 (3 Suppl):S92-7; discussion S114-5

[23] Dai W, Field LJ, Rubart M, Reuter S, Hale SL, Zweigerdt R, Graichen RE, Kay GL, Jyrala AJ, Colman A, Davidson BP, Pera M and Kloner RA. 2007. Survival and maturation of human embryonic stem cellderived cardiomyocytes in rat hearts. J Mol Cell Cardiol. 43 (4):504-16

[24] Dimmeler S, Zeiher AM and Schneider MD. 2005. Unchain my heart: the scientific foundations of cardiac repair. J Clin Invest. 115 (3):572-83

[25] Dobrucki LW, Tsutsumi Y, Kalinowski L, Dean J, Gavin M, Sen S, Mendizabal M, Sinusas AJ and Aikawa R. 2010. Analysis of angiogenesis induced by local IGF-1 expression after myocardial infarction using microSPECT-CT imaging. J Mol Cell Cardiol. 48 (6):1071-9

[26] Dow J, Simkhovich BZ, Kedes L and Kloner RA. 2005. Washout of transplanted cells from the heart: a potential new hurdle for cell transplantation therapy. Cardiovasc Res. 67 (2):301-7

[27] Dubois NC, Craft AM, Sharma P, Elliott DA, Stanley EG, Elefanty AG, Gramolini A and Keller G. 2011. SIRPA is a specific cell-surface marker for isolating cardiomyocytes derived from human pluripotent stem cells. Nat Biotechnol. 29 (11):1011-8

[28] Elliott DA, Braam SR, Koutsis K, Ng ES, Jenny R, Lagerqvist EL, Biben C, Hatzistavrou T, Hirst CE, Yu QC, Skelton RJ, Ward-van Oostwaard D, Lim SM, Khammy O, Li X, Hawes SM, Davis RP, Goulburn AL, Passier R, Prall OW, Haynes JM, Pouton CW, Kaye DM, Mummery CL, Elefanty AG and Stanley EG. 2011. NKX2-5eGFP/w hESCs for isolation of human cardiac progenitors and cardiomyocytes. Nat Methods. 8 (12):1037-40

[29] Ellison GM, Torella D, Dellegrottaglie S, Perez-Martinez C, Perez de Prado A, Vicinanza C, Purushothaman S, Galuppo V, laconetti C, Waring CD, Smith A, Torella M, Cuellas Ramon C, Gonzalo-Orden JM, Agosti V, Indolfi C, Galinanes M, Fernandez-Vazquez F and NadalGinard B. 2011. Endogenous cardiac stem cell activation by insulin-like growth factor-1/hepatocyte growth factor intracoronary injection fosters survival and regeneration of the infarcted pig heart. J Am Coll Cardiol. 58 (9):977-86 
[30] Eschenhagen T, Fink C, Remmers U, Scholz H, Wattchow J, Weil J, Zimmermann W, Dohmen HH, Schafer H, Bishopric N, Wakatsuki T and Elson EL. 1997. Three-dimensional reconstitution of embryonic cardiomyocytes in a collagen matrix: a new heart muscle model system. FASEB J. 11 (8):683-94

[31] Eschenhagen T and Zimmermann WH. 2005. Engineering myocardial tissue. Circ Res. 97 (12):1220-31

[32] Fink C, Ergun S, Kralisch D, Remmers U, Weil J and Eschenhagen T. 2000. Chronic stretch of engineered heart tissue induces hypertrophy and functional improvement. FASEB J. 14 (5):669-79

[33] Giovarelli M, Musiani P, Modesti A, Dellabona P, Casorati G, Allione A, Consalvo M, Cavallo F, di Pierro F and De Giovanni C. 1995. Local release of IL-10 by transfected mouse mammary adenocarcinoma cells does not suppress but enhances antitumor reaction and elicits a strong cytotoxic lymphocyte and antibody-dependent immune memory. The Journal of Immunology. 155 (6):3112-23

[34] Graichen R, Xu X, Braam SR, Balakrishnan T, Norfiza S, Sieh S, Soo SY, Tham SC, Mummery C, Colman A, Zweigerdt R and Davidson BP. 2008. Enhanced cardiomyogenesis of human embryonic stem cells by a small molecular inhibitor of p38 MAPK. Differentiation. 76 (4):357-70

[35] Gray NA, Jr. and Selzman CH. 2006. Current status of the total artificial heart. Am Heart J. 152 (1):4-10

[36] Guarita-Souza LC, Teixeira de Carvalho KA, Francisco JC, Simeoni R and Faria-Neto JR. 2008. Cellular transplantation for the treatment of non-ischaemic dilated cardiomyopathies. European Heart Journal Supplements. 10 (Suppl K):K7-K10

[37] Hare JM. 2011. Bone marrow therapy for myocardial infarction. JAMA. 306 (19):2156-7

[38] Hierlihy AM, Seale P, Lobe CG, Rudnicki MA and Megeney LA. 2002. The post-natal heart contains a myocardial stem cell population. FEBS Lett. 530 (1-3):239-43

[39] Hudson J, Titmarsh D, Hidalgo A, Wolvetang E and Cooper-White J. 2012. Primitive cardiac cells from human embryonic stem cells. Stem Cells Dev. 21 (9):1513-23

[40] Hudson JE and Zimmermann WH. 2011. Tuning Wnt-signaling to enhance cardiomyogenesis in human embryonic and induced pluripotent stem cells. J Mol Cell Cardiol. 51 (3):277-9

[41] Iwanaga Y, Kihara Y, Yoneda T, Aoyama T and Sasayama S. 2000. Modulation of in vivo cardiac hypertrophy with insulin-like growth factor- 
1 and angiotensin-converting enzyme inhibitor: relationship between change in myosin isoform and progression of left ventricular dysfunction. JAC. 36 (2):635-642

[42] Iwasaki H, Eguchi S, Ueno H, Marumo F and Hirata Y. 2000. Mechanical stretch stimulates growth of vascular smooth muscle cells via epidermal growth factor receptor. American journal of physiology. Heart and circulatory physiology. 278 (2):H521-9

[43] Jackson KA, Majka SM, Wang H, Pocius J, Hartley CJ, Majesky MW, Entman ML, Michael LH, Hirschi KK and Goodell MA. 2001. Regeneration of ischemic cardiac muscle and vascular endothelium by adult stem cells. J Clin Invest. 107 (11):1395-402

[44] Kajstura J, Fiordaliso F, Andreoli AM, Li B, Chimenti S, Medow MS, Limana F, Nadal-Ginard B, Leri A and Anversa P. 2001. IGF-1 overexpression inhibits the development of diabetic cardiomyopathy and angiotensin II-mediated oxidative stress. Diabetes. 50 (6):1414-24

[45] Kamp TJ and Chiamvimonvat N. 2006. Mission impossible: IGF-1 and PTEN specifically "Akt"ing on cardiac L-type Ca2+ channels. Circ Res. 98 (11):1349-51

[46] Kattman SJ, Huber TL and Keller GM. 2006. Multipotent flk-1+ cardiovascular progenitor cells give rise to the cardiomyocyte, endothelial, and vascular smooth muscle lineages. Dev Cell. 11 (5):723-32

[47] Kattman SJ, Koonce CH, Swanson BJ and Anson BD. 2011. Stem cells and their derivatives: a renaissance in cardiovascular translational research. J Cardiovasc Transl Res. 4 (1):66-72

[48] Kattman SJ, Witty AD, Gagliardi M, Dubois NC, Niapour M, Hotta A, Ellis $\mathrm{J}$ and Keller G. 2011. Stage-specific optimization of activin/nodal and BMP signaling promotes cardiac differentiation of mouse and human pluripotent stem cell lines. Cell Stem Cell. 8 (2):228-40

[49] Kattman SJ, Witty AD, Gagliardi M, Dubois NC, Niapour M, Hotta A, Ellis $\mathrm{J}$ and Keller G. 2011. Stage-Specific Optimization of Activin/Nodal and BMP Signaling Promotes Cardiac Differentiation of Mouse and Human Pluripotent Stem Cell Lines. Stem Cell. 8 (2):228-240

[50] Kehat I, Kenyagin-Karsenti D, Snir M, Segev H, Amit M, Gepstein A, Livne E, Binah O, Itskovitz-Eldor J and Gepstein L. 2001. Human embryonic stem cells can differentiate into myocytes with structural and functional properties of cardiomyocytes. J Clin Invest. 108 (3):407-14

[51] Kehat I, Khimovich L, Caspi O, Gepstein A, Shofti R, Arbel G, Huber I, Satin J, Itskovitz-Eldor J and Gepstein L. 2004. Electromechanical 
integration of cardiomyocytes derived from human embryonic stem cells. Nat Biotechnol. 22 (10):1282-9

[52] Kelm JM and Fussenegger M. 2004. Microscale tissue engineering using gravity-enforced cell assembly. Trends in biotechnology. 22 (4):195-202

[53] Kempf H, Lecina M, Ting S, Zweigerdt R and Oh S. 2011. Distinct regulation of mitogen-activated protein kinase activities is coupled with enhanced cardiac differentiation of human embryonic stem cells. Stem Cell Res. 7 (3):198-209

[54] Kim YK, Kim SJ, Yatani A, Huang Y, Castelli G, Vatner DE, Liu J, Zhang Q, Diaz G, Zieba R, Thaisz J, Drusco A, Croce C, Sadoshima J, Condorelli G and Vatner SF. 2003. Mechanism of enhanced cardiac function in mice with hypertrophy induced by overexpressed Akt. J Biol Chem. 278 (48):47622-8

[55] Kinney MA, Sargent CY and McDevitt TC. 2011. The Multiparametric Effects of Hydrodynamic Environments on Stem Cell Culture. Tissue Engineering Part B: Reviews. 17 (4):249-262

[56] Kinugawa S, Tsutsui H, Ide T, Nakamura R, Arimura K, Egashira K and Takeshita A. 1999. Positive inotropic effect of insulin-like growth factor1 on normal and failing cardiac myocytes. Cardiovascular Research. 43 (1):157-164

[57] Klaus A, Saga Y, Taketo MM, Tzahor E and Birchmeier W. 2007. Distinct roles of $\mathrm{Wnt} /$ beta-catenin and Bmp signaling during early cardiogenesis. Proc Natl Acad Sci U S A. 104 (47):18531-6

[58] Koh GY, Klug MG, Soonpaa MH and Field LJ. 1993. Differentiation and long-term survival of $\mathrm{C} 2 \mathrm{C} 12$ myoblast grafts in heart. Journal of Clinical Investigation. 92 (3):1548-1554

[59] Komuro I, Kudo S, Yamazaki T, Zou Y, Shiojima I and Yazaki Y. 1996. Mechanical stretch activates the stress-activated protein kinases in cardiac myocytes. Faseb Journal. 10 (5):631-636

[60] Kreutziger KL, Muskheli V, Johnson P, Braun K, Wight TN and Murry CE. 2011. Developing vasculature and stroma in engineered human myocardium. Tissue Eng Part A. 17 (9-10):1219-28

[61] Laflamme MA, Chen KY, Naumova AV, Muskheli V, Fugate JA, Dupras SK, Reinecke H, Xu C, Hassanipour M, Police S, O'Sullivan C, Collins L, Chen Y, Minami E, Gill EA, Ueno S, Yuan C, Gold J and Murry CE. 2007. Cardiomyocytes derived from human embryonic stem cells in pro-survival factors enhance function of infarcted rat hearts. Nat Biotechnol. 25 (9):1015-24 
[62] Laflamme MA, Gold J, Xu C, Hassanipour M, Rosler E, Police S, Muskheli $V$ and Murry CE. 2005. Formation of Human Myocardium in the Rat Heart from Human Embryonic Stem Cells. The American Journal of Pathology. 167 (3):663-671

[63] Laflamme MA and Murry CE. 2005. Regenerating the heart. Nat Biotechnol. 23 (7):845-56

[64] Lazar RM, Shapiro PA, Jaski BE, Parides MK, Bourge RC, Watson JT, Damme L, Dembitsky W, Hosenpud JD, Gupta L, Tierney A, Kraus T and Naka Y. 2004. Neurological events during long-term mechanical circulatory support for heart failure: the Randomized Evaluation of Mechanical Assistance for the Treatment of Congestive Heart Failure (REMATCH) experience. Circulation. 109 (20):2423-7

[65] Leung BM and Sefton MV. 2010. A modular approach to cardiac tissue engineering. Tissue Eng Part A. 16 (10):3207-18

[66] Li RK, Jia ZQ, Weisel RD, Mickle DA, Choi A and Yau TM. 1999. Survival and function of bioengineered cardiac grafts. Circulation. 100 (19 Suppl):II63-9

[67] Li RK, Mickle DA, Weisel RD, Zhang J and Mohabeer MK. 1996. In vivo survival and function of transplanted rat cardiomyocytes. Circ Res. $78(2): 283-8$

[68] Livak KJ and Schmittgen TD. 2001. Analysis of relative gene expression data using real-time quantitative PCR and the 2(-Delta Delta C(T)) Method. Methods. 25 (4):402-8

[69] Lunde $\mathrm{K}$ and Aakhus S. 2008. Intracoronary injection of mononuclear bone marrow cells after acute myocardial infarction: lessons from the ASTAMI trial. European Heart Journal Supplements. 10 (Suppl K):K35K38

[70] Macrez N, Mironneau C, Carricaburu V, Quignard JF, Babich A, Czupalla C, Nurnberg B and Mironneau J. 2001. Phosphoinositide 3Kinase Isoforms Selectively Couple Receptors to Vascular L-Type Ca2+ Channels. Circulation Research. 89 (8):692-699

[71] Makkar RR, Smith RR, Cheng K, Malliaras K, Thomson LEJ, Berman D, Czer LSC, Marbán L, Mendizabal A, Johnston PV, Russell SD, Schuleri KH, Lardo AC, Gerstenblith G and Marbán E. 2012. Intracoronary cardiosphere-derived cells for heart regeneration after myocardial infarction (CADUCEUS): a prospective, randomised phase 1 trial. The Lancet. 379 (9819):895-904

[72] Mallory GK, White PD and Salcedo-Salgar J. 1939. The speed of healing of myocardial infarction-A study of the pathologic anatomy in seventy two cases. The American Heart Journal. 18 (6):647-671 
[73] Martens TP, See F, Schuster MD, Sondermeijer HP, Hefti MM, Zannettino A, Gronthos S, Seki T and Itescu S. 2006. Mesenchymal lineage precursor cells induce vascular network formation in ischemic myocardium. Nat Clin Pract Cardiovasc Med. 3 Suppl 1 S18-22

[74] Matsuura K, Honda A, Nagai T, Fukushima N, Iwanaga K, Tokunaga M, Shimizu T, Okano T, Kasanuki H, Hagiwara N and Komuro I. 2009. Transplantation of cardiac progenitor cells ameliorates cardiac dysfunction after myocardial infarction in mice. J Clin Invest. 119 (8):2204-17

[75] McDevitt TC, Laflamme MA and Murry CE. 2005. Proliferation of cardiomyocytes derived from human embryonic stem cells is mediated via the IGF/PI 3-kinase/Akt signaling pathway. J Mol Cell Cardiol. 39 (6):865-73

[76] Menasché P. 2009. Cell-based Therapy for Heart Disease: A Clinically Oriented Perspective. Molecular Therapy. 17 (5):758-766

[77] Menasche P, Alfieri O, Janssens S, McKenna W, Reichenspurner $H$, Trinquart L, Vilquin JT, Marolleau JP, Seymour B, Larghero J, Lake S, Chatellier G, Solomon S, Desnos M and Hagege AA. 2008. The Myoblast Autologous Grafting in Ischemic Cardiomyopathy (MAGIC) trial: first randomized placebo-controlled study of myoblast transplantation. Circulation. 117 (9):1189-200

[78] MERIT-HF-Investigators. 1999. Effect of metoprolol CR/XL in chronic heart failure: Metoprolol $\mathrm{CR} / \mathrm{XL}$ Randomised Intervention Trial inCongestive Heart Failure (MERIT-HF). The Lancet. 353 (9169):20012007

[79] Messina E, De Angelis L, Frati G, Morrone S, Chimenti S, Fiordaliso F, Salio M, Battaglia M, Latronico MV, Coletta M, Vivarelli E, Frati L, Cossu $G$ and Giacomello A. 2004. Isolation and expansion of adult cardiac stem cells from human and murine heart. Circ Res. 95 (9):91121

[80] Millis RM, Alvin ZV, Zhao A and Haddad GE. 2012. Effects of IGF-1 on IK and IK1 Channels via PI3K/Akt Signaling in Neonatal Cardiac Myocytes. International Journal of Cell Biology. 2012 1-6

[81] Moazami N, Roberts K, Argenziano M, Catanese K, Mohr JP, Rose EA and Oz MC. 1997. Asymptomatic microembolism in patients with longterm ventricular assist support. ASAIO J. 43 (3):177-80

[82] Mohsin S, Siddiqi S, Collins B and Sussman MA. 2011. Empowering Adult Stem Cells for Myocardial Regeneration. Circulation Research. 109 (12):1415-1428 
[83] Morrissey M. 2012. Willem J Kolff (1911-2009): physician, inventor and pioneer: father of artificial organs. J Med Biogr. 20 (3):136-8

[84] Mourkioti F and Rosenthal N. 2005. IGF-1, inflammation and stem cells: interactions during muscle regeneration. Trends Immunol. 26 (10):535-42

[85] Müller-Ehmsen J. 2002. Survival and Development of Neonatal Rat Cardiomyocytes Transplanted into Adult Myocardium. Journal of Molecular and Cellular Cardiology. 34 (2):107-116

[86] Muller-Ehmsen J, Peterson KL, Kedes L, Whittaker P, Dow JS, Long TI, Laird PW and Kloner RA. 2002. Rebuilding a damaged heart: long-term survival of transplanted neonatal rat cardiomyocytes after myocardial infarction and effect on cardiac function. Circulation. 105 (14):1720-6

[87] Mummery C, Ward-van Oostwaard D, Doevendans P, Spijker R, van den Brink S, Hassink R, van der Heyden M, Opthof T, Pera M, de la Riviere AB, Passier R and Tertoolen L. 2003. Differentiation of human embryonic stem cells to cardiomyocytes: role of coculture with visceral endoderm-like cells. Circulation. 107 (21):2733-40

[88] Murry CE, Field LJ and Menasche P. 2005. Cell-based cardiac repair: reflections at the 10-year point. Circulation. 112 (20):3174-83

[89] Musarò A, Giacinti C, Borsellino G, Dobrowolny G, Pelosi L, Cairns L, Ottolenghi S, Cossu G, Bernardi G, Battistini L, Molinaro M and Rosenthal N. 2004. Stem cell-mediated muscle regeneration is enhanced by local isoform of insulin-like growth factor 1. Proceedings of the National Academy of Sciences of the United States of America. $101(5): 1206-1210$

[90] Musarò A, Giacinti C, Dobrowolny G, Pelosi L and Rosenthal N. 2004. The Role of Igf-1 on Muscle Wasting: a Therapeutic Approach. 1-4

[91] Musaro A, McCullagh K, Paul A, Houghton L, Dobrowolny G, Molinaro M, Barton ER, Sweeney HL and Rosenthal N. 2001. Localized Igf-1 transgene expression sustains hypertrophy and regeneration in senescent skeletal muscle. Nat Genet. 27 (2):195-200

[92] Nagaya N, Kangawa K, Itoh T, Iwase T, Murakami S, Miyahara Y, Fujii $T$, Uematsu $M$, Ohgushi $H$, Yamagishi $M$, Tokudome $T$, Mori $H$, Miyatake $\mathrm{K}$ and Kitamura S. 2005. Transplantation of mesenchymal stem cells improves cardiac function in a rat model of dilated cardiomyopathy. Circulation. 112 (8):1128-35

[93] Naito H, Melnychenko I, Didie M, Schneiderbanger K, Schubert P, Rosenkranz S, Eschenhagen $T$ and Zimmermann WH. 2006. Optimizing engineered heart tissue for therapeutic applications as surrogate heart muscle. Circulation. 114 (1 Suppl):I72-8 
[94] Nie Y, Bergendahl V, Hei DJ, Jones JM and Palecek SP. 2009. Scalable culture and cryopreservation of human embryonic stem cells on microcarriers. Biotechnol Prog. 25 (1):20-31

[95] Norman JC. 1975. THE ARTIFICIAL HEART: PERSPECTIVES, PROSPECTS AND PROBLEMS OF A HIGH APPLIED TECHNOLOGY An Editorial Comment. Cardiovasc Dis. 2 (3):259-264

[96] Oh H, Bradfute SB, Gallardo TD, Nakamura T, Gaussin V, Mishina Y, Pocius J, Michael LH, Behringer RR, Garry DJ, Entman ML and Schneider MD. 2003. Cardiac progenitor cells from adult myocardium: homing, differentiation, and fusion after infarction. Proc Natl Acad Sci U S A. $100(21): 12313-8$

[97] Osterziel KJ, Strohm O, Schuler J, Friedrich M, Hänlein D, Willenbrock R, Anker SD, Poole-Wilson PA, Ranke MB and Dietz R. 1998. Randomised, double-blind, placebo-controlled trial of human recombinant growth hormone in patients with chronic heart failure due to dilated cardiomyopathy. The Lancet. 351 (9111):1233-1237

[98] Oz MC, Konertz WF, Kleber FX, Mohr FW, Gummert JF, Ostermeyer J, Lass M, Raman J, Acker MA and Smedira N. 2003. Global surgical experience with the Acorn cardiac support device. J Thorac Cardiovasc Surg. $126(4): 983-91$

[99] Paige SL, Osugi T, Afanasiev OK, Pabon L, Reinecke $\mathrm{H}$ and Murry CE. 2010. Endogenous Wnt/B-Catenin Signaling Is Required for Cardiac Differentiation in Human Embryonic Stem Cells. PLoS ONE. 5 (6):e11134

[100] Passier R, van Laake LW and Mummery CL. 2008. Stem-cell-based therapy and lessons from the heart. Nature. 453 (7193):322-9

[101] Pasumarthi KB and Field LJ. 2002. Cardiomyocyte cell cycle regulation. Circ Res. 90 (10):1044-54

[102] Perin EC, Willerson JT, Pepine CJ, Henry TD, Ellis SG, Zhao DX, Silva GV, Lai D, Thomas JD, Kronenberg MW, Martin AD, Anderson RD, Traverse JH, Penn MS, Anwaruddin S, Hatzopoulos AK, Gee AP, Taylor DA, Cogle CR, Smith D, Westbrook L, Chen J, Handberg E, Olson RE, Geither C, Bowman S, Francescon J, Baraniuk S, Piller LB, Simpson LM, Loghin C, Aguilar D, Richman S, Zierold C, Bettencourt J, Sayre SL, Vojvodic RW, Skarlatos SI, Gordon DJ, Ebert RF, Kwak M, Moye LA and Simari RD. 2012. Effect of transendocardial delivery of autologous bone marrow mononuclear cells on functional capacity, left ventricular function, and perfusion in chronic heart failure: the FOCUSCCTRN trial. JAMA. 307 (16):1717-26 
[103] Perrini S, Laviola L, Carreira MC, Cignarelli A, Natalicchio A and Giorgino F. 2010. The GH/IGF1 axis and signaling pathways in the muscle and bone: mechanisms underlying age-related skeletal muscle wasting and osteoporosis. J Endocrinol. 205 (3):201-10

[104] Pitt B, Zannad F, Remme WJ, Cody R, Castaigne A, Perez A, Palensky $\mathrm{J}$ and Wittes $\mathrm{J}$. 1999. The effect of spironolactone on morbidity and mortality in patients with severe heart failure. Randomized Aldactone Evaluation Study Investigators. N Engl J Med. 341 (10):709-17

[105] Qiao H, Surti S, Choi SR, Raju K, Zhang H, Ponde DE, Kung HF, Karp $\mathrm{J}$ and Zhou R. 2009. Death and proliferation time course of stem cells transplanted in the myocardium. Mol Imaging Biol. 11 (6):408-14

[106] Quignard JF, Mironneau J, Carricaburu V, Fournier B, Babich A, Nurnberg B, Mironneau C and Macrez N. 2001. Phosphoinositide 3kinase gamma mediates angiotensin II-induced stimulation of L-type calcium channels in vascular myocytes. J Biol Chem. 276 (35):3254551

[107] Rabinovsky ED, Gelir E, Gelir S, Lui H, Kattash M, DeMayo FJ, Shenaq SM and Schwartz RJ. 2003. Targeted expression of IGF-1 transgene to skeletal muscle accelerates muscle and motor neuron regeneration. FASEB J. 17 (1):53-5

[108] Reinecke H, Minami E, Zhu WZ and Laflamme MA. 2008. Cardiogenic differentiation and transdifferentiation of progenitor cells. Circ Res. 103 (10):1058-71

[109] Reinecke $\mathrm{H}$ and Murry CE. 2002. Taking the death toll after cardiomyocyte grafting: a reminder of the importance of quantitative biology. J Mol Cell Cardiol. 34 (3):251-3

[110] Reinecke H, Poppa V and Murry CE. 2002. Skeletal muscle stem cells do not transdifferentiate into cardiomyocytes after cardiac grafting. $J$ Mol Cell Cardiol. 34 (2):241-9

[111] Renganathan M, Messi ML and Delbono O. 1998. Overexpression of IGF-1 exclusively in skeletal muscle prevents age-related decline in the number of dihydropyridine receptors. J Biol Chem. 273 (44):28845-51

[112] Richards M, Tan SP, Tan JH, Chan WK and Bongso A. 2004. The transcriptome profile of human embryonic stem cells as defined by SAGE. STEM CELLS. 22 (1):51-64

[113] Rommel C, Bodine SC, Clarke BA, Rossman R, Nunez L, Stitt TN, Yancopoulos GD and Glass DJ. 2001. Mediation of IGF-1-induced skeletal myotube hypertrophy by $\mathrm{PI}(3) \mathrm{K} / \mathrm{Akt} / \mathrm{mTOR}$ and $\mathrm{PI}(3) K / A k t / G S K 3$ pathways. Nat Cell Biol. 3 (11):1009-13 
[114] Rubart M and Field LJ. 2006. Cardiac regeneration: repopulating the heart. Annu Rev Physiol. 68 29-49

[115] Sabbah HN. 2005. Global left ventricular remodeling with the Acorn Cardiac Support Device: hemodynamic and angiographic findings in dogs with heart failure. Heart Fail Rev. 10 (2):109-15

[116] Sachlos E and Auguste DT. 2008. Embryoid body morphology influences diffusive transport of inductive biochemicals: a strategy for stem cell differentiation. Biomaterials. 29 (34):4471-80

[117] Schachinger V, Erbs S, Elsasser A, Haberbosch W, Hambrecht R, Holschermann H, Yu J, Corti R, Mathey DG, Hamm CW, Suselbeck T, Assmus B, Tonn T, Dimmeler S and Zeiher AM. 2006. Intracoronary bone marrow-derived progenitor cells in acute myocardial infarction. $\mathrm{N}$ Engl J Med. 355 (12):1210-21

[118] Schopperle WM, Kershaw DB and DeWolf WC. 2003. Human embryonal carcinoma tumor antigen, Gp200/GCTM-2, is podocalyxin. Biochemical and Biophysical Research Communications. 300 (2):285290

[119] Shake JG, MD, Gruber PJ, MD, PhD, Baumgartner WA, MD, Senechal G, MS, Meyers J, BS, Redmond JM, MD, Pittenger MF, PhD, Martin BJ and PhD. 2002. Mesenchymal Stem Cell Implantation in a Swine Myocardial Infarct Model: Engraftment and Functional Effects. 1-8

[120] Shiba Y, Fernandes S, Zhu WZ, Filice D, Muskheli V, Kim J, Palpant NJ, Gantz J, Moyes KW, Reinecke H, Van Biber B, Dardas T, Mignone JL, Izawa A, Hanna R, Viswanathan M, Gold JD, Kotlikoff MI, Sarvazyan N, Kay MW, Murry CE and Laflamme MA. 2012. Human ES-cell-derived cardiomyocytes electrically couple and suppress arrhythmias in injured hearts. Nature. 489 (7415):322-5

[121] Shimizu T, Sekine H, Yang J, Isoi Y, Yamato M, Kikuchi A, Kobayashi $\mathrm{E}$ and Okano T. 2006. Polysurgery of cell sheet grafts overcomes diffusion limits to produce thick, vascularized myocardial tissues. FASEB J. 20 (6):708-10

[122] Shimizu T, Yamato M, Isoi Y, Akutsu T, Setomaru T, Abe K, Kikuchi A, Umezu M and Okano T. 2002. Fabrication of pulsatile cardiac tissue grafts using a novel 3-dimensional cell sheet manipulation technique and temperature-responsive cell culture surfaces. Circulation Research. 90 (3):e40

[123] Shyu KG, Ko WH, Yang WS, Wang BW and Kuan P. 2005. Insulin-like growth factor-1 mediates stretch-induced upregulation of myostatin expression in neonatal rat cardiomyocytes. Cardiovasc Res. 68 (3):405-14 
[124] Singh H, Mok P, Balakrishnan T, Rahmat SN and Zweigerdt R. 2010. Up-scaling single cell-inoculated suspension culture of human embryonic stem cells. Stem Cell Res. 4 (3):165-79

[125] Slaughter MS, Rogers JG, Milano CA, Russell SD, Conte JV, Feldman D, Sun B, Tatooles AJ, Delgado RM, 3rd, Long JW, Wozniak TC, Ghumman W, Farrar DJ and Frazier OH. 2009. Advanced heart failure treated with continuous-flow left ventricular assist device. N Engl J Med. 361 (23):2241-51

[126] SOLVD-Investigators. 1992. Effect of enalapril on mortality and the development of heart failure in asymptomatic patients with reduced left ventricular ejection fractions. The SOLVD Investigattors. N Engl J Med. 327 (10):685-91

[127] Song YH. 2005. Muscle-specific expression of IGF-1 blocks angiotensin II-induced skeletal muscle wasting. Journal of Clinical Investigation. 115 (2):451-458

[128] Soonpaa MH, Koh GY, Klug MG and Field LJ. 1994. Formation of nascent intercalated disks between grafted fetal cardiomyocytes and host myocardium. Science. 264 (5155):98-101

[129] Strauer BE and Steinhoff G. 2011. 10 years of intracoronary and intramyocardial bone marrow stem cell therapy of the heart: from the methodological origin to clinical practice. J Am Coll Cardiol. 58 (11):1095-104

[130] Taekema DG, Ling CHY, Blauw GJ, Meskers CG, Westendorp RGJ, de Craen AJM and Maier AB. 2011. Circulating levels of IGF1 are associated with muscle strength in middle-aged- and oldest-old women. European Journal of Endocrinology. 164 (2):189-196

[131] Takahashi K, Tanabe K, Ohnuki M, Narita M, Ichisaka T, Tomoda K and Yamanaka S. 2007. Induction of pluripotent stem cells from adult human fibroblasts by defined factors. Cell. 131 (5):861-72

[132] Takahashi $\mathrm{K}$ and Yamanaka S. 2006. Induction of pluripotent stem cells from mouse embryonic and adult fibroblast cultures by defined factors. Cell. 126 (4):663-76

[133] Taylor DA, Atkins BZ, Hungspreugs $P$, Jones TR, Reedy MC, Hutcheson KA, Glower DD and Kraus WE. 1998. Regenerating functional myocardium: improved performance after skeletal myoblast transplantation. Nat Med. 4 (8):929-33

[134] Thoennissen NH, Allroggen A, Ritter M, Dittrich R, Schmid C, Schmid $\mathrm{HH}$, Ringelstein EB and Nabavi DG. 2006. Influence of inflammation 
and pump dynamic on cerebral microembolization in patients with Continuous-Flow DeBakey LVAD. ASAIO J. 52 (3):243-7

[135] Thomson JA, Itskovitz-Eldor J, Shapiro SS, Waknitz MA, Swiergiel JJ, Marshall VS and Jones JM. 1998. Embryonic stem cell lines derived from human blastocysts. Science. 282 (5391):1145-7

[136] Tian Y and Morrisey EE. 2012. Importance of Myocyte-Nonmyocyte Interactions in Cardiac Development and Disease. Circulation Research. 110 (7):1023-1034

[137] Tiburcy $M$, Didie $M$, Boy $O$, Christalla $P$, Doker $S$, Naito $H$, Karikkineth BC, El-Armouche A, Grimm M, Nose M, Eschenhagen T, Zieseniss A, Katschinksi DM, Hamdani N, Linke WA, Yin $X$, Mayr $M$ and Zimmermann WH. 2011. Terminal differentiation, advanced organotypic maturation, and modeling of hypertrophic growth in engineered heart tissue. Circ Res. 109 (10):1105-14

[138] Tomita S, Li RK, Weisel RD, Mickle DA, Kim EJ, Sakai T and Jia ZQ. 1999. Autologous transplantation of bone marrow cells improves damaged heart function. Circulation. 100 (19 Suppl):II247-56

[139] Turovets N, Semechkin A, Kuzmichev L, Janus J, Agapova L and Revazova E. 2011. Derivation of human parthenogenetic stem cell lines. Methods Mol Biol. 767 37-54

[140] Tzahor E. 2007. Wnt/beta-catenin signaling and cardiogenesis: timing does matter. Dev Cell. 13 (1):10-3

[141] Vallier L, Reynolds D and Pedersen RA. 2004. Nodal inhibits differentiation of human embryonic stem cells along the neuroectodermal default pathway. Dev Biol. 275 (2):403-21

[142] van Laake LW, Passier R, Monshouwer-Kloots J, Verkleij AJ, Lips DJ, Freund C, den Ouden K, Ward-van Oostwaard D, Korving J, Tertoolen LG, van Echteld CJ, Doevendans PA and Mummery CL. 2007. Human embryonic stem cell-derived cardiomyocytes survive and mature in the mouse heart and transiently improve function after myocardial infarction. Stem Cell Res. 1 (1):9-24

[143] Van Winkle AP, Gates ID and Kallos MS. 2012. Mass transfer limitations in embryoid bodies during human embryonic stem cell differentiation. Cells Tissues Organs. 196 (1):34-47

[144] Vasan RS, Sullivan LM, D'Agostino RB, Roubenoff R, Harris T, Sawyer DB, Levy D and Wilson PWF. 2003. Serum Insulin-like Growth Factor I and Risk for Heart Failure in Elderly Individuals without a Previous Myocardial Infarction: The Framingham Heart Study. Annals of Internal Medicine. 139 (8):642-648 
[145] Vunjak-Novakovic G and Scadden DT. 2011. Biomimetic platforms for human stem cell research. Cell Stem Cell. 8 (3):252-61

[146] Walsh RG. 2005. Design and features of the Acorn CorCap Cardiac Support Device: the concept of passive mechanical diastolic support. Heart Fail Rev. 10 (2):101-7

[147] Welch S, Plank D, Witt S, Glascock B, Schaefer E, Chimenti S, Andreoli AM, Limana F, Leri A, Kajstura J, Anversa P and Sussman MA. 2002. Cardiac-specific IGF-1 expression attenuates dilated cardiomyopathy in tropomodulin-overexpressing transgenic mice. Circ Res. 90 (6):641-8

[148] Xu C, Police S, Rao N and Carpenter MK. 2002. Characterization and enrichment of cardiomyocytes derived from human embryonic stem cells. Circ Res. 91 (6):501-8

[149] Xu XQ, Zweigerdt R, Soo SY, Ngoh ZX, Tham SC, Wang ST, Graichen R, Davidson B, Colman A and Sun W. 2008. Highly enriched cardiomyocytes from human embryonic stem cells. Cytotherapy. 10 (4):376-89

[150] Xue T, Cho HC, Akar FG, Tsang SY, Jones SP, Marban E, Tomaselli GF and Li RA. 2005. Functional integration of electrically active cardiac derivatives from genetically engineered human embryonic stem cells with quiescent recipient ventricular cardiomyocytes: insights into the development of cell-based pacemakers. Circulation. 111 (1):11-20

[151] Yamashita K, Kajstura J, Discher DJ, Wasserlauf BJ, Bishopric NH, Anversa P and Webster KA. 2001. Reperfusion-activated Akt kinase prevents apoptosis in transgenic mouse hearts overexpressing insulinlike growth factor-1. Circulation Research. 88 (6):609-614

[152] Yildirim $Y$, Naito $H$, Didie $M$, Karikkineth BC, Biermann D, Eschenhagen T and Zimmermann WH. 2007. Development of a biological ventricular assist device: preliminary data from a small animal model. Circulation. 116 (11 Suppl):I16-23

[153] Zhang M, Methot D, Poppa V, Fujio Y, Walsh K and Murry CE. 2001. Cardiomyocyte grafting for cardiac repair: graft cell death and antideath strategies. J Mol Cell Cardiol. 33 (5):907-21

[154] Zimmermann WH. 2011. Embryonic and embryonic-like stem cells in heart muscle engineering. J Mol Cell Cardiol. 50 (2):320-6

[155] Zimmermann $\mathrm{WH}$ and Eschenhagen T. 2003. Cardiac tissue engineering for replacement therapy. Heart Fail Rev. 8 (3):259-69 
[156] Zimmermann WH, Fink C, Kralisch D, Remmers U, Weil J and Eschenhagen T. 2000. Three-dimensional engineered heart tissue from neonatal rat cardiac myocytes. Biotechnol Bioeng. 68 (1):106-14

[157] Zimmermann WH, Melnychenko I and Eschenhagen T. 2004. Engineered heart tissue for regeneration of diseased hearts. Biomaterials. 25 (9):1639-47

[158] Zimmermann WH, Melnychenko I, Wasmeier G, Didie M, Naito $H$, Nixdorff U, Hess A, Budinsky L, Brune $K$, Michaelis B, Dhein S, Schwoerer A, Ehmke $\mathrm{H}$ and Eschenhagen T. 2006. Engineered heart tissue grafts improve systolic and diastolic function in infarcted rat hearts. Nat Med. 12 (4):452-8

[159] Zimmermann WH, Schneiderbanger K, Schubert P, Didie M, Munzel F, Heubach JF, Kostin S, Neuhuber WL and Eschenhagen T. 2002. Tissue engineering of a differentiated cardiac muscle construct. Circ Res. 90 (2):223-30

[160] Zweigerdt R, Olmer R, Singh H, Haverich A and Martin U. 2011. Scalable expansion of human pluripotent stem cells in suspension culture. Nat Protoc. 6 (5):689-700 


\section{Cell Culture Reagents and Medium}

\section{bFGF stock solution}

1. Dissolve bFGF according to manufacturer's protocol to obtain a stock concentration of $10 \mu \mathrm{g} / \mathrm{ml}$.

2. Aliquot into sterile microfuge tubes and store at $-20^{\circ} \mathrm{C}$.

\section{bFGF working solution}

1. Add $10 \mu \mathrm{l}$ of bFGF stock solution into $10 \mathrm{ml}$ of hESC maintenance medium per $100 \mathrm{~mm}$ hES cultured plates (final bFGF concentration: 10 $\mathrm{ng} / \mathrm{ml})$.

\section{Collagenase IV stock solution}

1. Dissolve $10 \mathrm{mg}$ of collagenase IV in $1 \mathrm{ml}$ of DPBS+.

2. Sterile filter the solution, aliquot $(1 \mathrm{ml})$ in $15 \mathrm{ml}$ centrifuge tubes, and store at $-20^{\circ} \mathrm{C}$.

\section{Collagenase IV working solution}

1. Thaw 1 aliquot of Collagenase IV stock solution in a $37^{\circ} \mathrm{C}$ water bath.

2. Add $9 \mathrm{ml}$ pre-warmed DPBS+ into the stock solution just prior to usage.

3. Additional amounts of collagenase IV solution can be stored at $4{ }^{\circ} \mathrm{C}$ for 1 week. 


\section{hESC medium}

500 ml KO-DMEM (\#10829-018, Invitrogen)

128.2 ml KOSR (\#10828028, Invitrogen)

6.4 ml L-glutamine (200 mmol/L; \#25030-024, Invitrogen)

6.4 ml MEM NEAA (10 mmol/L; \#11140-050, Invitrogen)

bFGF is only added according to the required amount of medium used per hESC plate.

\section{HFF medium}

500 ml DMEM (\#42430, Invitrogen)

120 ml Fetal Bovine Serum (FBS; \#A15102, PAA)

$6 \mathrm{ml}$ Penicillin and Streptomycin (P/S: $5.000 \mathrm{U} / \mathrm{ml}$ and $5 \mathrm{mg} / \mathrm{ml}$; \#15070-063, Invitrogen)

\section{TSA medium}

500 ml DMEM + GlutaMax ${ }^{\text {TM }}$ (\#61965, Invitrogen) 120 ml Fetal Bovine Serum (FBS; \#A15102, PAA)

$6 \mathrm{ml}$ Penicillin and Streptomycin (P/S: $5.000 \mathrm{U} / \mathrm{ml}$ and $5 \mathrm{mg} / \mathrm{ml}$; \#15070-063, Invitrogen)

\section{Cryopreservation medium}

18 ml Fetal Bovine serum (FBS; \#A15102, PAA)

2 ml DMSO (\#276855, Sigma Aldrich)

DMSO is added to FBS and mixed just prior to resuspension of cells for cryopreservation at $-152^{\circ} \mathrm{C}$. 
SF (serum free) monolayer differentiation medium

500 ml RPMI 1640 with GlutaMAX ${ }^{\text {TM }}$ (\#61870, Invitrogen)

5 ml Sodium Pyruvate (100 mmol/L; \#11360-039, Invitrogen)

$5 \mathrm{ml}$ Penicillin and Streptomycin (P/S: $5.000 \mathrm{U} / \mathrm{ml}$ and $5 \mathrm{mg} / \mathrm{ml}$;

\#15070-063, Invitrogen)

All reagents are mixed well and stored at $4^{\circ} \mathrm{C}$ for two weeks. $2 \%$ B27

supplement is added just prior to use.

SF (serum free) adaptation medium containing

485 ml DMEM (\#11960, Invitrogen)

5 ml L-Glutamine (200 mmol/L; \#25030-024, Invitrogen)

5 ml MEM NEAA (10 mmol/L; \#11140-050, Invitrogen)

5 ml ITS-X supplement (100X; \#51500-056 Gibco, Invitrogen)

\section{bSFS (basal serum free differentiation medium)}

500 ml DMEM (\# 11960, Invitrogen)

5 ml L-Glutamine (200 mmol/L; \#25030-024, Invitrogen)

5 ml MEM NEAA (10 mmol/L; \#11140-050, Invitrogen)

900 l 2-beta mercaptoethanol (50 mmol/L; \#31350-010, Invitrogen)

690 ul Human Transferrin (4 mg/ml; \#030124SA, Gibco, Invitrogen)

$182 \mu$ l Sodium Pyruvate (100 mmol/L; \#11360-039, Invitrogen)

$50 \mu$ Sodium Selenite (100 $\mu \mathrm{g} / \mathrm{ml}$; \#S5361-25G, Sigma Aldrich) 


\section{hEHM medium (human bioengineered heart muscle medium)}

$500 \mathrm{ml}$ Iscove's MEM (\#F0465, Biochrom)

120 ml Fetal Bovine Serum (FBS; \#A15102, PAA)

6 ml L-Glutamine (200 mmol/L; \#25030-024, Invitrogen)

6 ml NEAA (10 mmol/L; \#11140-050, Invitrogen)

$6 \mathrm{ml}$ Penicillin and Streptomycin (P/S: $5.000 \mathrm{U} / \mathrm{ml}$ and $5 \mathrm{mg} / \mathrm{ml}$;

\#15070-063, Invitrogen)

4.34 l 2-ß-Mercaptoethanol (\#31350-010, Sigma)

\section{X DMEM}

1. Dissolve $669 \mathrm{mg}$ DMEM powder (\#52100-039, Invitrogen) in $5 \mathrm{ml}$ sterile water.

2. Filter the solution through a $0.22 \mu \mathrm{m}$ syringe filter

\section{X DMEM}

1 ml 10X DMEM

2 ml FBS (\#A15102, PAA)

100 l L-glutamine (200 mmol/L; \#25030-024, Invitrogen)

$100 \mu \mathrm{P} / \mathrm{S}$ (5.000 U/ml and $5 \mathrm{mg} / \mathrm{ml}$; \#15070-063, Invitrogen)

adjusted to $5 \mathrm{ml} \mathrm{ddH_{2 }} \mathrm{O}$. 
Collagenase I solution

1. Dissolve $100 \mathrm{mg}$ of collagenase $\mathrm{I}$ in $40 \mathrm{ml}$ of DPBS+ and $10 \mathrm{ml}$ FBS.

2. Sterile filter the solution, aliquot $(10 \mathrm{ml})$ in $15 \mathrm{ml}$ centrifuge tubes, and store at $-20^{\circ} \mathrm{C}$.

\section{DNAse I solution}

1. Suspend DNAse I in ice cold water at $1 \mathrm{mg} / \mathrm{ml}$. Sterile filter the solution, aliquot $(5 \mathrm{ml})$ in $15 \mathrm{ml}$ centrifuge tubes, and store at $-20{ }^{\circ} \mathrm{C}$. Keep on ice after thawing. 
Reagents and solutions for Isometric force measurements

\section{Tyrode's solution}

$\mathrm{CaCl}_{2}$ stock (2.25M)

$165.57 \mathrm{~g} \quad \mathrm{CaCl}_{2} \times 2 \mathrm{H}_{2} \mathrm{O} \quad(\mathrm{Mw}=147.02)$

$500 \mathrm{ml} \quad \mathrm{ddH}_{2} \mathrm{O}$

First, dissolve calcium salt thoroughly in $\mathrm{ddH}_{2} \mathrm{O}$. This is stored at $4^{\circ} \mathrm{C}$ until required.

$\mathrm{MgCl}_{2}$ stock (1.05M)

$\begin{array}{ll}106.83 \mathrm{~g} & \mathrm{MgCl}_{2} \times 6 \mathrm{H}_{2} \mathrm{O} \quad(\mathrm{Mw}=203.01) \\ 500 \mathrm{ml} & \mathrm{ddH}_{2} \mathrm{O}\end{array}$

Next, dissolve magnesium salt thoroughly in $\mathrm{ddH}_{2} \mathrm{O}$ to make a stock solution as indicated.

Then, 3 stock solutions are made up as indicated. Stock solutions are stored at $4^{\circ} \mathrm{C}$ until required. $\mathrm{Ca}^{2+}$ concentration in Stock 1 can be adjusted as shown below.

\section{Stock I}

$\begin{array}{llll}\text { Tyrode }\left[\mathrm{Ca}^{2+}\right]= & 1.8 \mathrm{mM} & 0.4 \mathrm{mM} & 0.2 \mathrm{mM} \\ \mathrm{NaCl}(\mathrm{Mw}=58.44) & 175 \mathrm{~g} & 175 \mathrm{~g} & 175 \mathrm{~g} \\ \mathrm{KCl}(\mathrm{Mw}=74.56) & 10 \mathrm{~g} & 10 \mathrm{~g} & 10 \mathrm{~g} \\ \mathrm{CaCl}_{2} \text { stock }(2.25 \mathrm{M}) & 20 \mathrm{ml} & 4.44 \mathrm{ml} & 2.22 \mathrm{ml} \\ \mathrm{MgCl}_{2} \text { stock }(1.05 \mathrm{M}) & 25 \mathrm{ml} & 25 \mathrm{ml} & 25 \mathrm{ml} \\ \text { adjusted with dd } \mathrm{H}_{2} \mathrm{O} & 1000 \mathrm{ml} & 1000 \mathrm{ml} & 1000 \mathrm{ml}\end{array}$


Stock II
$\mathrm{NaHCO}_{3}(\mathrm{Mw}=84.01)$
$50 \mathrm{~g}$
$\mathrm{H}_{2} \mathrm{O}$
$1000 \mathrm{ml}$

Stock III

$\mathrm{NaH}_{2} \mathrm{PO}_{4}(\mathrm{Mw}=137.99) \quad 5.8 \mathrm{~g}$

$\mathrm{H}_{2} \mathrm{O} \quad 1000 \mathrm{ml}$

All stock solutions can be stored after reconstitution at $40 \mathrm{C}$ until required.

\section{Tyrode's Working Solution}

\begin{tabular}{|l|l|l|l|l|}
\hline Stock I & $40 \mathrm{ml}$ & $80 \mathrm{ml}$ & $120 \mathrm{ml}$ & $200 \mathrm{ml}$ \\
\hline Stock II & $38 \mathrm{ml}$ & $76 \mathrm{ml}$ & $114 \mathrm{ml}$ & $140 \mathrm{ml}$ \\
\hline Stock III & $10 \mathrm{ml}$ & $20 \mathrm{ml}$ & $30 \mathrm{ml}$ & $50 \mathrm{ml}$ \\
\hline Glucose & $1 \mathrm{~g}$ & $2 \mathrm{~g}$ & $3 \mathrm{~g}$ & $5 \mathrm{~g}$ \\
\hline Ascorbic acid & $50 \mathrm{mg}$ & $100 \mathrm{mg}$ & $150 \mathrm{mg}$ & $250 \mathrm{mg}$ \\
\hline $\mathrm{H}_{2} \mathrm{O}$ & $1 \mathrm{~L}$ & $2 \mathrm{~L}$ & $3 \mathrm{~L}$ & $5 \mathrm{~L}$ \\
\hline
\end{tabular}

Prior to isometric force measurements, Tyrode's working solutions were mixed as indicated above, dissolved thoroughly and poured into thermostatted force transducer reservoirs as measurement buffer. 


\title{
Cloning Reagents and Medium
}

\section{LB-Medium}

\author{
$20 \mathrm{~g}$ Bacto-Tryptone \\ $20 \mathrm{~g}$ Bacto Yeast Extract \\ $20 \mathrm{~g} \mathrm{NaCl}$
}

Dissolve the above reagents with $1 \mathrm{LddH_{2 }}$ O and equilibrate the medium with $0.1 \mathrm{~N} \mathrm{NaOH}$ to $\mathrm{pH}$ 7.4. Top up to $2 \mathrm{~L}$ with $\mathrm{ddH}_{2} \mathrm{O}$ in a glass bottle and autoclave. LB medium can be stored in $4^{\circ} \mathrm{C}$ for 3 weeks.

\section{Agarose plates for bacterial colony cultures}

Weigh $7.5 \mathrm{~g}$ molecular biology grade agarose into a glass bottle. Add 500ml LB-Medium and agitate to an even suspension. Autoclave the bottle and allow it to cool below $50^{\circ} \mathrm{C}$. Add required antibiotics and agitate to mix the solution well. Pour about $20 \mathrm{ml}$ of the molten agar into sterile $10 \mathrm{~cm}$ Petri dishes and allow these to cool and solidify. Store at $4^{\circ} \mathrm{C}$ for a maximum of 2 weeks.

Antibiotics supplementation in 500 ml LB-Medium:

$2.5 \mathrm{ml}$ Kanamycin and/or

$2.0 \mathrm{ml}$ Ampicillin 


\section{Ampicillin-Stock}

$25 \mathrm{mg} / \mathrm{ml}$

Weigh out $50 \mathrm{mg}$ of Ampicillin and dissolve in $2 \mathrm{ml}$ of $\mathrm{dd}_{2} \mathrm{O}$. Aliquot and freeze in $-20^{\circ} \mathrm{C}$

\section{Kanamycin-Stock}

$10 \mathrm{mg} / \mathrm{ml}$

Weigh out $20 \mathrm{mg}$ of Kanamycin and dissolve in $2 \mathrm{ml}$ of $\mathrm{dd}_{2} \mathrm{O}$. Aliquot and freeze in $-20^{\circ} \mathrm{C}$ 


\section{Protein blot Reagents}

\section{6x Lämmli Loading buffer}

$\begin{array}{lll}2.4 \mathrm{~g} & \text { SDS } \\ 12 \mathrm{mg} & \text { Bromophenol blue } \\ 13.8 \mathrm{ml} & \text { Glycerol, } 87 \% \\ 5.8 \mathrm{ml} & \text { Tris-HCL, } 1.0 \mathrm{M}, \mathrm{pH} 6.8 \\ 1.85 \mathrm{~g} & \text { DTT }\end{array}$

First add SDS, Glycerol and Tris- $\mathrm{HCL}$ in a glass beaker and heat to $50^{\circ} \mathrm{C}$ for $10-20$ minutes. When reagents are completely dissolved, add Bromophenol

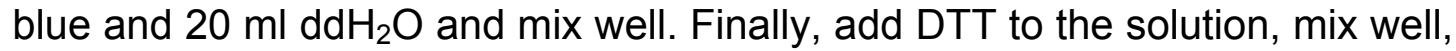
aliquot and freeze in $-20^{\circ} \mathrm{C}$.

\subsection{Tris-HCl pH 6.8}

$\begin{array}{ccc}400 \mathrm{ml} & \mathrm{ddH}_{2} \mathrm{O} \\ 30.28 \mathrm{~g} & \text { Tris- } \mathrm{HCl}\end{array}$

Adjusted to $\mathrm{pH} 6.8$ and topped up to $500 \mathrm{ml} \mathrm{H}_{2} \mathrm{O}$

\section{$1.5 \mathrm{M}$ Tris- $\mathrm{HCl} \mathrm{pH} 8.8$}

$\begin{array}{ccc}400 & \mathrm{ml} & \mathrm{ddH}_{2} \mathrm{O} \\ 90.85 \mathrm{~g} & \text { Tris- } \mathrm{HCl}\end{array}$

Adjusted to $\mathrm{pH} 8.8$ and topped up to $500 \mathrm{ml} \mathrm{H}_{2} \mathrm{O}$. 
SDS PAGE with $30 \%$ Acrylamide

Separating Gel (for 2 gels)

\begin{tabular}{|l|c|c|c|c|c|c|c|}
\hline \% SDS Agarose gel & $5 \%$ & $6 \%$ & $8 \%$ & $10 \%$ & $12 \%$ & $15 \%$ & $18 \%$ \\
\hline For kDa-proteins & $220-60$ & $150-50$ & $105-40$ & $90-25$ & $60-20$ & $45-10$ & $40-4$ \\
\hline $\mathrm{H}_{2} \mathrm{O}$ & 5.6 & 5.3 & 4.6 & 4.0 & 3.3 & 2.3 & 1.3 \\
\hline $30 \%$ Acrylamide & 1.7 & 2.0 & 2.7 & 3.3 & 4.0 & 5.0 & 6.0 \\
\hline $1.5 \mathrm{M}$ Tris pH 8,8 & 2.5 & 2.5 & 2.5 & 2.5 & 2.5 & 2.5 & 2.5 \\
\hline $10 \%$ SDS & 0.1 & 0.1 & 0.1 & 0.1 & 0.1 & 0.1 & 0.1 \\
\hline $10 \%$ APS & 0.1 & 0.1 & 0.1 & 0.1 & 0.1 & 0.1 & 0.1 \\
\hline TEMED & 0.01 & 0.008 & 0.006 & 0.004 & 0.004 & 0.004 & 0.004 \\
\hline
\end{tabular}

volumes in $\mathrm{ml}$

Stacking Gel (for 4 gels)

\begin{tabular}{|l|c|}
\hline & Vol (ml) \\
\hline $\mathrm{H}_{2} \mathrm{O}$ & 5.6 \\
\hline $30 \%$ Acrylamide & 1.7 \\
\hline $0.5 \mathrm{M}$ Tris $\mathrm{pH} 6.8$ & 2.5 \\
\hline $10 \%$ SDS & 0.1 \\
\hline $10 \%$ APS & 0.1 \\
\hline TEMED & 0.01 \\
\hline
\end{tabular}

$10 \%$ APS: $150 \mathrm{mg}$ APS dissolved in $1500 \mu \mathrm{lddH_{2 }} \mathrm{O}$.

\section{Nitrocellulose membrane preparation}

Membranes were immersed in $100 \%$ Methanol for 10 seconds. Next, they were washed in $\mathrm{ddH}_{2} \mathrm{O}$ for 5 minutes and placed in transfer buffer and 
allowed to equilibrate for 10 minutes. Thereafter, PVDF membranes are activated for SDS gel blot transfers.

10x Transfer-Buffer I (for Proteins under 80-100 kDa)

\begin{tabular}{|l|l|}
\hline $60.5 \mathrm{~g}$ & Tris-Base \\
\hline $288 \mathrm{~g}$ & Glycine \\
\hline
\end{tabular}

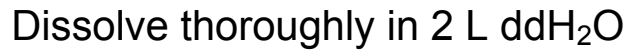

\section{1x Transfer Stock Solution Buffer}

$200 \mathrm{ml} \quad$ 10x Puffer

$400 \mathrm{ml} \quad$ Methanol

Adjusted to $2 \mathrm{~L} \mathrm{ddH_{2 }} \mathrm{O}$.

\section{Ponceau-S-Solution}

Ponceau-S-solution was purchased from Applichem and used neat for staining of western blot membranes.

Membranes were incubated in Ponceau-S solution for 1-5 minutes in room temperature and then rinsed with $\mathrm{dd}_{2} \mathrm{O}$ until the background turns white and stained bands are clearly contrasted. After image documentation, the ponceau stains are rinsed away in TBST. 
10x TBS Solution

$121.14 \mathrm{~g}$ Tris-Base

$175.32 \mathrm{~g} \quad \mathrm{NaCl}$

Add all reagents and $1.5 \mathrm{~L}$ of $\mathrm{ddH}_{2} \mathrm{O}$ in a suitable glass beaker and mix until all reagents are dissolved. Equilibrate the solution with fuming $\mathrm{HCl}$ till $\mathrm{pH} 7.5$, then top up till $2 \mathrm{~L}$ with $\mathrm{ddH}_{2} \mathrm{O}$.

\section{1x TBST Stock Solution}

$\begin{array}{ll}100 \mathrm{ml} & 10 x \text { TBS } \\ 900 \mathrm{ml} & \mathrm{H}_{2} \mathrm{O} \\ 1 \mathrm{ml} & \text { Tween 20 }\end{array}$

Mix all reagents until they dissolve. Tween 20 is extremely viscous and requires about $10-15$ minutes to dissolve completely.

10x Gel-Electrophoresis Buffer = Running Buffer $(\mathrm{pH} \mathrm{8,3-8,7})$

$\begin{array}{cl}60.6 \mathrm{~g} & \text { Tris- Base } \\ 288 \mathrm{~g} & \text { Glycine } \\ 20 \mathrm{~g} & \text { SDS }\end{array}$

Dissolve all reagents in $1 \mathrm{~L} d d \mathrm{H}_{2} \mathrm{O}$ and topped up to $2 \mathrm{~L} \mathrm{ddH}_{2} \mathrm{O}$ and mix thoroughly. During gel electrophoresis, $1: 10 \mathrm{ml}$ dilution with $\mathrm{ddH}_{2} \mathrm{O}$ is prepared fresh to obtain $1 \mathrm{X}$ running buffer. 


\section{DNA Agarose Gel Electrophoresis Reagents}

\section{0x TAE}

$\begin{array}{lll}242 & \mathrm{~g} & \text { Tris-Base } \\ 100 \mathrm{ml} & \text { EDTA 0.5M pH 8.0 } \\ 57.1 & \mathrm{ml} & \text { Glacial Acetic Acid }\end{array}$

Dissolve first in $800 \mathrm{ml}, \mathrm{pH} 8.5$ adjusted and topped up to $1 \mathrm{~L} \mathrm{H}_{2} \mathrm{O}$. Gel electrophoresis run is diluted $1: 50$ to obtain $1 \mathrm{X}$ TAE gel running buffer prior to use.

6x DNA loading buffer (2 coloured)

75 mg Bromophenol-Blue

$25 \quad \mathrm{mg}$ Xylene cyanol

$100 \mathrm{ml} \quad 30 \%$ Glycerol

All reagents are mixed thoroughly and can be stored in $4^{\circ} \mathrm{C}$ indefinitely

\subsection{NaOAc pH 5.4}

Anhydrous NaOAc: $\mathrm{M}=82.03 \mathrm{~g} / \mathrm{mol}$

To make $0.3 \mathrm{M}$ of $\mathrm{NaOAc}, 24.609 \mathrm{~g}$ of anhydrous NaOAc was dissolved thoroughly in $70 \mathrm{ml} \mathrm{H}_{2} \mathrm{O}$ and adjusted to $\mathrm{pH} 5.4$ with dropwise addition of

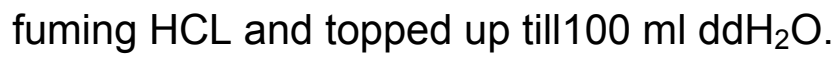




\section{Reagents for Immunohistochemistry}

\section{Permeabilizing / Blocking buffer}

$500 \mathrm{ml}$ Phosphate Buffered Saline (0.05 M, pH 7.4, Invitrogen)

$25 \mathrm{ml} \quad$ Fetal Calf Serum

$5 \quad \mathrm{~g} \quad$ Bovine Serum Albumin

$2.5 \quad \mathrm{ml}$ Triton $\mathrm{X}-100$

All reagents are mixed together thoroughly. Triton $X-100$ is viscous and requires constant stirring to dissolve. Blocking buffer can be aliquot and stored at $-20^{\circ} \mathrm{C}$. 


\begin{tabular}{|l|l|l|l|}
\hline Gene & $\mathbf{5}$ ' Forward primer & $\mathbf{3}^{\prime}$ Reverse primer & Taqman probe \\
\hline Cardiac & CCGGGAGAAGATGACTCAGA & GCAAAGCGTAGCCCTCATAG & CTGGCCGTACCACAGGCATTGTTCT \\
\hline Skeletal & TGCCCATTTATGAGGGCTAC & GCCATCTCGTTCTCGAAGTC & CGTGACCACAGCTGAGCGCGAGAT \\
\hline actin & & & \\
\hline B MHC & GAAGTCCTCCCTCAAGCTCA & CAAAGTGAGGATGGGTGGTC & ACTGCCGATACTGGGGACAGTGGT \\
\hline RyR 2 & TGGAAATGGTGTTGGAGATG & AATTCGGAACGAGATGCTTG & TTCATCTCTGGTCAGGTTGTATTGCTCGT \\
\hline SERCA & GAGTTGAACCCTCCCACAAG & CCAATCTCGGCTTTCTTCAG & AGATTACAGCTATGACTGGCGATGGCGT \\
\hline CSQ 2 & CTACCATGAGCCGGTGTCTT & GCTTCTTTCTTGGCATCCAC & ATCGTGCTTGAGCTTGTGGCCCA \\
\hline PLB & CCCAGCTAAACACCCGTAAG & TCCATGATACCAGCAGGACA & GATGATCACAGCTGCCAAGGCTACCT \\
\hline
\end{tabular}

Table 3. Primers and probes used in quantitative PCR. 


\title{
Cardiac Differentiation of Human Embryonic Stem Cells and their Assembly into Engineered Heart Muscle
}

\author{
Poh Loong Soong, ${ }^{1}$ Malte Tiburcy, ${ }^{1}$ and Wolfram-Hubertus Zimmermann ${ }^{1}$ \\ ${ }^{1}$ Department of Pharmacology, Heart Research Center Göttingen (HRCG), University \\ Medical Center Göttingen, Göttingen, Germany
}

\begin{abstract}
The advent of pluripotent human embryonic stem cells has created the unique opportunity for the development of a wide variety of humanized cellular tools for basic research, as well as industrial and clinical applications. It has, however, become apparent that embryonic stem cell derivatives in classical monolayer or embryoid body culture do not resemble bona fide tissues, mainly because of their limited organotypic organization and maturation in these culture formats. This shortcoming may be addressed by tissue engineering technologies aiming at the provision of a "natural" growth environment to facilitate organotypic tissue assembly. In this unit, we provide two harmonized basic protocols for (1) cardiac differentiation of human embryonic stem cells under serum-free conditions and (2) the assembly of the stem cell-derived cardiomyocytes into engineered heart muscle. This protocol can be easily adapted to bioengineer heart muscle also from other stem cell-derived cardiomyocytes, including cardiomyocytes from human-induced pluripotent stem cells. Curr. Protoc. Cell Biol. 55:23.8.1-23.8.21. (C) 2012 by John Wiley \& Sons, Inc.
\end{abstract}

Keywords: human embryonic stem cells $\bullet$ pluripotent stem cells $\bullet$ cardiac differentiation $\bullet$ cardiomyocytes $\bullet$ tissue engineering $\bullet$ engineered heart muscle

\section{INTRODUCTION}

The introduction of robust protocols to derive and maintain human embryonic stem cells (hESCs) in a self-renewing state with pluripotent differentiation potential (Thomson et al., 1998) is likely to have an enormous impact on the utility of cell models in human developmental biology, as well as drug discovery and development (Braam and Mummery, 2010). Moreover, hESCs and other pluripotent stem cells appear to be a promising source for cell-based organ repair (Laflamme et al., 2007).

hESCs can give rise to derivatives of the three germ lines-ectoderm, mesoderm, and endoderm. Other human pluripotent stem cells, including induced pluripotent stem cells (Takahashi et al., 2007) and parthenogenetic stem cells (Turovets et al., 2011), have similar biological properties. hESC are nevertheless considered the "gold standard" for a pluripotent stem cell, and mechanisms underlying pluripotent stem cell biology must be scrutinized in hESC to attain general acceptance. Ectodermal differentiation is apparently the default differentiation pathway in most hESC lines (Vallier et al., 2004). Spontaneous mesoderm and in particular cardiomyocyte differentiation are minimal, but may be enhanced by stage-specific differentiation protocols, adapted to simulate the paracrine milieu that governs embryonic heart development (Kattman et al., 2011a). Alternatively, cardiomyocytes may be isolated and enriched by manual dissection of spontaneously beating areas within differentiating embryoid bodies (EBs; Kehat et al., 2001; Xu et al., 2002), Percoll gradient centrifugation (Laflamme et al., 2007), genetic selection in 
transgenic hESC lines (Xu et al., 2008), or immune-assisted cell sorting via unique cell surface markers (Dubois et al., 2011; Elliott et al., 2011).

Isolated cardiomyocytes from hESCs display morphological and electrophysiological features of fetal cardiomyocytes (Kehat et al., 2001; Mummery et al., 2003). Advancing maturation in monolayer and EB cultures is severely compromised. Hence, it appears necessary to introduce novel culture formats to unlock the intrinsic capacity of ESCderived cardiomyocytes to form heart muscle surrogates in vitro. To this end, tissue engineering has been developed, as it may not only enable the adjustment of paracrine, but also of biophysical conditions, which may both be essential to facilitate bona fide heart muscle formation for a wide variety of applications, including (1) basic research (e.g., in developmental biology), (2) industrial (e.g., in drug development and toxicity screens), and (3) clinical (e.g., in cell-based heart repair) applications.

The complex architecture of the heart and its associated function, as well as the scarcity of adequate cell material, impose considerable challenges on the cardiac tissue engineer. Firstly, cardiomyocytes, even at an early developmental stage, are largely post-mitotic and thus refractory to commonly used cell amplification protocols. Secondly, the heart is a multi-cellular organ with a delicate balance of myocytes and nonmyocytes, each with specific roles in tissue organization, function, and maintenance. Thirdly, the myocytes have to be organized in a highly specialized functional syncytium embedded in extracellular matrix. Accordingly, it is essential to (1) have access to large quantities of bona fide cardiomyocytes, (2) supplement the myocyte pool with supporting stromal cells, and (3) provide an extracellular matrix to hold the cellular components together. In vitro vascularization is not required for myocardial tissue engineering if size limitations are considered (Tiburcy et al., 2011), but will be a prerequisite for the survival of tissue-engineered heart muscle if applied as surrogate tissue in vivo. Whether "precapillarization" of tissue engineered heart muscle already in vitro will be instrumental under these circumstances remains to be documented.

Here we provide two harmonized protocols to firstly enable the allocation of a somatic cell pool with defined cardiomyocyte and mesodermal nonmyocyte content from hESCs, and secondly allow the construction of human engineered heart muscle (EHT; Zimmermann et al., 2000) with the characteristic morphological and functional features of native myocardium (i.e., anisotropic arrangement, force developing contractions, and electrical conductivity). The cardiomyocyte derivation protocol we provide here is not optimized for cardiomyocyte purity, but for process reliability, low costs, and fast cardiomyocyte allocation. Moreover, it is scalable to enable mass cardiomyocyte derivation and subsequent assembly of engineered heart muscle.

\section{STRATEGIC PLANNING}

This unit contains two protocols: Basic Protocol 1 describes a method to robustly generate cardiomyocytes from hESCs under serum-free conditions; Basic Protocol 2 describes a method to engineer human myocardium. Basic Protocol 2 can also be utilized with minor modification to engineer heart muscle from other cardiomyocyte sources, including induced pluripotent and other stem cells; the main prerequisite is that the input cell population contains more than $10 \%$ immature cardiomyocytes and more than $40 \%$ mesodermal stromal cells. The described protocols should be highly robust in the hands of researchers familiar with basic mammalian cell culture. However, it must be emphasized that handling and maintaining of hESC is challenging and may require additional expert training.

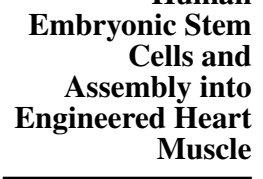

23.8.2 
NOTE: All protocol steps, with the exception of the casting mold and silicone holder preparations, must be performed under sterile conditions. Casting molds and silicone holders can be autoclaved and reused.

NOTE: All cultures should be maintained in a humidified incubator at $37^{\circ} \mathrm{C}$ supplemented with $5 \% \mathrm{CO}_{2}$.

NOTE: Legal requirements for hESC use in academia and industry can vary substantially and users of our protocols are recommended to contact the relevant regulatory authorities to attain approval for the intended studies.

\section{CARDIAC DIFFERENTIATION IN HUMAN EMBRYONIC STEM CELLS CULTURES}

The ability to maintain high-quality hESC cultures is an essential precondition for the successful execution of the following protocols. Basic hESC cultures are generally maintained under serum. We prefer to induce cardiogenesis in serum-free conditions for optimal control of this highly sensitive process. This protocol describes the adaptation of standard hESC-cultures to serum-free conditions and the induction of cardiac differentiation by MAPK inhibition in embryoid body cultures.

\section{Materials}

hESCs (e.g., HES3 hESCs)

100-mm feeder cell-coated culture plates (see Support Protocol 1)

hESC maintenance medium (see recipe)

Dulbecco's phosphate-buffered saline with $\mathrm{Mg}^{2+}$ and $\mathrm{Ca}^{2+}$ (DPBS+; Invitrogen, cat. no. 14040-091)

Collagenase IV working solution (see recipe)

SF adaptation medium (see recipe)

bSFS medium (see recipe)

SB203580 (CalBiochem, cat. no. 559389-5MG)

100-mm tissue culture dishes (Nunc, cat. no. 150679)

Stereomicroscope (Leica, cat. no. MZ8)

Glass Pasteur pipets

Stem Cell EZ passaging Tool (Invitrogen, cat. no. 23181-010)

Cell scraper

Graded disposable serological pipets

50-ml centrifuge tubes (BD Falcon, cat. no. 352070), sterile

Centrifuge

100-mm ultra-low petri dishes (Corning, cat. no. 3262)

$40-\mu \mathrm{m}$ cell strainers (BD Falcon, cat. no. 352340)

Tube rack

\section{Culture of hESC}

1. Seed hESC $\left(2 \times 10^{6}\right)$ on a $100-\mathrm{mm}$ feeder cell-coated culture plate containing $10 \mathrm{ml} \mathrm{hESC}$ culture medium. Place the plates in the incubator.

Feeder cells can be, e.g., mouse embryonic fibroblasts or human foreskin fibroblasts; both have to be growth-inhibited either by mitomycin $C$ or $\gamma$-irradiation.

2. Grow hEHCs to $60 \%$ to $90 \%$ confluency. Change the hESC culture medium every day (use $10 \mathrm{ml}$ culture medium per 100-mm culture dish).

Good-quality hESC colonies show a "pancake-like" appearance composed of densely packed cells with a high nucleus:cytoplasm ratio, a clear demarcation, and a rather circular morphology (Fig. 23.8.1A). 

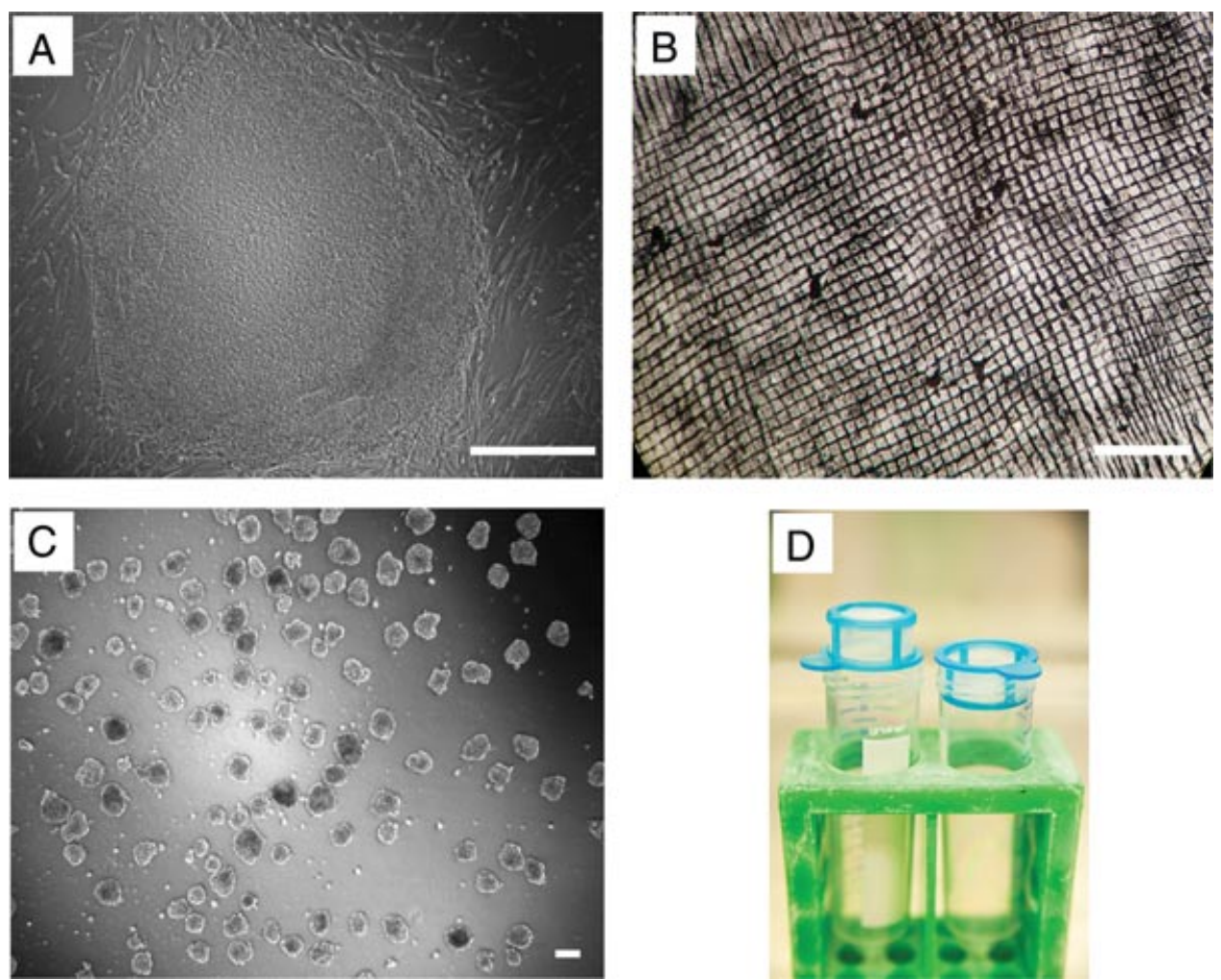

Figure 23.8.1 hESC culture and processing (all displayed data are from HES3). (A) Single hESC colony on irradiated human foreskin fibroblast. Notice the "pancake" morphology with clearly defined borders. The absence of raised centers/cystic areas indicates that this is a good quality hESC colony. Scale bar: $500 \mu \mathrm{m}$. (B) hESC colony manually "scored" using the StemPro EZ Passage tool. Scale bar: $1 \mathrm{~cm}$. (C) EBs with uniform size formed from manually cut hESC colonies at culture day 1 of serum-free differentiation. Scale bar: $100 \mu \mathrm{m}$. (D) 50-ml centrifuge tubes with cell strainers inverted (left) and correctly fitted (right) in the collection tube. EBs will be retained by the inverted cell strainer while cell debris will flow through and can be discarded. After turning over the cell strainer, the EBs can be washed into a fresh collection tube for further processing.

3. Split at a 1:9 ratio for further propagation.

Time to split cultures can vary depending on the adaptation of the hESC to the culture conditions. Well-established cultures are typically split after 7 days.

4. For splitting, aspirate cell culture medium from hESC plates. If necessary, aspirate cystic/differentiated parts of hESC colonies under optical control using a stereomicroscope.

Place the stereomicroscope underneath a laminar flow hood to ensure sterile handling of cell cultures.

5. Rinse the tissue culture plate once with $5 \mathrm{ml}$ DPBS+.

6. Aspirate DPBS+ and add $3 \mathrm{ml}$ collagenase IV working solution. Incubate for 4 to $6 \mathrm{~min}$ at $37^{\circ} \mathrm{C}$.

Avoid over-digestion to prevent detachment of entire "feeder-mat" with hESC cell colonies.

Embryonic Stem

Cells and

Assembly into

Engineered Heart

Muscle

7. Remove the hESC plate carefully from the incubator and aspirate the collagenase IV working solution with a glass Pasteur pipet.

Ensure that the Pasteur pipet does not contact the hESC colonies. hESC colonies are now loosely located on the culture dish and can be easily aspirated. 
8. Quickly, but carefully, use the Stem Cell EZ Passage Tool to score the entire plate by the rolling method. Rotate the plate $90^{\circ}$ and repeat scoring (Fig. 23.8.1B). The resulting squares are referred to as "cell rafts."

The scoring step can also be performed with alternative tools (e.g., glass needle). We find the Stem Cell EZ Passage Tool very well suited to produce homogeneously sized cell rafts $\left(\sim 1 \mathrm{~mm}^{2}\right)$.

9. Add $10 \mathrm{ml} \mathrm{hESC}$ medium to neutralize the enzymatic activity of the collagenase.

10. Detach the cell rafts with a cell scraper.

Use short strokes starting from the edge of the plate inwards.

11. Verify that most of the cell rafts have been mechanically detached from the plate.

Inspect using a stereomicroscope.

12. Using a 10-ml disposable serological pipet, aspirate the cell rafts and transfer into a 50-ml sterile centrifuge tube.

Prewet the pipet interior to minimize adhesion of cell rafts.

13. Repeat steps 2 to 12 for each individual hESC plate.

Drying of cultures must be prevented. Parallel plates can be handled once a sufficient level of experience has been reached.

14. Pool the cell rafts into one $50-\mathrm{ml}$ sterile centrifuge tube and pellet by centrifuging for $4 \mathrm{~min}$ at $300 \times g$, room temperature.

15. Discard the supernatant.

\section{Adapt to serum-free conditions}

16. Resuspend the cell pellet in $10 \mathrm{ml} \mathrm{SF}$ adaptation medium.

Trituration of the cell pellet 5 times is sufficient to dislodge most cell rafts without breaking them up too much.

17. Pool cell rafts from two $100-\mathrm{mm}$ hESC plates into one $100-\mathrm{mm}$ ultra-low petri dish containing $10 \mathrm{ml}$ prewarmed SF adaptation medium.

18. Incubate the ultra-low petri dishes in a $37^{\circ} \mathrm{C}$ incubator with $5 \% \mathrm{CO}_{2}$.

Homogeneously sized EBs form within 24 hr (Fig. 23.8.1C).

\section{Cardiac differentiation}

19. Insert a $40-\mu \mathrm{m}$ cell strainer in inverted orientation into an open $50-\mathrm{ml}$ centrifuge tube and place carefully in a tube rack (Fig. 23.8.1D).

20. Carefully remove the ultra-low petri dishes from the incubator.

21. Using a sterile 10-ml serological pipet, gently aspirate the entire culture medium including EBs and pass through the inverted cell strainer.

During serum-free adaptation and EB formation, cells are constantly shed. This straining step is important to separate single cells and cell debris from the formed EBs.

22. Rinse the ultra-low petri dishes once with $10 \mathrm{ml}$ bSFS medium and pass again through the inverted cell strainer.

EBs are collected on top of the cell strainer. Work quickly to prevent drying of EBs.

We introduce bSFS here to reduce the insulin content. Insulin can interfere with cardiogenesis in hESC culture. 
23. After the flow through is complete, turn the cell strainer so that it sits properly inside the opening of a new sterile 50-ml centrifuge tube (Fig. 23.8.1D).

The EBs are now at the bottom of the cell strainer and can be washed inside the centrifugation tube.

24. Add $10 \mathrm{ml}$ bSFS containing $5 \mu \mathrm{M} \mathrm{SB} 203580$ in the dark.

SB203580 is a highly light-sensitive MAPK inhibitor.

25. Transfer the entire volume back into the source ultra-low petri dish.

26. Place the culture plates back into the incubator.

This is marked as day 1 of differentiation.

27. Perform medium change every day following steps 19 to 26 , until culture day 3 where it is then changed every 2 days.

The daily washing steps during the first 3 culture days minimize the amount of cell debris that develops during serum-free adaptation.

Spontaneously beating EBs can be observed from culture day 8 onwards (see Video 1 at http://www.currentprotocols.com/protocol/cb2308).

EB culture can be continued for several weeks for cardiomyocyte harvest. We typically harvest EBs for further processing (see Basic Protocol 2) on culture day 13.

$B A S I C$ PROTOCOL 2

\section{BIOENGINEERING OF HEART MUSCLE}

ESC-derived cardiomyocytes in classical monolayer or EB culture do not resemble postnatal myocytes or myocardial tissue. Tissue engineering aims at assembling cells typically in biological extracellular matrix into tissue-like organoids. This protocol describes the generation of EHT with morphological and functional properties of native myocardium. This protocol can be used with several human cardiomyocyte sources including embryonic and induced pluripotent stem cells. This protocol requires the provision of casting molds.

\section{Materials}

Culture day 13 EBS in ultra-low petri dishes (see Basic Protocol 1)

Collagenase I (see recipe)

DNase I (see recipe)

Iscove MEM F0465 (Biochrom)

0.25\% Trypsin-EDTA (Invitrogen, cat. no. 24200-056)

Fetal bovine serum (FBS; PAA, cat. no. A15102)

hEHT medium (see recipe)

Dulbecco's phosphate-buffered saline without $\mathrm{Mg}^{2+}$ and $\mathrm{Ca}^{2+}$ (DPBS-; Invitrogen, cat. no. 14190-94)

$70 \%(\mathrm{v} / \mathrm{v})$ ethanol

15- and 50-ml centrifuge tubes

$37^{\circ} \mathrm{C}$ shaking water bath

10-ml serological pipets

Centrifuge (Eppendorf, cat. no. 5804R)

Glass Pasteur pipet

Hemacytometer

Casting molds (see Support Protocol 2; Figure 23.8.2A)

Silicone holders (Fig. 23.8.2B)

Sterile curved forceps

$100-\mu 1$ pipet tips, sterile 

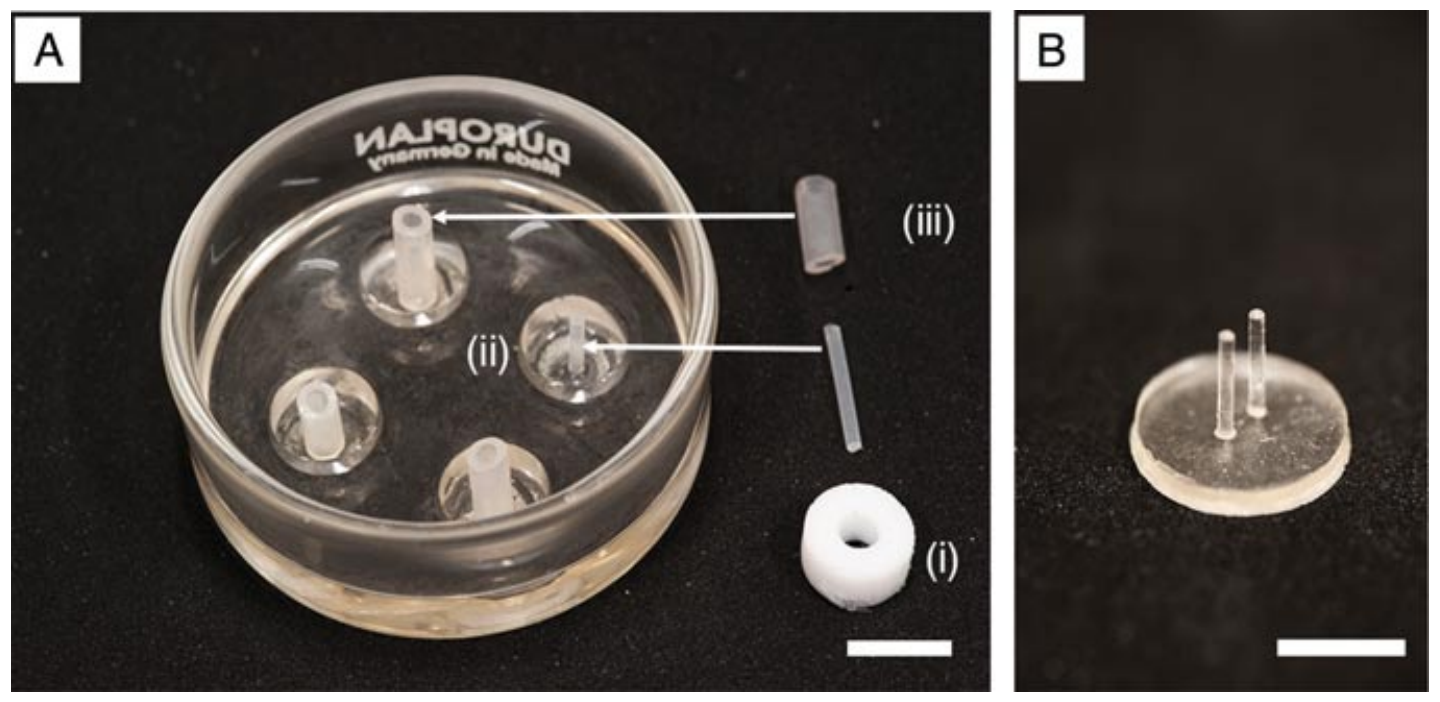

Figure 23.8.2 Casting mold and silicone holder for extended culture under defined mechanical load. (A) Glass culture dish filled with transparent silicone and four circular recesses with central spacers: (i) Teflon disc of 11-mm diameter and 5-mm height with central hole used as spacer during the silicone hardening process; (ii) recess with thin silicone core; (iii) silicone tubing used as inner spacer during the EHT formation process placed over a central silicon core. (B) Flexible silicone poles (length: $11 \mathrm{~mm}$, thickness: $1.5 \mathrm{~mm}$, inner/outer distance: $3 / 6 \mathrm{~mm}$ ) with circular base (diameter: $20 \mathrm{~mm}$, thickness: $1.6 \mathrm{~mm}$ ) as resilient holder (resilient force can be adapted as desired by for example altering the silicone curing conditions or changing the pole dimensions). Scale bars: $10 \mathrm{~mm}$.

\section{Perform enzymatic digestion of hESC-EBs to obtain single cells}

1. Harvest culture day 13 EBs from the ultra-low petri dishes (from Basic Protocol 1) and pool into a 50-ml centrifuge tube.

2. Let settle for $15 \mathrm{~min}$ at room temperature.

3. Aspirate the supernatant carefully and add $5 \mathrm{ml}$ collagenase I and $100 \mu \mathrm{l}$ DNase I (20 $\mu \mathrm{l} / \mathrm{ml}$ collagenase solution).

At this stage, the EBs are only loosely pelleted and care should be taken to avoid aspiration of EBs.

4. Incubate at $37^{\circ} \mathrm{C}$ in a shaking water bath for $45 \mathrm{~min}$.

5. Add $20 \mathrm{ml}$ Iscove MEM and triturate at least 5 times with a 10-ml serological pipet to mechanically aid in dispersion of compact EBs.

Always prewet the pipets to minimize cell adhesion.

6. Centrifuge the tube for $5 \mathrm{~min}$ at $200 \times \mathrm{g}$, room temperature.

7. Aspirate the supernatant and add $5 \mathrm{ml}$ of $0.25 \%$ Trypsin-EDTA into the tube.

8. Incubate the tube in the $37^{\circ} \mathrm{C}$ shaking water bath again for 5 to $10 \mathrm{~min}$.

Keep the time as short as possible to minimize cell damage. Aim at a dissociation of $>80 \%$ of the starting amount of EBs.

9. Triturate briefly with a glass Pasteur pipet to disperse any remaining cell clumps.

10. Add $20 \mathrm{ml}$ Iscove MEM supplemented with fetal bovine serum at 1:1 ratio with $400 \mu \mathrm{l}$ DNase I and triturate with a 10-ml serological pipet until a uniform cell suspension is obtained. 
11. Centrifuge the tube for $5 \mathrm{~min}$ at $200 \times g, 4^{\circ} \mathrm{C}$.

12. Aspirate the supernatant and discard.

13. Resuspend the cell pellet evenly in $20 \mathrm{ml}$ cold hEHT medium.

14. Perform a cell count with a hemacytometer.

We anticipate to retrieve $\sim 8 \times 10^{6}$ cells per ultra-low petri dish. Cell viability should be $>90 \%$ based on Trypan blue exclusion assay.

15. Transfer $1 \times 10^{6}$ cells into a separate $15-\mathrm{ml}$ centrifuge tube and centrifuge for $5 \mathrm{~min}$ at $200 \times g, 4^{\circ} \mathrm{C}$. Keep the remaining cells on ice.

16. Aspirate the supernatant and rinse with $10 \mathrm{ml}$ cold DPBS-.

17. Centrifuge the $15-\mathrm{ml}$ tube for an additional $5 \mathrm{~min}$ at $200 \times \mathrm{g}, 4^{\circ} \mathrm{C}$, and aspirate the supernatant leaving an intact cell pellet.

18. Tap the base of the $15-\mathrm{ml}$ centrifuge tube at least 5 times to dislodge the cell pellet and add $3 \mathrm{ml}$ of ice-cold $70 \%$ ethanol in a dropwise manner while gently shaking ("vortex").

19. Store the tube of ethanol-fixed cells at $4{ }^{\circ} \mathrm{C}$ until required for flow cytometry and morphological cell smear analyses (Fig. 23.8.3).

The maximum storage time for ethanol-fixed cells should not exceed 1 week.

20. Centrifuge the remaining cells for $5 \mathrm{~min}$ at $200 \times g, 4^{\circ} \mathrm{C}$.

21. Aspirate the supernatant and resuspend the cell pellet in an appropriate volume of cold hEHT medium.

Adjust the volume of the cell suspension according to the EHT reconstitution protocol (see below and Table 23.8.1).

\section{Generate human EHTs}

22. Mix the components in the exact order as indicated in Table 23.8.1 into a prechilled 15-ml (for 4 EHTs) or 50-ml (for 20 EHTs) centrifuge tube.

All reagents must be cold and kept on ice throughout the entire procedure. Work quickly to prevent reagents from warming up.

23. Triturate the EHT master mix on ice with a prechilled serological pipet to ensure homogeneous distribution of cells.

24. Quickly distribute $500 \mu \mathrm{l}$ of the cell-collagen mixture into the individual casting mold recesses (Fig. 23.8.2A).

25. Place the casting molds with minimal agitation in a $37^{\circ} \mathrm{C}$ humidified incubator with $5 \% \mathrm{CO}_{2}$ for $1 \mathrm{hr}$.

26. Remove the dishes and move into a sterile laminar hood and overlay carefully with $6 \mathrm{ml}$ prewarmed hEHT medium. Ensure that all hEHTs are completely covered with medium.

27. Return the dishes into the incubator for $24 \mathrm{hr}$.

28. Remove the dishes from the incubator and move into the laminar flow and exchange the hEHT medium.

Microscopic inspection at this time point should demonstrate evenly distributed cells within the hydrogel. Isolated beating of single cells and cell clusters should be visible. 


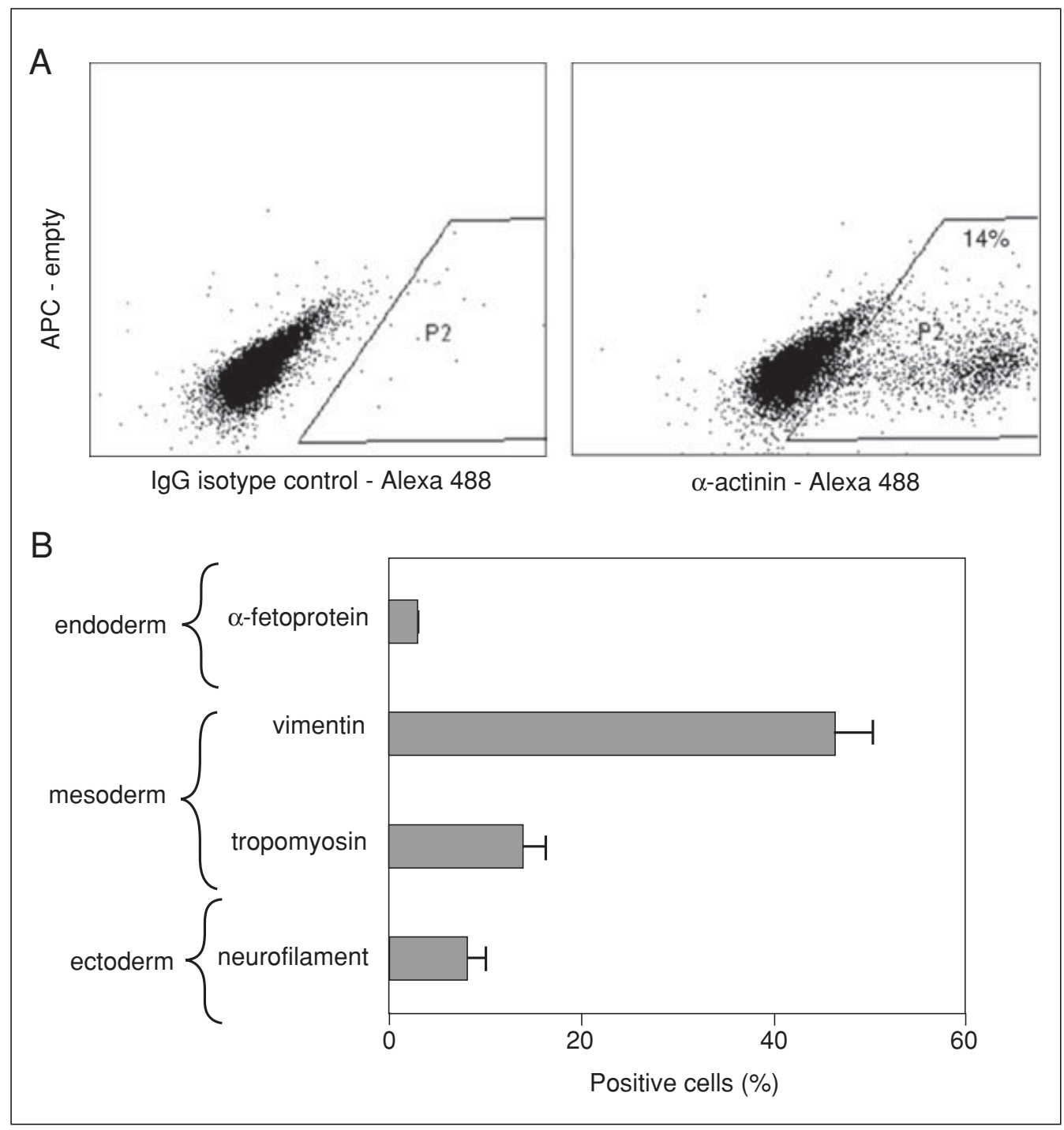

Figure 23.8.3 Assessment of hESC-EB cell composition by flow cytometry and fluorescence microscopy (all data from HES3 EBs). (A) hESC-EBs on culture day 13 should contain $>10 \%$ cardiomyocytes ( $\alpha$-sarcomeric actinin-positive; right panel); left panel: isotype control. Analysis was performed by flow cytometry (input cell number $1 \times 10^{6}$ ). (B) Microscopic analysis of cell smears after enzymatic dispersion of hESC-EBs, demonstrating mainly mesodermal components (vimentin and tropomyosin positive cells) and few cells positive for endodermal (alpha-fetoprotein), as well as ectodermal (pan-neurofilament) markers. Oct 4 and Nanog (marking residual pluripotent cells) were not detectable.

The hEHTs will progressively condense and will be ready for transfer onto resilient silicone holders (Fig. 23.8.2B).

hEHT should be fully condensed around the central silicone tube within the casting mold recess (Fig. 23.8.2A) on EHT culture day 3. The EHT transfer may be postponed by 2 days if condensation is not complete by culture day 3 .

\section{Transfer hEHTs onto flexible silicone holders for mechanical stretching}

29. Place the necessary number of silicone holders into a tissue culture plate, fill with hEHT medium.

Silicone holders can be adjusted in size to facilitate EHT culture in variable culture plate formats (single dish to 48-well plate).

30. Remove casting mold dishes from the incubator under the laminar hood. 
Table 23.8.1 Composition of Master Mix for Generation of EHTs

\begin{tabular}{lcc}
\hline & \multicolumn{2}{c}{ Volume $(\mu \mathrm{l})$} \\
\hline Number of EHTs & 4 & 20 \\
${\text { Collagen }(3.2 \mathrm{mg} / \mathrm{ml})^{a}}^{a}$ & 440 & 2,200 \\
$2 \times \mathrm{DMEM}^{(\text {see recipe })}$ & 535 & 2,675 \\
$0.1 \mathrm{~N} \mathrm{NaOH}^{b}$ & 95 & 475 \\
Matrigel (BD, cat. no. 354234) & 200 & 1,000 \\
Cell suspension $^{c}$ & 829 & 4,145 \\
TOTAL VOLUME & 2,100 & 10,500 \\
\hline
\end{tabular}

${ }^{a}$ We prefer to prepare collagen type 1 from rat tail tendons by classical acid solubilization technique (adapted to 3 to $5 \mathrm{mg} / \mathrm{ml}$ ). Stability of collagen at $4{ }^{\circ} \mathrm{C}$ is approximately 1 year. Quality of most commercially available collagens is insufficient.

${ }^{b}$ Add dropwise until phenol red color indicator changes from yellow (acidic) to pink.

${ }^{c}$ Adjust to $1.5 \times 10^{6}$ cells per EHT.

31. Gently pinch the top of the removable silicone tubing of a casting mold dish with curved forceps and slowly remove the silicone tube. Ensure that the EHT is attached around the silicone tube.

32. Place the silicone tube over one of the paired silicone poles of a silicone holder and release the EHT by gentle shaking or nudging of the EHT carefully with a pipet tip.

EHTs typically slip from the silicon tubing with little extra manipulation.

33. Using another sterile pipet tip, gently bend the other silicone pole to suspend the EHT between the two poles.

The EHTs are fragile at this stage and it is crucial that they are transferred from the casting molds in an extremely careful manner. Tissue ruptures at this stage constitute predetermined breaking points during subsequent EHT culture.

This step also has to be executed quickly to prevent drying of the EHT.

34. Position EHT horizontally suspended on the resilient silicone holder.

35. Transfer the holder with EHT into a tissue culture dish with fresh hEHT medium and ensure that EHTs are fully covered.

36. Incubate for $24 \mathrm{hr}$ at $37^{\circ} \mathrm{C}$.

37. Exchange medium and always ensure that EHTs are fully submerged. From now on exchange medium every other day.

The EHTs will further condense around the poles over the next 5 to 7 days and start to contract visibly. The resilient silicone poles facilitate auxotonic contractions (see video 2 at http://www.currentprotocols.com/protocol/cb2308). Their size can be easily adjusted as desired.

EHT are ready for end-point analyses on culture day 10 or may be cultured for an extended period of time (for at least 6 months).

Embryonic

nic Stem

Cells and

Assembly into

Engineered Heart Muscle

23.8.10

We control the quality of EHT typically at culture day 10 by assessment of contractile properties under isometric conditions with and without field stimulation in thermostatted $\left(37^{\circ} \mathrm{C}\right)$ organ baths filled with modified Tyrode's solution (Fig. 23.8.4A) (Zimmermann et al., 2000). This is typically followed by additional morphological (Fig. 23.8.4B) and other analyses (see Anticipated Results). 

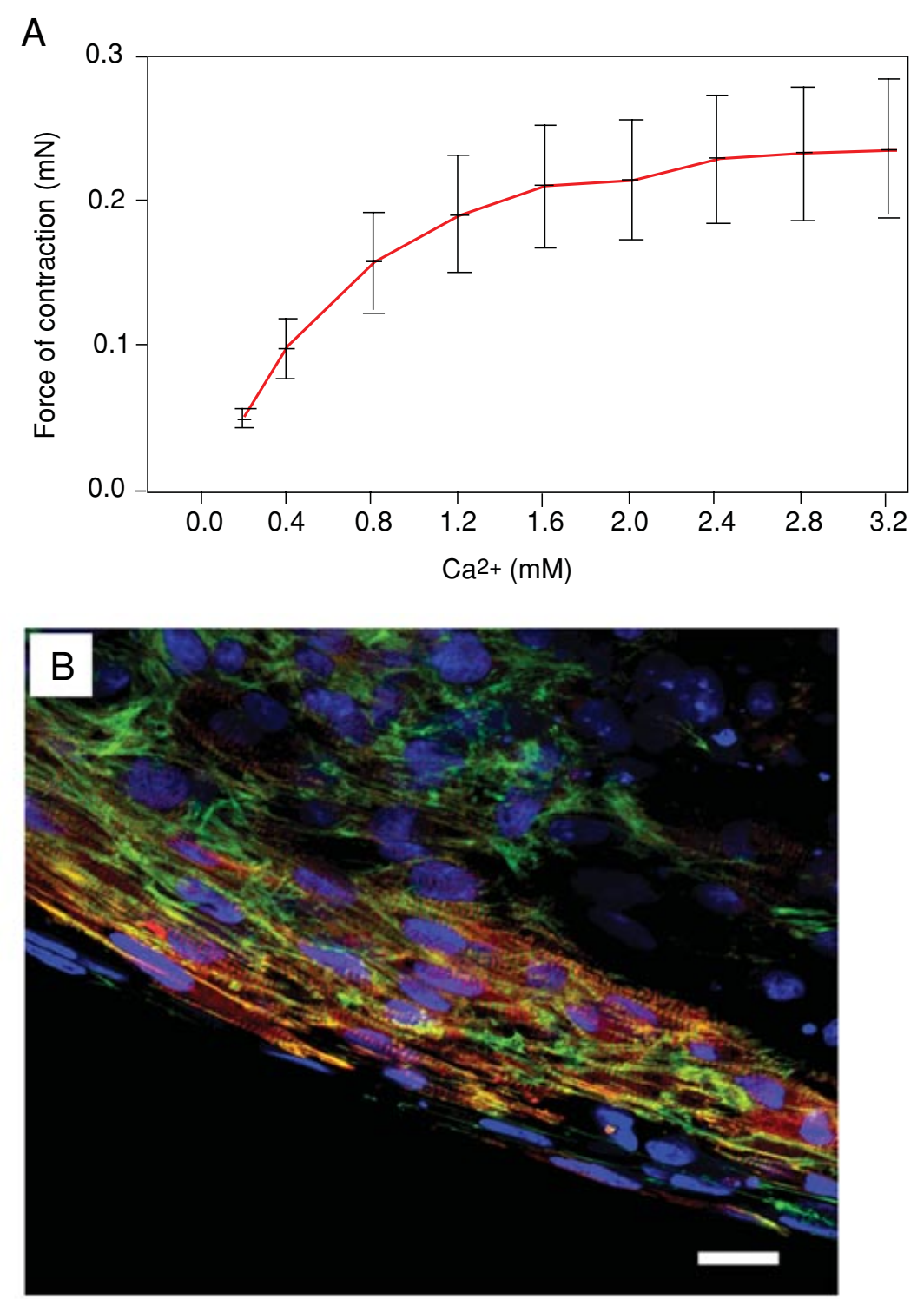

Figure 23.8.4 Functional and morphological parameters of hEHTs. (A) Force of contraction measured under isometric conditions at $37^{\circ} \mathrm{C}$ and electrical field stimulation at $2 \mathrm{~Hz}(n=4)$. A positive inotropic response (increase in force of contraction) is anticipated for muscle preparations under increasing extracellular calcium concentrations. (B) Demonstration of an aligned muscle bundle with characteristic sarcomeric cross-striation by confocal microscopy (red: $\alpha$-actinin; green: f-actin; blue; DAPI stained nuclei). Scale bar: $20 \mu \mathrm{m}$. For the color version of this figure go to http://www.currentprotocols.com/protocol/cb2308.

Embryonic stem cells are typically maintained in a pluripotent state on fibroblast feeders. Feeder cultures can be prepared from fetal mice or human foreskin. Basic Protocol 1 utilizes human foreskin fibroblast (HFF) feeder cell-coated culture plates prepared as outlined in this protocol.

\section{Materials}

Human foreskin fibroblasts (HFF; ATCC\# SCRC-1041)

HFF maintenance medium (see recipe)

Human basic fibroblast growth factor (bFGF; Stemgent, cat. no. 03-0002 or

Miltenyi Biotech, cat. no. 130-093-841) 
$37^{\circ} \mathrm{C}$ water bath

15-ml conical tubes

Hemacytometer

Standard inverted microscope

Irradiation source

100-mm tissue culture plates

$37^{\circ} \mathrm{C}, 5 \% \mathrm{CO}_{2}$ incubator

1. Thaw a vial of frozen $\mathrm{HFF}$ cells in a $37^{\circ} \mathrm{C}$ water bath.

2. Transfer HFFs into a $15-\mathrm{ml}$ conical tube containing $9 \mathrm{ml}$ prewarmed HFF maintenance medium.

3. Centrifuge the cells for $4 \mathrm{~min}$ at $300 \times g$, room temperature.

4. Aspirate the supernatant and resuspend the cells in $10 \mathrm{ml} \mathrm{HFF}$ maintenance medium.

Perform steps 1 to 4 quickly and without interruption to minimize cell damage.

5. Count the number of cells using a hemacytometer under a standard inverted microscope.

Viability should be $>90 \%$ based on Trypan blue exclusion.

6. Transfer the desired number of HFFs for feeder layer plating into a separate $15-\mathrm{ml}$ or 50-ml conical tube.

Calculate $2 \times 10^{6}$ irradiated HFFs per 100-mm tissue culture plate. Mark the conical tube for irradiation.

Plate the remaining HFFs into $75-\mathrm{cm}^{2}$ tissue culture flasks $\left(2.2 \times 10^{6} \mathrm{HFFs} / 75-\mathrm{cm}^{2}\right.$ flask $)$ and supplement the medium with $10 \mathrm{ng} / \mathrm{ml} \mathrm{bFGF}$ for continual passaging.

Alternatively, cryopreserve in 90\% fetal bovine serum (FBS; PAA, cat. no. A15-102) and $10 \%$ DMSO; freeze down for storage in liquid nitrogen or $-152^{\circ} \mathrm{C}$ freezer.

7. Expose the tube marked for irradiation to 30-Gray $\gamma$-irradiation for $20 \mathrm{~min}$ at room temperature.

Irradiation causes the HFFs to be mitotically arrested.

8. Centrifuge the irradiated HFFs for $4 \mathrm{~min}$ at $300 \times g$, room temperature.

9. Aspirate the supernatant and resuspend the cells in $10 \mathrm{ml}$ HFF maintenance medium for each $100-\mathrm{mm}$ tissue culture plate.

10. Place the $100-\mathrm{mm}$ tissue culture plates containing irradiated $\mathrm{HFFs}$ in a $37^{\circ} \mathrm{C}$ incubator with $5 \% \mathrm{CO}_{2}$.

These plates can be used as feeder layer for hESC cultures after $24 \mathrm{hr}$.

SUPPORT PROTOCOL 2

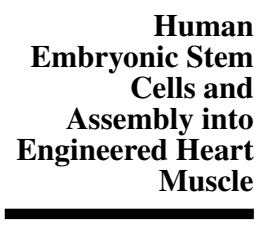

23.8.12

\section{PREPARATION OF CASTING MOLDS FOR EHT CULTURE}

EHTs are typically created in a defined circular geometry in casting molds (Fig. 23.8.2). The circular geometry is advantageous in terms of tissue formation and cellular orientation compared to, e.g., lattice formats (Zimmermann et al., 2000). Casting molds can be adapted in size depending on the respective application (Naito et al., 2006, Yildirim et al., 2007). For large-scale applications in cardiac repair, fusion of individual units to complex tissue-engineered myocardium can be performed (Naito et al., 2006; Zimmermann et al., 2006). 
Sylgard silicone elastomer and curing agent 184 (Dow Corning, cat. no. 1673921) Distilled water

Teflon spacer (Fig. 23.8.2A,i, custom made: 11-mm diameter, 5-mm height) $60 \times 20-\mathrm{mm}$ glass petri dishes (Schott Duran, cat. no. 217554101)

50 -ml centrifuge tubes

Forceps

Silicone core (Figure 23.8.2A,ii, 1-mm diameter)

$55^{\circ} \mathrm{C}$ incubator

5-liter glass beakers

Silicone tubing (Figure 23.8.2A,iii, 4-mm diameter; VWR, cat. no. 224-0563)

Aluminum foil

Autoclave

1. Place four Teflon spacers evenly spaced in a glass petri dish (Fig. 23.8.2A).

2. Into a 50-ml centrifuge tube, pipet $9 \mathrm{ml}$ Sylgard silicone and $1 \mathrm{ml}$ of curing agent and mix well.

3. Centrifuge the tube for $3 \mathrm{~min}$ at $300 \times g$, room temperature, to get rid of air bubbles.

4. Pour the silicone mixture into the glass dish around the Teflon spacers.

Avoid air bubbles.

5. Let set for $24 \mathrm{hr}$ at room temperature or place in a $55^{\circ} \mathrm{C}$ drying incubator for at least $1 \mathrm{hr}$ for the silicone to cure.

6. Carefully remove the Teflon spacers with forceps (Fig. 23.8.2A, i).

7. Apply a droplet of premixed silicone to each of the centers of the four recesses, attach a short silicone core upright (Fig. 23.8.2A,ii), and allow this to cure overnight at $55^{\circ} \mathrm{C}$.

8. Place the newly fabricated molds in a 5-liter glass beaker filled with distilled water, boil, drain, and dry. Discard water and repeat boiling steps at least 4 times.

This step removes cell toxic residuals from the casting molds.

9. Place silicone tubings (Fig. 23.8.2A,iii) over the silicone cores, wrap in aluminum foil, and autoclave.

Casting molds can be reused indefinitely.

\section{REAGENTS AND SOLUTIONS}

Use deionized, distilled water in all recipes and protocol steps. For common stock solutions, see APPENDIX 2A; for suppliers, see SUPPLIERS APPENDIX.

\section{bFGF stock solution}

Dissolve human basic fibroblast growth factor (bFGF; Stemgent, cat. no. 03-0002 or Miltenyi Biotech, cat. no. 130-093.841) according to the manufacturer's protocol to obtain a stock concentration of $10 \mu \mathrm{g} / \mathrm{ml}$. Divide into $50-\mu \mathrm{l}$ aliquots into sterile microcentrifuge tubes. Store up to 2 months at $-20^{\circ} \mathrm{C}$.

\section{bFGF working solution}

Add $10 \mu \mathrm{l}$ bFGF stock solution (see recipe) into $10 \mathrm{ml} \mathrm{hESC}$ maintenance medium (see recipe) per 100-mm hES cultured plates (final bFGF concentration: $10 \mathrm{ng} / \mathrm{ml}$ ). 


\section{bSFS (basal serum-free differentiation medium)}

$500 \mathrm{ml}$ DMEM (Invitrogen, cat. no. 11960)

$5 \mathrm{ml} \mathrm{L}$-glutamine (200 mmol/liter; Invitrogen, cat. no. 25030-024)

$5 \mathrm{ml}$ MEM NEAA (10 mmol/liter; Invitrogen, cat. no. 11140-050)

$900 \mu 1$ 2-mercaptoethanol (50 mmol/liter; Invitrogen, cat. no. 31350-010)

$690 \mu \mathrm{l}$ human transferrin $(4 \mathrm{mg} / \mathrm{ml}$; Invitrogen, cat. no. 0030124SA)

$182 \mu \mathrm{l}$ sodium pyruvate (100 mmol/liter; Invitrogen, cat. no. 11360-039)

$50 \mu \mathrm{l}$ sodium selenite $(100 \mu \mathrm{g} / \mathrm{ml}$; Sigma Aldrich, cat. no. S5361-25G)

Store up to 2 weeks at $4^{\circ} \mathrm{C}$

\section{Collagenase I solution}

Dissolve $100 \mathrm{mg}$ collagenase I (Sigma Aldrich, cat. no. C0130) in $40 \mathrm{ml}$ Dulbecco's phosphate-buffered saline with $\mathrm{Mg}^{2+}$ and $\mathrm{Ca}^{2+}$ (DPBS+; Invitrogen, cat. no. 14040-091) and $10 \mathrm{ml}$ fetal bovine serum (FBS). Sterile filter the solution. Divide into $10-\mathrm{ml}$ aliquots in 15-ml centrifuge tubes and store up to 2 months at $-20^{\circ} \mathrm{C}$.

\section{Collagenase IV stock solution}

Dissolve $10 \mathrm{mg}$ collagenase IV (Worthington, cat. no. CLS4) in $1 \mathrm{ml}$ DPBS+. Sterile filter the solution. Divide into $1-\mathrm{ml}$ aliquots in $15-\mathrm{ml}$ centrifuge tubes and store up to 2 months at $-20^{\circ} \mathrm{C}$.

\section{Collagenase IV working solution}

Thaw one aliquot of collagenase IV stock solution (see recipe) in a $37^{\circ} \mathrm{C}$ water bath Add $9 \mathrm{ml}$ prewarmed DPBS+ into the stock solution just prior to usage

Additional amounts of collagenase IV solution can be stored up to 1 week at $4{ }^{\circ} \mathrm{C}$

\section{DMEM, $2 \times$}

$1 \mathrm{ml} 10 \times \mathrm{DMEM}$ (see recipe)

$2 \mathrm{ml}$ fetal bovine serum (FBS; PAA, cat. no. A15102)

$100 \mu \mathrm{l} \mathrm{L}$-glutamine (200 mmol/liter; Invitrogen, cat. no. 25030-024)

$100 \mu \mathrm{l}$ penicillin/streptomycin $(5000 \mathrm{U} / \mathrm{ml}$ and $5 \mathrm{mg} / \mathrm{ml}$; Invitrogen, cat. no. 15070063)

$1.8 \mathrm{ml} \mathrm{H}_{2} \mathrm{O}$

Store up to 2 weeks at $4^{\circ} \mathrm{C}$

\section{DMEM, $10 \times$}

Dissolve 669 mg DMEM powder (Invitrogen, cat. no. 52100-039) in $5 \mathrm{ml}$ sterile water

Filter the solution through a $0.22-\mu \mathrm{m}$ syringe filter

Store up to 2 weeks at $4^{\circ} \mathrm{C}$

\section{DNase I solution}

Suspend DNase I (Calbiochem, cat. no. 260913) in ice-cold water at $1 \mathrm{mg} / \mathrm{ml}$. Sterile filter the solution. Divide into 5-ml aliquots in 15-ml centrifuge tubes and store up to 2 months at $-20^{\circ} \mathrm{C}$. Keep on ice after thawing.

\section{hEHT medium (human bioengineered heart muscle medium)}

Embryonic Stem

Cells and

Assembly into

Engineered Heart Muscle
$500 \mathrm{ml}$ Iscove's MEM (Biochrom, cat. no. F0465)

$120 \mathrm{ml}$ fetal bovine serum (FBS; PAA, cat. no. A15102)

$6 \mathrm{ml} \mathrm{L-glutamine} \mathrm{(200} \mathrm{mmol/liter;} \mathrm{Invitrogen,} \mathrm{cat.} \mathrm{no.} \mathrm{25030-024)}$

$6 \mathrm{ml} \mathrm{NEAA} \mathrm{(10} \mathrm{mmol/liter;} \mathrm{Invitrogen,} \mathrm{cat.} \mathrm{no.} \mathrm{11140-050)}$ 
$6 \mathrm{ml}$ penicillin/streptomycin $(5000 \mathrm{U} / \mathrm{ml}$ and $5 \mathrm{mg} / \mathrm{ml}$; Invitrogen, cat. no. 15070063)

4.34 l 2-mercaptoethanol (Sigma, cat. no. 31350-010)

Store up to 2 weeks at $4{ }^{\circ} \mathrm{C}$

\section{hESC maintenance medium}

$500 \mathrm{ml}$ KO-DMEM (Invitrogen, cat. no. 10829-018)

$128.2 \mathrm{ml}$ Xeno-Free KnockOut-Serum Replacement (KOSR; Invitrogen, cat. no. 10828-028)

$6.4 \mathrm{ml} \mathrm{L}$-glutamine ( $200 \mathrm{mmol} /$ liter; Invitrogen, cat. no. 25030-024)

$6.4 \mathrm{ml}$ MEM NEAA (10 mmol/liter; Invitrogen, cat. no. 11140-050)

Human basic fibroblast growth factor (bFGF; Stemgent, cat. no. 03-0002 or Miltenyi Biotech, cat. no. 130-093.841) is only added according to the required amount of medium used per hESC plate

Store up to 2 weeks at $4^{\circ} \mathrm{C}$

\section{HFF maintenance medium}

500 ml DMEM (Invitrogen, cat. no. 42430)

$100 \mathrm{ml}$ fetal bovine serum (FBS; PAA, cat. no. A15-102)

$6.4 \mathrm{ml}$ penicillin/streptomycin $(5000 \mathrm{U} / \mathrm{ml}$ and $5 \mathrm{mg} / \mathrm{ml}$; Invitrogen, cat. no. 15070063)

Store up to 2 weeks at $4{ }^{\circ} \mathrm{C}$

\section{SF (serum-free) adaptation medium}

485 ml DMEM (Invitrogen, cat. no. 11960)

$5 \mathrm{ml} \mathrm{L}$-glutamine (200 mmol/liter; Invitrogen, cat. no. 25030-024)

$5 \mathrm{ml}$ MEM NEAA (10 mmol/liter; Invitrogen, cat. no. 11140-050)

$5 \mathrm{ml}$ ITS-X supplement $(100 \times$; Invitrogen, cat. no. 51500-056)

Store up to 2 weeks at $4^{\circ} \mathrm{C}$

\section{COMMENTARY}

\section{Background Information}

The advent of stable mouse ESC lines has without question revolutionized biological/biomedical sciences (Evans and Kaufman, 1981; Martin, 1981). Given the fast introduction of this seminal technology into a variety of animal species (Schnieke et al., 1997; Wilmut et al., 1997, 2002), it appeared only a matter of time until stable hESC lines would be established. The first successful isolation and culture of hESCs was reported in 1994 by Ariff Bongso and colleagues (Bongso et al., 1994). This was followed by the establishment of stable hESC lines by James Thomson and colleagues in 1998 (Thomson et al., 1998). In this study, pluripotency of the unique hESC lines was unambiguously established and culture conditions for long-term maintenance of $\mathrm{hESCs}$ were defined. Several groups have subsequently characterized specific derivatives of hESCs, including neurons (Schuldiner et al., 2001) and cardiomyocytes (Kehat et al., 2001). Despite its anticipated versatility for research and even clinical applications, difficulties in controlling the differentiation process and subsequently the tissue-like maturation of ESC derivatives have delayed its widespread use.

The properties of virtually unlimited selfrenewal and tri-lineage differentiation potential has generated the desire to scale-up hESC amplification and processing to, e.g., obtain large numbers of high-quality cardiomyocytes (Xu et al., 2011). The excitement in the cardiac research community is based on the expectation that human bona fide cardiomyocytes can finally be made widely available at quasiunlimited quantities, a scenario that was unrealistic so far because of the limited proliferation capacity in postnatal cardiomyocytes (Soonpaa et al., 1996; Bergmann et al., 2009). Unlimited availability of human cardiomyocytes would be a prerequisite not only for the introduction of novel cell-based therapies, but also for applications in drug discovery and safety pharmacology (Braam and Mummery, 2010).

When hESCs are allowed to spontaneously differentiate, they form EBs containing the
Stem Cells

23.8.15

Supplement 55 
three embryonic germ layers (Thomson et al., 1998). Their fate can be influenced by various growth factors (Schuldiner et al., 2000). When cultured for extended periods of time, spontaneously differentiating embryoid bodies develop cells that contract and possess structural, functional, and electrophysiological properties similar to those of fetal cardiomyocytes (Kehat et al., 2001). However, the amount of cardiomyocytes in standard EB cultures is typically below the $1 \%$ range. Adaptation of culture conditions by integration of the rapidly increasing knowledge from cardiac developmental biology has dramatically helped to optimize the differentiation processes towards the cardiac lineage (Kattman et al., 2006, 2011b). Moreover, further process optimization has enabled industrial-scale production of hESC-derived cardiomyocytes (Lecina et al., 2010; Melkoumian et al., 2010; Xu et al., 2011).

While the issue of limited scale appears to be in principle overcome, albeit at still unacceptable costs for widespread applications, it has to be acknowledged that hESC-derived cardiomyocytes resemble embryonic rather than postnatal stage cardiomyocytes. Importantly, even growth factor-enhanced monolayer or EB cultures appear to offer only limited support for organotypic maturation of hESC-derived cardiomyocytes. Conversely, three-dimensional culture does not only enable growth factor support, but also biophysical conditioning, a property that may be of pivotal importance especially for organs with predominantly biophysical functions.

The first macroscopic three-dimensional heart-like tissues were engineered from embryonic chick cardiomyocytes as in vitro models for pharmacological studies and as a testbed for target validation (Eschenhagen et al., 1997). This was followed by the advent of mammalian engineered heart tissues (EHTs; Zimmermann et al., 2000). In contrast to other original tissue-engineered heart muscle models (Bursac et al., 1999; Carrier et al., 1999; Li et al., 1999; Leor et al., 2000), EHTs displayed coordinated beating with directed force development and heart muscle-like physiological (e.g., Frank-Starling mechanism) and pharmacological responses (e.g., beta-adrenergic and muscarinic modulation of contractile properties). Subsequently, alternative tissue engineering modalities with comparable functionality have been introduced (Shimizu et al., 2002; Radisic et al., 2004; Tulloch et al., 2011). Importantly, EHT cultures support anisotropic tissue organization and maturation of im- mature cardiomyocytes (Zimmermann et al., 2002; Tiburcy et al., 2011). Based on this, it appeared straightforward to postulate that the EHT culture format would also support the assembly of immature hESC-derived cardiomyocytes into functional myocardium.

\section{Critical Parameters}

We find the following parameters to be crucial for the successful implementation of the described protocol:

1. The described culture media are supplemented with a variety of growth factors and serum components. It has to be anticipated that the activity of culture media supplements can vary substantially, despite having a nominally similar concentration. Hence, it is critical that batch testing of growth factors and sera be performed and considerable batches secured for the anticipated experiments. We expect that fully defined serum-free medium conditions will soon become available; this will clearly be another important milestone for further development of tissue-engineered myocardium.

2. It is essential to work with highestquality hESC cultures. These can be identified morphologically and should display round, flat, and cell-dense ("pancake") colonies (Fig. 23.8.1A). Any deviation from such morphology, such as "bubbly" or cystic centers, nondefined border zones, or wispy fragile centers suggests that the hESC colonies are "unhealthy." This can be due to several factors, including unwanted $\mathrm{pH}$ fluctuations in the culture medium, suboptimal oxygen levels, and depletion of critical nutrients and growth factors in the medium. Overcrowding of hESC colonies can also trigger cystic colony formation. Such cultures are unsuitable for downstream experiments and should be discarded. In addition, the quality of the hESC should be regularly scrutinized by flow cytometry or antibody staining for pluripotency markers (such as Oct4, SSEA4, Tra1-60; see Fig. 23.8.5) and karyotyping using advanced technologies such as chromosome painting and array-CGH analyses are necessary if one wants to claim a normal karyotype (Rudolph and Schlegelberger, 2009). Simple Giemsa-banding is in our view not sufficient to control for chromosomal integrity.

3. In this protocol, we use SB203580 for MAPK inhibition and improvement of cardiac differentiation in hESC cultures as originally described by Graichen and co-workers (Graichen et al., 2008). To achieve robust results, SB203580 must be handled with care in the dark to prevent loss of its activity.

\subsubsection{6}




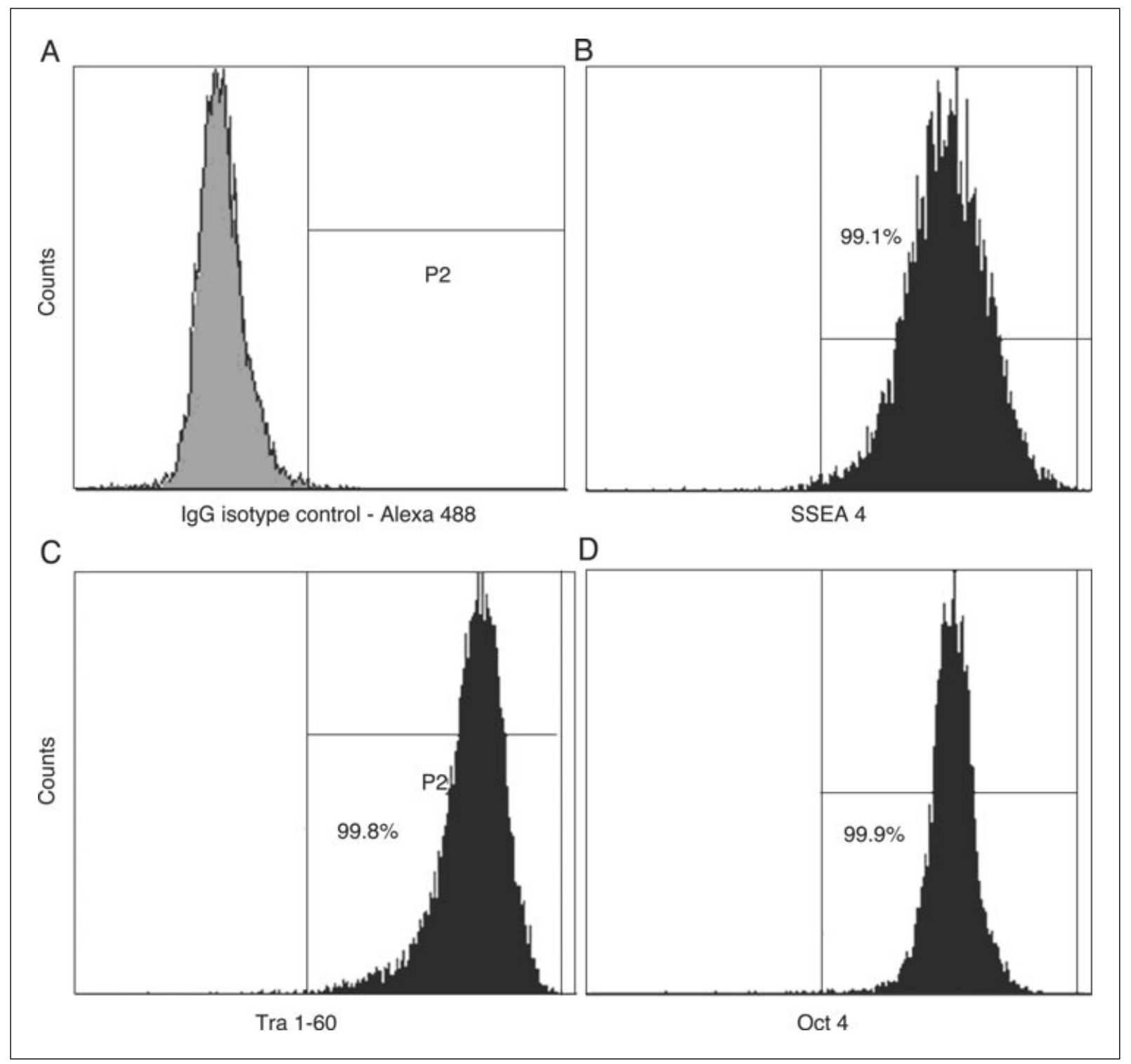

Figure 23.8.5 Assessment of pluripotency in hESC cultures by flow cytometry (all data from HES3). (A) IgG isotype control, (B) SSEA 4, (C) Tra 1-60, and (D) Oct 4. High-quality hESC cultures must exhibit uniform expression of the tested stemness surrogate markers.

4. We describe cardiac differentiation in serum-free medium. This helps enhance the robustness of this protocol as it avoids the supplementation with difficult to define animal sera. Our protocol is not optimized to achieve optimal cardiomyocyte purity, but for procedural simplicity, low costs, and fast cardiomyocyte generation. During the first day of serum-free adaptation, there will be plenty of shedding of dead cells, which must be removed from the medium to prevent damage of the remaining healthy cells. This is achieved by changing the medium daily for the first 3 days of differentiation.

5. The cardiomyocyte content in EB cultures should be regularly monitored by flow cytometry and fluorescence microscopy (e.g., see data in Fig. 23.8.3). Flow cytometry conditions (in particular gating parameters and antibody labeling) have to be carefully established to avoid false-positive or false-negative counts.

6. Our tissue engineering technology relies on the use of high-quality collagen type 1. Most commercially available collagens cannot be used as they lack cardio-instructive properties. We typically prepare collagen type 1 from rat tails using a classical acetic acid solubilization protocol (Eschenhagen et al., 2002). The collagen concentration in the collagen stock solution should be adjusted to $>3 \mathrm{mg} / \mathrm{ml}$ for optimal results. Collagen type 1 degrades spontaneously even if stored at $4^{\circ} \mathrm{C}$ in acetic acid. We recommend preparing fresh collagen stock solutions at least once a year.
Stem Cells

23.8.17 
Table 23.8.2 Possible Problems and Their Solutions

\begin{tabular}{ll}
\hline Problem & Possible solution \\
\hline $\begin{array}{l}\text { No or too little cardiac } \\
\text { differentiation in hESC cultures }\end{array}$ & Check the quality of undifferentiated hESCs \\
EHTs do not form/condense & $\begin{array}{l}\text { Prepare fresh bSFS } \\
\text { Pelation capacity }\end{array}$ \\
& Adjust the number of cells \\
& Confirm the quality of the cells \\
& Confirm proper cell myocyte/stroma cell \\
& composition \\
& Perform cell viability counts to determine \\
& quality of the cells \\
& Adjust cardiomyocyte content \\
EHTs do not beat & Confirm the quality of cardiomyocytes and \\
nonmyocytes with flow cytometry analysis
\end{tabular}

Alternatively, collagen formulations from commercial suppliers must be screened for suitable collagen batches.

7. The described EHT reconstitution mixture and in particular Matrigel are highly sensitive to temperature. Premature gelation during its preparation must be avoided under any circumstances. We perform all EHT preparation steps on ice. Gelation will subsequently be facilitated at $37^{\circ} \mathrm{C}$ in a standard cell culture incubator.

8. Casting mold and silicone holder dimensions have been optimized for EHT culture in a standard 12-well culture format. EHT size can be adapted and functional properties modified by alteration of the molds and holders. Single ring-shaped EHTs can be fused easily into larger functional syncytia by culturing EHTs in direct contact with each other (Naito et al., 2006). Ring-shaped EHTs allow easy assessment of contractile parameters as a quality control measure for tissue formation and tissue maturation (Zimmermann et al., 2002).

\section{Troubleshooting}

For troubleshooting information, see Table 23.8.2 for a list of possible problems and their solutions.

\section{Anticipated Results}

The following results are expected:

1. Small round EBs should be observed on culture day 1 of serum-free culture differentiation.

2. First spontaneously beating of EBs should be visible from culture day 8 .
3. The number and beating activity of EBs increases until culture day 13 .

4. Flow cytometry of dissociated day 13 EBs should yield: $>10 \%$ alpha-sarcomeric actinin (Fig. 23.8.2A) or tropomyosinpositive (Fig. 23.8.2B) cardiomyocytes, $>40 \%$ vimentin-positive mesodermal nonmyocytes (Fig. 23.8.2B), few endodermal (based on alpha-fetoprotein) or ectodermal (based on neurofilament) cells (Fig. 23.8.2B), and no pluripotent cells (based on Oct3/4 and/or Nanog).

5. Localized beating should be observed $24 \mathrm{hr}$ after EHT casting.

6. Synchronous contractions of EHT should be observed after 3 days in culture; beating will become more rigorous after transferring to silicone poles leading to macroscopically visible deflections of the silicone poles (see Video 2 at http://www.currentprotocols.com/protocol/ cb2308).

High-quality hEHTs should meet the following quality control parameters:

i. Spontaneous macroscopically visible contractions at $>60$ beats a minute at $37^{\circ} \mathrm{C}$ (see Video 2 at http://www.currentprotocols.com/ protocol/cb2308).

ii. Isometric force development of $>0.2$ $\mathrm{mN}$ at $2 \mathrm{mmol} /$ liter calcium concentration (Fig. 23.8.4A).

iii. Positive inotropic response to betaadrenergic receptor stimulation with isoprenaline ( $1 \mu \mathrm{mol} / \mathrm{liter})$, which can be antagonized by muscarinic receptor stimulation with carbamylcholine $(10 \mu \mathrm{mol} /$ liter $)$. 
iv. A tissue stiffness of $>20 \mathrm{kPa}$ measured by uniaxial tension testing.

v. Conduction velocity of $>0.1 \mathrm{~m} / \mathrm{sec}$ measured by high-speed optical imaging or for example multi-electrode arrays.

vi. Morphological identification of anisotropically organized muscle bundles with aligned sarcomeres (Fig. 23.8.4B).

vii. Absence of contaminating pluripotent cells (Oct4, Rex2, Nanog transcripts not detectable by quantitative PCR).

\section{Time Considerations}

Standard hESC cultures takes 7 days from thawing cells until passaging/initiation of differentiation. Daily medium change from culture day 2 post thawing is required.

Differentiation of hESC colonies into beating EBs requires at least 8 days.

We harvest beating EBs typically on culture day 13 or later for the generation of EHTs.

Condensation of EHTs requires 3 days.

EHT culture under defined mechanical load to enhance tissue formation requires 7 days.

Taken together, hESC-derived EHTs can be generated in 30 days (20 days hESC culture and differentiation followed by 10 days EHT generation).

\section{Acknowledgements}

WHZ is supported by the German Ministry of Education and Research (BMBF: 01GN 0827 and 01GN 0957), the German Research Foundation (DFG: ZI 708/7-1, 8-1, 10-1), EU FP7 - CARE MI, a Lower-Saxony/Technion Grant, and the German Center for Cardiovascular Research.

\section{Literature Cited}

Bergmann, O., Bhardwaj, R.D., Bernard, S., Zdunek, S., Barnabe-Heider, F., Walsh, S., Zupicich, J., Alkass, K., Buchholz, B.A., Druid, H., Jovinge, S., and Frisen, J. 2009. Evidence for cardiomyocyte renewal in humans. Science 324:98-102.

Bongso, A., Fong, C.Y., Ng, S.C., and Ratnam, S. 1994. Isolation and culture of inner cell mass cells from human blastocysts. Hum. Reprod. 9:2110-2117.

Braam, S.R. and Mummery, C.L. 2010. Human stem cell models for predictive cardiac safety pharmacology. Stem Cell Res. 4:155-156.

Bursac, N., Papadaki, M., Cohen, R.J., Schoen, F.J., Eisenberg, S.R., Carrier, R., Vunjak-Novakovic, G., and Freed, L.E. 1999. Cardiac muscle tissue engineering: Toward an in vitro model for electrophysiological studies. Am. J. Physiol. 277:H433-H444.

Carrier, R.L., Papadaki, M., Rupnick, M., Schoen, F.J., Bursac, N., Langer, R., Freed, L.E., and
Vunjak-Novakovic, G. 1999. Cardiac tissue engineering: Cell seeding, cultivation parameters, and tissue construct characterization. Biotechnol. Bioeng. 64:580-589.

Dubois, N.C., Craft, A.M., Sharma, P., Elliott, D.A., Stanley, E.G., Elefanty, A.G., Gramolini, A., and Keller, G. 2011. SIRPA is a specific cellsurface marker for isolating cardiomyocytes derived from human pluripotent stem cells. Nat. Biotechnol. 29:1011-1018.

Elliott, D.A., Braam, S.R., Koutsis, K., Ng, E.S., Jenny, R., Lagerqvist, E.L., Biben, C., Hatzistavrou, T., Hirst, C.E., Yu, Q.C., Skelton, R.J., Ward-van Oostwaard, D., Lim, S.M., Khammy, O., Li, X., Hawes, S.M., Davis, R.P., Goulburn, A.L., Passier, R., Prall, O.W., Haynes, J.M., Pouton, C.W., Kaye, D.M., Mummery, C.L., Elefanty, A.G., and Stanley, E.G. 2011. NKX2-5eGFP/w hESCs for isolation of human cardiac progenitors and cardiomyocytes. Nat. Methods 8:1037-1040.

Eschenhagen, T., Fink, C., Remmers, U., Scholz, H., Wattchow, J., Weil, J., Zimmermann, W., Dohmen, H.H., Schafer, H., Bishopric, N., Wakatsuki, T., and Elson, E.L. 1997. Threedimensional reconstitution of embryonic cardiomyocytes in a collagen matrix: A new heart muscle model system. FASEB J. 11:683-694.

Eschenhagen, T., Didie, M., Munzel, F., Schubert, P., Schneiderbanger, K., and Zimmermann, W.H. 2002. 3D engineered heart tissue for replacement therapy. Basic Res. Cardiol. 97:146152.

Evans, M.J. and Kaufman, M.H. 1981. Establishment in culture of pluripotential cells from mouse embryos. Nature 292:154-156.

Graichen, R., Xu, X., Braam, S.R., Balakrishnan, T., Norfiza, S., Sieh, S., Soo, S.Y., Tham, S.C., Mummery, C., Colman, A., Zweigerdt, R., and Davidson, B.P. 2008. Enhanced cardiomyogenesis of human embryonic stem cells by a small molecular inhibitor of p38 MAPK. Differentiation 76:357-370.

Kattman, S.J., Huber, T.L., and Keller, G.M. 2006. Multipotent flk-1+ cardiovascular progenitor cells give rise to the cardiomyocyte, endothelial, and vascular smooth muscle lineages. Dev. Cell 11:723-732.

Kattman, S.J., Koonce, C.H., Swanson, B.J., and Anson, B.D. 2011a. Stem cells and their derivatives: A renaissance in cardiovascular translational research. J. Cardiovasc. Transl. Res. 4:6672.

Kattman, S.J., Witty, A.D., Gagliardi, M., Dubois, N.C., Niapour, M., Hotta, A., Ellis, J., and Keller, G. 2011b. Stage-specific optimization of activin/nodal and BMP signaling promotes cardiac differentiation of mouse and human pluripotent stem cell lines. Cell Stem Cell 8:228240.

Kehat, I., Kenyagin-Karsenti, D., Snir, M., Segev, H., Amit, M., Gepstein, A., Livne, E., Binah, O., Itskovitz-Eldor, J., and Gepstein, L. 2001. Human embryonic stem cells can differentiate into myocytes with structural and functional
Stem Cells

23.8.19 
properties of cardiomyocytes. J. Clin. Invest. 108:407-414.

Laflamme, M.A., Chen, K.Y., Naumova, A.V., Muskheli, V., Fugate, J.A., Dupras, S.K., Reinecke, H., Xu, C., Hassanipour, M., Police, S., O'Sullivan, C., Collins, L., Chen, Y., Mi nami, E., Gill, E.A., Ueno, S., Yuan, C., Gold, J., and Murry, C.E. 2007. Cardiomyocytes derived from human embryonic stem cells in prosurvival factors enhance function of infarcted rat hearts. Nature Biotechnol. 25:1015-1024.

Lecina, M., Ting, S., Choo, A., Reuveny, S., and Oh, S. 2010. Scalable platform for human embryonic stem cell differentiation to cardiomyocytes in suspended microcarrier cultures. Tissue Eng. Part C Methods 16:1609-1619.

Leor, J., Aboulafia-Etzion, S., Dar, A., Shapiro, L., Barbash, I.M., Battler, A., Granot, Y., and Cohen, S. 2000. Bioengineered cardiac grafts: A new approach to repair the infarcted myocardium? Circulation 102:56-61.

Li, R.K., Jia, Z.Q., Weisel, R.D., Mickle, D.A., Choi, A., and Yau, T.M. 1999. Survival and function of bioengineered cardiac grafts. Circulation 100:63-69.

Martin, G.R. 1981. Isolation of a pluripotent cell line from early mouse embryos cultured in medium conditioned by teratocarcinoma stem cells. Proc. Natl. Acad. Sci. U.S.A. 78:76347638.

Melkoumian, Z., Weber, J.L., Weber, D.M., Fadeev, A.G., Zhou, Y., Dolley-Sonneville, P., Yang, J., Qiu, L., Priest, C.A., Shogbon, C., Martin, A.W., Nelson, J., West, P., Beltzer, J.P., Pal, S., and Brandenberger, R. 2010. Synthetic peptideacrylate surfaces for long-term self-renewal and cardiomyocyte differentiation of human embryonic stem cells. Nat. Biotechnol. 28:606-610.

Mummery, C., Ward-van Oostwaard, D., Doevendans, P., Spijker, R., van den Brink, S., Hassink, R., van der Heyden, M., Opthof, T., Pera, M., de la Riviere, A.B., Passier, R., and Tertoolen, L. 2003. Differentiation of human embryonic stem cells to cardiomyocytes: Role of coculture with visceral endoderm-like cells. Circulation 107:2733-2740.

Naito, H., Melnychenko, I., Didie, M., Schneiderbanger, K., Schubert, P., Rosenkranz, S., Eschenhagen, T., and Zimmermann, W.H. 2006. Optimizing engineered heart tissue for therapeutic applications as surrogate heart muscle. Circulation 114:72-78.

Radisic, M., Park, H., Shing, H., Consi, T., Schoen, F.J., Langer, R., Freed, L.E., and Vunjak-Novakovic, G. 2004. Functional assembly of engineered myocardium by electrical stimulation of cardiac myocytes cultured on scaffolds. Proc. Natl. Acad. Sci. U.S.A. 101:18129-18134.

Rudolph, C. and Schlegelberger, B. 2009. Spectral karyotyping and fluorescence in situ hybridization of murine cells. Methods Mol. Biol. 506:453-466

Schnieke, A.E., Kind, A.J., Ritchie, W.A., Mycock, K., Scott, A.R., Ritchie, M., Wilmut, I., Colman,
A., and Campbell, K.H. 1997. Human factor IX transgenic sheep produced by transfer of nuclei from transfected fetal fibroblasts. Science 278:2130-2133.

Schuldiner, M., Yanuka, O., Itskovitz-Eldor, J., Melton, D.A., and Benvenisty, N. 2000. Effects of eight growth factors on the differentiation of cells derived from human embryonic stem cells. Proc. Natl. Acad. Sci. U.S.A. 97:11307-11312.

Schuldiner, M., Eiges, R., Eden, A., Yanuka, O., Itskovitz-Eldor, J., Goldstein, R.S., and Benvenisty, N. 2001. Induced neuronal differentiation of human embryonic stem cells. Brain Res. 913:201-205.

Shimizu, T., Yamato, M., Isoi, Y., Akutsu, T., Setomaru, T., Abe, K., Kikuchi, A., Umezu, M., and Okano, T. 2002. Fabrication of pulsatile cardiac tissue grafts using a novel 3dimensional cell sheet manipulation technique and temperature-responsive cell culture surfaces. Circ. Res. 90:e40.

Soonpaa, M.H., Kim, K.K., Pajak, L., Franklin, M., and Field, L.J. 1996. Cardiomyocyte DNA synthesis and binucleation during murine development. Am. J. Physiol. 271:H2183-H2189.

Takahashi, K., Tanabe, K., Ohnuki, M., Narita, M., Ichisaka, T., Tomoda, K., and Yamanaka, S. 2007. Induction of pluripotent stem cells from adult human fibroblasts by defined factors. Cell 131:861-872.

Thomson, J.A., Itskovitz-Eldor, J., Shapiro, S.S., Waknitz, M.A., Swiergiel, J.J., Marshall, V.S., and Jones, J.M. 1998. Embryonic stem cell lines derived from human blastocysts. Science 282:1145-1147.

Tiburcy, M., Didie, M., Boy, O., Christalla, P., Doker, S., Naito, H., Karikkineth, B.C., El-Armouche, A., Grimm, M., Nose, M., Eschenhagen, T., Zieseniss, A., Katschinksi, D.M., Hamdani, N., Linke, W.A., Yin, X., Mayr, M., and Zimmermann, W.H. 2011. Terminal differentiation, advanced organotypic maturation, and modeling of hypertrophic growth in engineered heart tissue. Circ. Res. 109:1105-1114.

Tulloch, N.L., Muskheli, V., Razumova, M.V., Korte, F.S., Regnier, M., Hauch, K.D., Pabon, L., Reinecke, H., and Murry, C.E. 2011. Growth of engineered human myocardium with mechanical loading and vascular coculture. Circ. Res. 109:47-59.

Turovets, N., Semechkin, A., Kuzmichev, L., Janus, J., Agapova, L., and Revazova, E. 2011. Derivation of human parthenogenetic stem cell lines. Methods Mol. Biol. 767:37-54.

Vallier, L., Reynolds, D., and Pedersen, R.A. 2004. Nodal inhibits differentiation of human embryonic stem cells along the neuroectodermal default pathway. Dev. Biol. 275:403-421.

Wilmut, I., Schnieke, A.E., McWhir, J., Kind, A.J., and Campbell, K.H. 1997. Viable offspring derived from fetal and adult mammalian cells. $\mathrm{Na}$ ture 385:810-813.

Wilmut, I., Beaujean, N., de Sousa, P.A., Dinnyes, A., King, T.J., Paterson, L.A., Wells, D.N., and 
Young, L.E. 2002. Somatic cell nuclear transfer. Nature 419:583-586.

$\mathrm{Xu}, \mathrm{C}$., Police, S., Rao, N., and Carpenter, M.K. 2002. Characterization and enrichment of cardiomyocytes derived from human embryonic stem cells. Circ. Res. 91:501-508.

Xu, C., Police, S., Hassanipour, M., Li, Y., Chen, Y., Priest, C., O'Sullivan, C., Laflamme, M.A., Zhu, W.Z., Van Biber, B., Hegerova, L., Yang, J., Delavan-Boorsma, K., Davies, A., Lebkowski, J., and Gold, J.D. 2011. Efficient generation and cryopreservation of cardiomyocytes derived from human embryonic stem cells. Regen. Med. 6:53-66.

Xu, X.Q., Zweigerdt, R., Soo, S.Y., Ngoh, Z.X., Tham, S.C., Wang, S.T., Graichen, R., Davidson, B., Colman, A., and Sun, W. 2008. Highly enriched cardiomyocytes from human embryonic stem cells. Cytotherapy 10:376389.

Yildirim, Y., Naito, H., Didie, M., Karikkineth, B.C., Biermann, D., Eschenhagen, T., and Zim- mermann, W.H. 2007. Development of a biological ventricular assist device: Preliminary data from a small animal model. Circulation 116:I1623.

Zimmermann, W.H., Fink, C., Kralisch, D., Remmers, U., Weil, J., and Eschenhagen, T. 2000. Three-dimensional engineered heart tissue from neonatal rat cardiac myocytes. Biotechnol. Bioeng. 68:106-114.

Zimmermann, W.H., Schneiderbanger, K., Schubert, P., Didie, M., Munzel, F., Heubach, J.F., Kostin, S., Neuhuber, W.L., and Eschenhagen, T. 2002. Tissue engineering of a differentiated cardiac muscle construct. Circ. Res. 90:223-230.

Zimmermann, W.H., Melnychenko, I., Wasmeier, G., Didie, M., Naito, H., Nixdorff, U., Hess, A., Budinsky, L., Brune, K., Michaelis, B., Dhein, S., Schwoerer, A., Ehmke, H., and Eschenhagen, T. 2006. Engineered heart tissue grafts improve systolic and diastolic function in infarcted rat hearts. Nat. Med. 12:452-458. 


\section{Personal data}

Poh Loong SOONG

Born: Kuala Lumpur, Malaysia

Nationality: $\quad$ Singaporean

Marital Status: $\quad$ Married to Simin Chen, MSc

\section{Profession since June 2008}

Ph.D. candidate in the Department of Pharmacology (Director: Prof. Dr. Wolfram H.- Zimmermann)

\section{Working Experience}

$2007-2008$

$2005-2007$
Research Associate (Grade 4), Institute of Medical Biology (IMB), Agency for Science Technology and Research (ASTAR), Singapore

Research Associate, ES Cell International Pte Ltd (ESI) Singapore

\section{Tertiary education}

$2002-2005$

National University of Singapore, Singapore

Studies:

Microbiology and Immunology

Degree:

Master of Science (MSc.)

$2001-2002$

University of Melbourne, Australia

Studies:

Microbiology and Immunology

Degree:

Bachelors of Science with Honours (BSc. (Hons.))

$1997-2000$

National University of Singapore, Singapore

Studies:

Microbiology and Immunology

Degree:

Bachelors of Science (BSc.) 


\section{Specific Animal Handling courses}

$01 / 2005$

"Responsible care and use of laboratory animals course", Biological Resource Center (BRC), ASTAR Singapore Course contents: regulations on animal use in Singapore, general husbandry of small laboratory animals, blood collection, disease. Certificate number BRC/ACUC/151/2005.

2001

"Animal Handling and Biosafety Course", University of Melbourne, Australia (1 semester 2 h/week); Course contents: general husbandry of small laboratory animals, injections, blood sampling, and safety containment.

Professional Societies

2005 - present

$2005-2008$

$2005-2008$

Stem Cell Society, Singapore (SCSS)

Singapore Association for Laboratory Animal Science (SALAS)

Singapore Society of Microbiology and Biotechnology (SSMB)

\section{Language skills}

English: native language, written and oral

Mandarin: first language, written and oral

Cantonese: second language, oral

German: basic level, written and oral

\section{Extended qualifications}

Soft skills in Microsoft Office (Word, Excel, PowerPoint), Endnote, Photoshop, Final Cut Pro, GraphPad Prism 


\section{Publications:}

1. Soong PL, Tiburcy $M$ and Zimmermann W-H (2012). Cardiac Differentiation of Human Embryonic Stem Cells and their Assembly into Engineered Heart Muscle. Curr Protoc Cell Biol 2012.

2. Hentze H, Soong PL, Wang ST, Phillips B, Thomas P, Norris D. (2009) Teratoma Formation by Human Embryonic Stem Cells: Evaluation of Essential Parameters for Future Safety Studies. Stem Cell Res 2(3): 198-210.

3. Phillips B, Hentze $H$, Rust $W$, Chen $Q$, Chipperfield $H$, Tan EK, Abraham S, Sadasivam A, Soong PL, Wang ST, Lim R, Sun W, Colman A, Dunn R. (2007) Directed differentiation of human embryonic stem cells into the pancreatic endocrine lineage. Stem Cells Dev 16(4):561-578.

Book

4. Soong PL. The spike and $3 A$ proteins of SARS-Coronavirus: expressions and interactions in mammalian cells (2011). ISBN: 978-38465-5025-0

Book Chapters

5. Narasaraju T, Soong PL, Meulen J, Goudsmit J and Chow VTK (2010) SARS Coronavirus Spike Protein Expression in HL-CZ Human Promonocytic Cells: Monoclonal Antibody and Cellular Transcriptomic Analyses. Molecular Biology of the SARS-Coronavirus Part 4: 289304.

\section{Posters}

1. Soong $\mathrm{PL}$, Tiburcy $M$, Hudson J, Christoph J, Luther $S$ and Zimmermann W-H (2012). A Biomimetic Approach to Scale Up Engineered Human Myocardium. 10 ${ }^{\text {th }}$ Annual Meeting, ISSCR, Yokohama Japan. Poster

\section{Achievements and Awards}

2012 R\&D Systems - ISSCR Travel Grant for ISSCR Poster 2012

2002 - 2005 NUS Graduate Research Scholarship (MSc scholarship)

2003 PBL Tutor for Medical undergraduates (M1), Dept. of Medicine, NUS

2002 - 2004 Postgraduate Representative, Dept of Microbiology, NUS

1998 Undergraduate Research Opportunities Scholarship (UROPS), NUS (Bartonella henselae EFTu Genbank: AF299079)

1989 Science Project (Distinction Award), St Josephs Institution. 